\title{
(ब(-)
}

AUTARQUIA ASSOCIADA À UNIVERSIDADE DE SÃO PAULO

ESTUDO DOS EFEITOS NA DOSE DEVIDO À HETEROGENEIDADE EM BRAQUITERAPIA COM FONTES DE ${ }^{125}$ I

\author{
ISABELA SOARES LOPES BRANCO
}

Dissertação apresentada como parte dos requisitos para obtenção do Grau de Mestre em Ciências na Área de Tecnologia Nuclear - Reatores

Orientador:

Prof. Dr. Hélio Yoriyaz 


\title{
INSTITUTO DE PESQUISAS ENERGÉTICAS E NUCLEARES
}

Autarquia associada à Universidade de São Paulo

\section{ESTUDO DOS EFEITOS NA DOSE DEVIDO À HETEROGENEIDADE EM BRAQUITERAPIA COM FONTES DE ${ }^{125}$ I}

\section{ISABELA SOARES LOPES BRANCO}

\author{
Dissertação apresentada como parte dos \\ requisitos para obtenção do Grau de \\ Mestre em Ciências na Área \\ de Tecnologia Nuclear - Reatores \\ Orientador: \\ Prof. Dr. Hélio Yoriyaz
}

Versão Corrigida

Versão Original disponível no IPEN

São Paulo

2017 
Autorizo a reprodução e divulgação total ou parcial deste trabalho, por qualquer meio convencional ou eletrônico, para fins de estudo e pesquisa, desde que citada a fonte.

\section{Como citar:}

BRANCO, I. S. L. Estudo dos Efeitos na Dose Devido à Heterogeneidade em Braquiterapia com Fontes de ${ }^{125}$ I. 2017. 116p. Dissertação (Mestrado em Tecnologia Nuclear), Instituto de Pesquisas Energéticas e Nucleares, IPEN-CNEN/SP, São Paulo. Disponível em: <www.teses.usp.br> (data de consulta no formato: $\mathrm{dd} / \mathrm{mm}$ / aaaa)

FICHA CATALOGRÁFICA

Branco, Isabela Soares Lopes

Estudo dos Efeitos na Dose Devido à Heterogeneidade em Braquiterapia com Fontes de $1^{125}$ / Isabela Soares Lopes Branco; orientador Hélio Yoriyaz. -- São Paulo, 2017.

$116 p$.

Dissertação (Mestrado) -- Programa de Pós-Graduação em Tecnologia Nuclear (Reatores) -- Instituto de Pesquisas Energéticas e Nucleares, São Paulo, 2017.

1. Dosimetria. 2. Braquiterapia. 3. lodo-125. 4. Heterogeneidade. 
Esta dissertação é dedicada aos meus amados pais e irmã por todo o apoio, dedicação, carinho e por todos os momentos e lembranças felizes. 


\section{AgRADECIMENTOS}

Agradeço a toda a minha família, especificamente aos meus pais, Hélio Lopes Branco e Solange Regina Soares Branco, e a minha irmã Thais Soares Lopes Branco por todo o carinho, amparo, amizade, ensinamentos e por sempre estarem presentes, ainda que à distância.

Ao Prof. Dr. Hélio Yoriyaz por todas as orientações e dedicação no desenvolvimento e elaboração deste projeto, pela oportunidade de crescimento científico, além do ensino e experiências partilhadas.

Ao Prof. Dr. Marco Antônio Rodrigues Fernandes, primeiro orientador, incentivador na área acadêmica, agradeço pelo auxilio na realização deste e outros estudos.

Aos Drs. Carlos Alberto Zeituni, Paulo de Tarso Dalledone Siqueira, Julian Marco Barbosa Shorto por todas as colaborações na elaboração deste projeto e dos objetos simuladores, pelos ensinamentos, pelas dúvidas esclarecidas e por direcionar as correções referentes a este trabalho.

A minha querida "coorientadora" MSc. Paula Cristina Guimarães Antunes por todo o suporte e ensinamentos dados desde o princípio deste projeto de mestrado, pelas horas consumidas na elaboração dos objetos simuladores, arquivos de entrada do MCNP e estudo de artigos, além do companheirismo durante a realização dos mesmos.

Aos amigos do Instituto de Pesquisas Energéticas e Nucleares, Talita Salles Coelho, Tássio Antônio Cavalieri, Dayane Faria Silva, Fabio de Paiva, Michelle Kenia Soares De Sena, Clayton Henrique De Souza e Renata Aline Del Nero, pelos momentos compartilhados durante estes anos no IPEN.

A Iremar Alves Da Silva Junior e Raphael Elias Diniz pelo auxilio nas irradiações.

A Divisão de Oficinas (IEO) do IPEN pela eficiência e prontidão na confecção dos variados objetos simuladores desenvolvidos durante a realização deste trabalho.

Aos amigos do Hospital das Clínicas da Faculdade de Medicina de Ribeirão Preto pelo acréscimo de ensinamentos, além da concessão de tempo para escrita e finalização desta dissertação.

A Comissão de Aperfeiçoamento de Pessoal do Nível Superior (CAPES) pelo financiamento da bolsa de estudos concedida durante o desenvolvimento deste trabalho.

Muito Obrigada. 
"O homem é do tamanho de seu sonho" 


\section{RESUMO}

\section{BRANCO, I. S. L. Estudo dos Efeitos na Dose devido À Heterogeneidade Em} Braquiterapia Com Fontes De ${ }^{125}$ I. 2017. 116p. Dissertação (Mestrado) - Instituto de Pesquisas Energéticas e Nucleares, São Paulo, 2017.

A braquiterapia de baixas taxas de dose realizada com sementes de ${ }^{125}$ I tem sido amplamente usada por décadas em variados sítios anatômicos, com bons resultados clínicos. 0 advento de algoritmos para cálculo de dose baseados em modelos (MBDCAs) permitiu aprimorar o estudo de deposição da dose considerando heterogeneidades como diferentes tecidos, órgãos, aplicadores com composições diferentes da água, proporcionando a análise em geometrias complexas. As simulações matemáticas realizadas através destes algoritmos possibilitam o desenvolvimento de modelos fisicamente mais acurados que estendem sua aplicabilidade à verificação de sistemas de planejamento em braquiterapia. Neste trabalho foram estudadas configurações de objetos simuladores confeccionados para medidas experimentais e simulados através do código MCNP de Monte Carlo a fim de observar as diferenças ocasionadas pela introdução de heterogeneidades quando presentes fontes de ${ }^{125}$ I de baixa taxa de dose. Para este propósito, distintas as vertentes do tema foram abordadas, entre elas o estudo da influência exercida pelos parâmetros de densidade e composição dos materiais tecido equivalentes. Os resultados obtidos demonstraram que, o efeito que a composição de cada um dos materiais exerce sobre a deposição de dose é mais expressivo que o efeito de sua densidade. Em outro estudo, foi estabelecida uma relação para estimar, de maneira simples, a dose de atenuação de tecidos heterogêneos a partir da aferição ou simulação da dose obtida num objeto simulador constituído por PMMA, metodologia que pode ser desenvolvida e implementada na rotina clínica. Para complementação das análises dos estudos dosimétricos com a presença de heterogeneidades, foi realizada a validação da geometria simulada da semente de ${ }^{125}$ I, onde se reproduziu a metodologia de cálculo dosimétrico presente no TG-43 da AAPM. Além disto, foi realizado o estudo teórico da dependência energética dos dosímetros termoluminescentes para analisar a variação de sua resposta conforme a energia. A metodologia desenvolvida para o estudo dos efeitos da heterogeneidade na deposição de dose é recomendada na avaliação de sistemas de planejamento computadorizados que possuem algoritmos de cálculo de dose baseados em modelos, quando utilizadas fontes de ${ }^{125} \mathrm{I}$ com baixa taxa de dose, de forma a contribuir na incorporação de novas estimativas de doses com maior acurácia. 


\section{ABSTRACT}

\section{BRANCO, I. S. L. Study of the Dose Effects due to the heterogeneity} in brachytherapy with ${ }^{125}$ I Sources. 2017. 116p. Master's degree dissertation - Instituto de Pesquisas Energéticas e Nucleares, São Paulo, 2017.

The low dose rate brachytherapy performed with ${ }^{125}$ I seeds has been widely used for decades in various anatomical sites with good clinical results. The advent of model-based dose calculation algorithms (MBDCAs) allowed improving the study of dose deposition considering patients heterogeneities such as tissues and organs with different compositions, patient contouring, and influence of applicators, providing the analysis in complex geometries. The mathematical simulations performed through algorithms enable the development of models physically much more accurate, extending its applicability to verify brachytherapy planning systems. In this work, different configurations of phantoms were confectioned for experimental studies and simulations using the Monte Carlo MCNP code to observe the differences caused by the introduction of heterogeneities for low dose rate brachytherapy using ${ }^{125}$ I sources. For this purpose, different aspects of the theme were discussed, among them the influence exerted by the density and composition parameters of the tissue equivalent materials. The results showed that each material composition effect in the dose deposition is more expressive than its density effect. In another study, a ratio was established to estimate the heterogeneous tissues attenuation from the dose measurement or simulation obtained using a PMMA phantom, this methodology can be developed and implemented in the clinical routine. In order to complement the analysis of the dosimetric studies with heterogeneities presence, the ${ }^{125}$ I seed simulated geometry was validated, showing the reproduction of the calculation methodology present in TG43 of the AAPM. In addition, the theoretical study of the energy dependence of the thermoluminescent dosimeters was performed to analyze the variation its response according to energy. The methodology developed for the heterogeneity effects study on dose deposition is recommended for the evaluation of planning systems that use model-based dose calculation algorithms for low dose rate ${ }^{125}$ I sources, in order to contribute to the incorporation of dose estimates with greater accuracy. 


\section{SUMÁRIO}

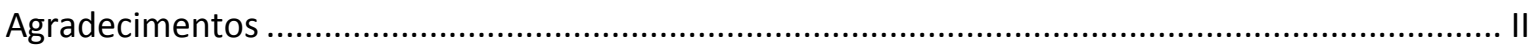

Resumo

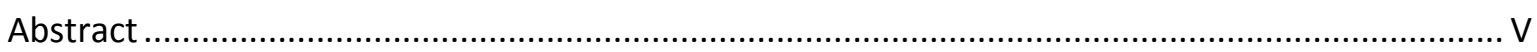

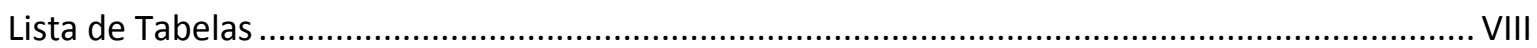

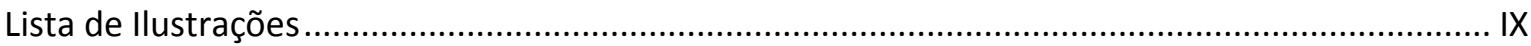

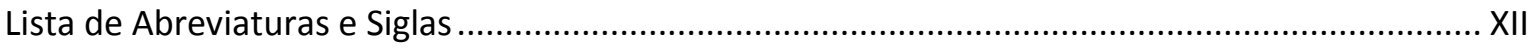

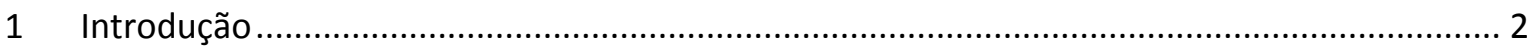

1.1 Câncer: Definições e Incidências .......................................................................... 2

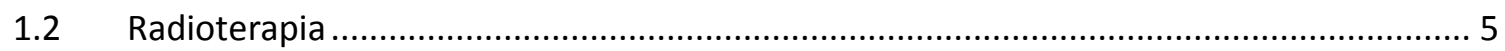

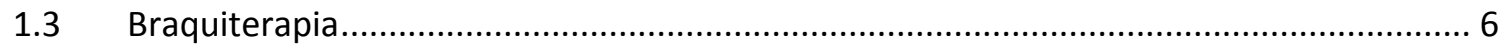

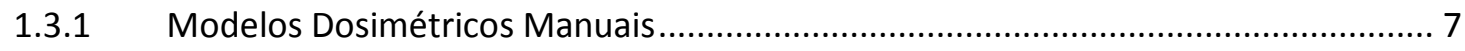

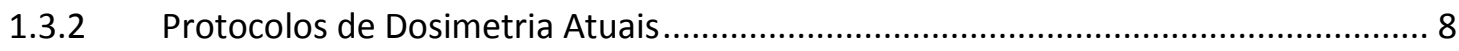

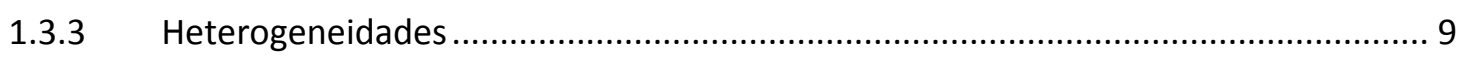

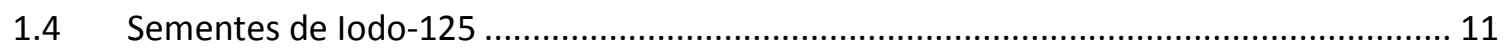

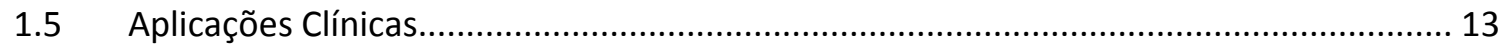

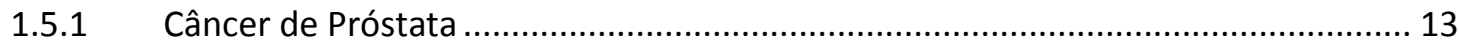

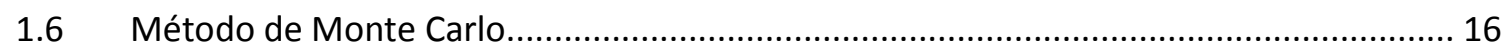

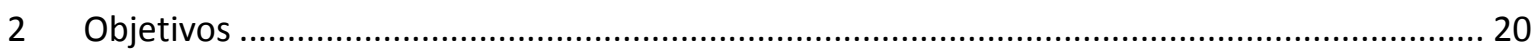

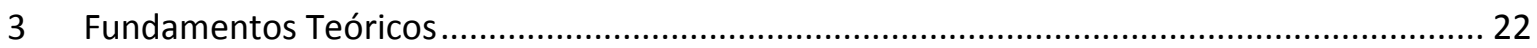

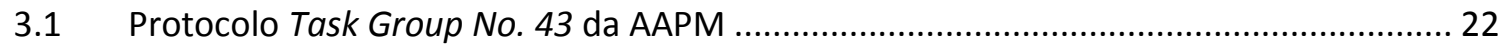

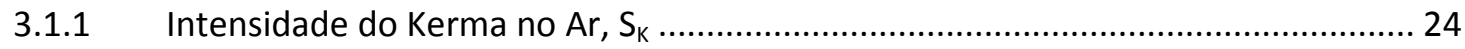

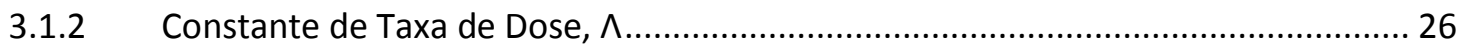

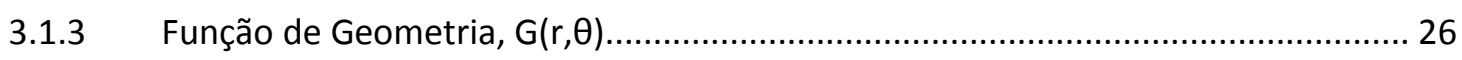

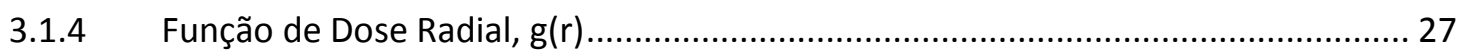

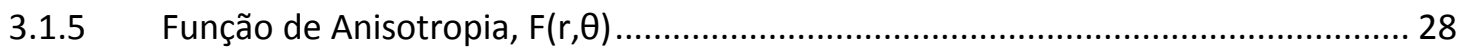

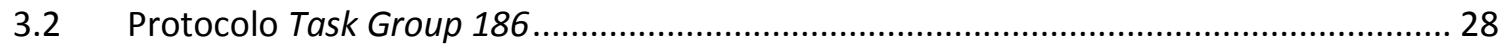

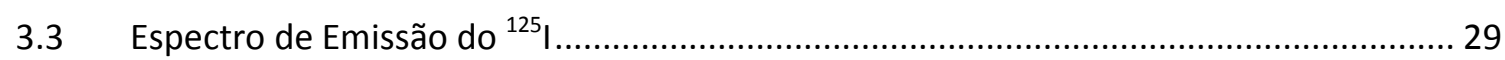

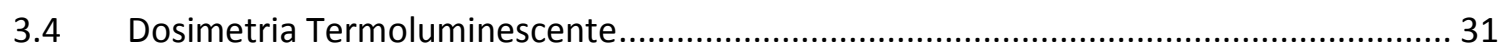

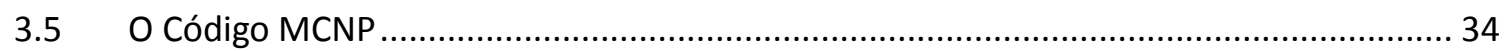

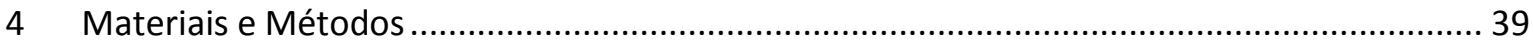

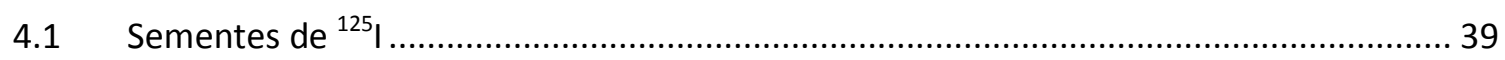

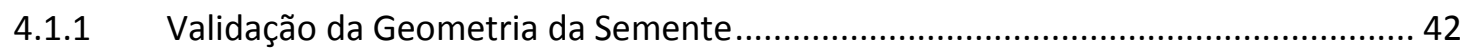

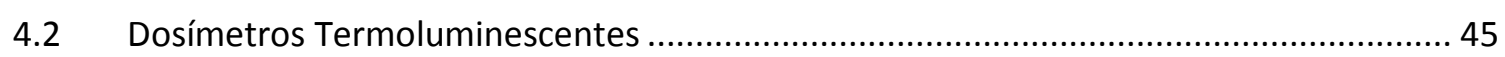

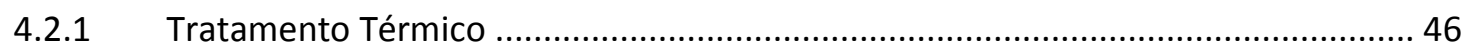

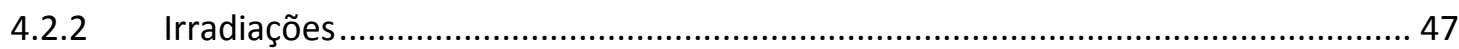

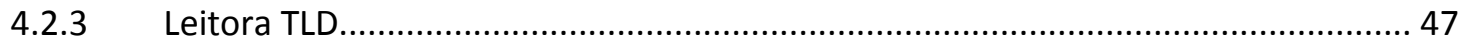


4.2.4 Selecionamento dos Dosímetros Termoluminescentes........................................ 49

4.2.5 Dependência Energética ........................................................................................ 51

4.3 Objetos Simuladores Contendo Material Tecido Equivalente .......................................... 54

4.3.1 Influência da Densidade e Composição .................................................................. 59

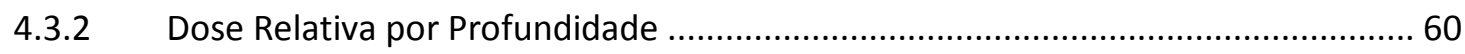

4.3.3 Objetos Simuladores com Variados Materiais Tecidos Equivalentes...................... 63

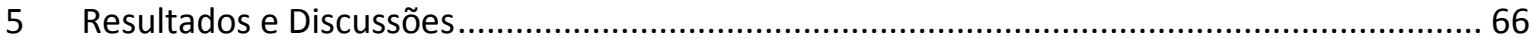

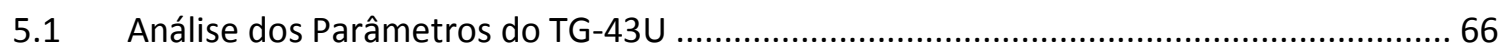

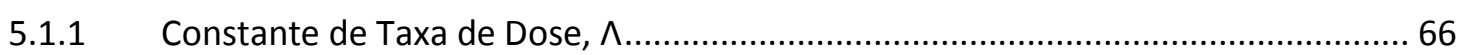

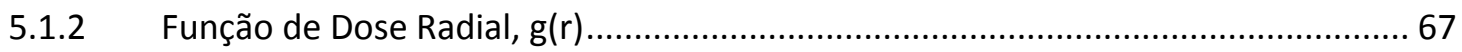

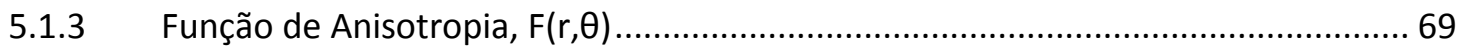

5.2 Selecionamento dos Dosímetros Termoluminescentes.................................................. 70

5.3 Dependência Energética para Fótons …………........................................................ 72

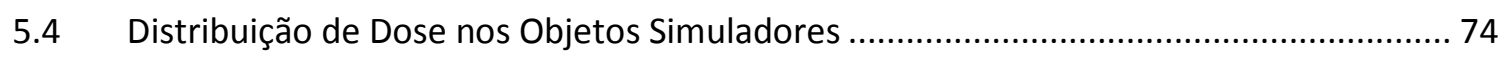

5.4.1 Influência da Densidade e Composição ………………………………………….... 74

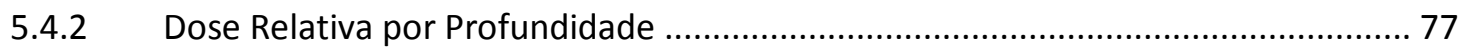

5.4.3 Objetos Simuladores com Variados Materiais Tecidos Equivalentes....................... 85

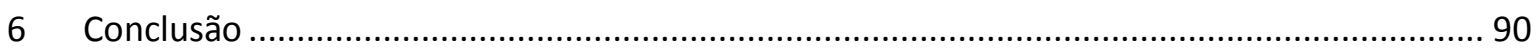

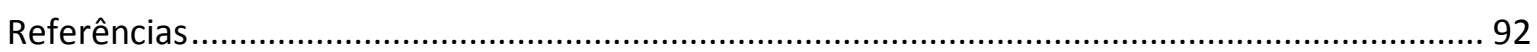

Apêndice A - Geometria da Semente de ${ }^{125}$ I - Amersham Modelo 6711 ........................................ 99

Apêndice B - Banco de Dados das Simulações e Experimentos com Objetos Simuladores............ 100 


\section{LISTA DE TABELAS}

Tabela 1. Emissão de partículas resultantes do decaimento do isótopo ${ }^{125} \mathrm{I}$ em ${ }^{125} \mathrm{Te}$, sendo elas elétrons (auger e de conversão interna), raios-x característicos e raios $\psi$.

Tabela 2. Stopping power de colisão, de radiação e total variando com a energia para o meio ar seco, além de suas contribuições em porcentagem que compõem o valor do stopping power total

Tabela 3. Propriedades dos TLDs-100 microcubos utilizados neste trabalho.

Tabela 4. Parâmetros de operação da leitora Harshaw 3500 para leitura dos TLDs-100 na forma de microcubos.

Tabela 5. Parâmetros principais dos espectros utilizados nas simulações referentes à dependência energética dos TLDs.

Tabela 6. Feixes de Energia utilizados nas simulações referentes à dependência energética dos TLDs no artigo de DAVIS et al., (2003).

Tabela 7. Feixes de Energia utilizados nas simulações referentes a dependência energética dos TLDs no artigo de NUNN et al., (2008).

Tabela 8. Composição dos materiais tecido equivalentes utilizados nas simulações e experimentos.

Tabela 9. Comparação dos valores de Constante de Taxa de Dose $(\Lambda)$ da semente de ${ }^{125} \mathrm{I}$, modelo Amersham 6711.

Tabela 10. Incertezas referentes à Constante de Taxa de Dose $(\Lambda)$ para o método WAFAC da semente de ${ }^{125} \mathrm{I}$, modelo Amersham 6711.

Tabela 11. Fatores de Conversão obtidos de acordo com o cilindro de material tecido

Tabela 12. Estimativas de Doses a partir dos Fatores de Conversão obtidos de acordo com o cilindro de material tecido equivalente adotado e espessura $\Delta x$

Tabela 13. Dados simulados e experimentais da atenuação no PMMA conforme variação da distância fonte-detector, correspondentes às curvas exibidas na Figura 39. 100

Tabela 14. Dados simulados e experimentais da atenuação no material tecido equivalente de fígado conforme variação da distância fonte-detector, correspondentes às curvas exibidas na Figura 40 . 101

Tabela 15. Dados simulados e experimentais da atenuação no material tecido equivalente de pulmão exalado conforme variação da distância fonte-detector, correspondentes às curvas exibidas na Figura 41. 102

Tabela 16. Dados simulados e experimentais da atenuação no material tecido equivalente de Osso $1000 \mathrm{mg} / \mathrm{cc}$ HA conforme variação da distância fonte-detector, correspondentes às curvas exibidas na Figura 42 


\section{LISTA DE ILUSTRAÇõES}

Figura 1. Diferenças histológicas entre tumores benignos e malignos.

Figura 2. Sítios anatômicos mais comuns afetados por câncer conforme distribuição geográfica mundial e sexo (referente ao ano de 2012).

Figura 3. Estimativas para os anos de 2016 e 2017 da incidência de casos novos de câncer, segundo sexo e localização primária do tumor.

Figura 4. Coeficientes de absorção de energia em massa dos tecidos indicados normalizados pelo mesmo coeficiente calculado em água.

Figura 5. Ilustração de alguns modelos de semente de ${ }^{125} \mathrm{I}$ mostrando sua geometria interna ao invólucro de titânio, sendo a) Amersham, OncoSeed, 6711 b) BEBIG GmbH/ Theragenics Co., IsoSeed, 125.506 c) IBt, InterSource, 1251L d) Mills Bio. Pharm., ProstaSeed, 125SL e) NASI, Prospera, Med3631 - ideal f) Implant Sciences, IPlant, 3500. 12

Figura 6. Padrão de Gleason ressaltando a diferença histológica dos diferentes níveis de acordo com o grau de indiferenciação celular. 15

Figura 7. Anatomia dos sistemas reprodutivos e urinários masculinos, mostrando a próstata, os testículos, a bexiga, outros órgãos em corte coronal e estágios do câncer de próstata.

Figura 8. Número de Publicações incluindo o termo "Monte Carlo" nos anos de 1949 até 2016. . 17 Figura 9. Representação esquemática do sistema de coordenadas introduzido pelo TG-43 e usado para cálculos dosimétricos em braquiterapia.

Figura 10. Sistema de medição da câmara WAFAC. 25

Figura 11. Diagrama Esquemático do decaimento do radioisótopo ${ }^{125}$ | para o estado excitado e posteriormente para o estado estável de ${ }^{125} \mathrm{Te}$.

Figura 12. Modelos de bandas de energia mostrando as transições eletrônicas em um material termoluminescente. (1) Excitação de um elétron da Banda de Valência para a Banda de Condução. (2) e (4) Elétrons e buracos armadilhados, respectivamente. (3) e (5) Elétrons e buracos livres depois de receberem energia suficiente para serem liberados. (6) e (7) Elétrons e buracos recombinando com seus portadores de cargas opostas e liberando um fóton no processo.

Figura 13. Curva de Emissão Termoluminescente do TLD-100 obtida através de irradiação com ${ }^{60} \mathrm{Co}$.

Figura 14. Representação Esquemática da Semente de ${ }^{125}$ I (Modelo Amersham 6711) seccionada longitudinalmente, sendo destacadas a composição de sua estrutura geométrica em a) e genericamente as superfícies utilizadas para sua representação com o código em b).

Figura 15. Radiografia de cinco sementes mostrando a variação na posição da haste de prata e do material radioativo.

Figura 16. Representação esquemática da disposição das sementes de ${ }^{125} \mathrm{I}$ em uma placa de PMMA com dimensões de $9.0 \times 9.0 \times 1.0 \mathrm{~cm}^{3}$.

Figura 17. Representação esquemática da geometria simulada para obtenção da Intensidade de Kerma no Ar - Sk (Figura fora de escala).

Figura 18. Representação esquemática da geometria simulada para obtenção da taxa de dose $D(r, \theta)$. (Figura fora de escala).

Figura 19. Muflas do grupo CEN/IPEN utilizadas no tratamento térmico dos dosímetros termoluminescentes.

Figura 20. Irradiação dos TLDs com ${ }^{137}$ Cs para o processo de selecionamento dos dosímetros termoluminescentes. 
Figura 21. Leitora Harshaw, modelo 3500

Figura 22. Representação esquemática da configuração do objeto simulador para irradiações com feixe de ${ }^{137} \mathrm{Cs}$ - vista lateral (Figura fora de escala).

Figura 23. Espectros de Raios- $X$ das qualidades RQR3, RQR8 e RQT9.

Figura 24. Exemplificação dos cilindros de materiais tecido equivalentes utilizados neste trabalho. Para realização dos experimentos foi retirada a tampa com identificação dos materiais, resultando em dimensões de $42 \mathrm{~mm}$ de altura e $30 \mathrm{~mm}$ de diâmetro. 55

Figura 25. Representação esquemática da configuração do objeto simulador para irradiações com semente de ${ }^{125}$ I a fim de observar a distribuição de dose conforme a inserção de materiais tecido equivalentes. A esquerda observam-se as estruturas presentes em cada uma das placas de PMMA, e a direita o objeto simulador com estas placas sobrepostas demonstrando sua conformação real reproduzida nas simulações e experimentos. As coordenadas cartesianas adotadas também são representadas na parte central da imagem.

Figura 26. Representação esquemática do plano $x z$ no ponto $y=0,4 \mathrm{~cm}$ (segundo coordenadas estabelecidas na Figura 25 e nas simulações deste trabalho) da configuração do objeto simulador, contendo material tecido equivalente, para irradiações com semente de ${ }^{125} \mathrm{l}$. 57

Figura 27. Representação esquemática do plano $x z$ no ponto $y=0,4 \mathrm{~cm}$ (segundo coordenadas estabelecidas na Figura 25 e nas simulações deste trabalho) da configuração do objeto simulador para irradiações com semente de ${ }^{125} \mathrm{I}$, porém, sem a presença de material tecido equivalente, sendo a placa de espessura variável constituída inteiramente por PMMA...

Figura 28. Representação esquemática do plano $x z$ no ponto $y=0,4 \mathrm{~cm}$ (segundo coordenadas estabelecidas na Figura 25 e nas simulações deste trabalho) da configuração do objeto simulador contendo material tecido equivalente (à esquerda), e da configuração do objeto simulador constituído inteiramente por PMMA (à direita). Em ambas situações, as irradiações foram realizadas com semente de ${ }^{125} \mathrm{I}$ e com a ausência do TLD, porém, o volume de sua célula foi mantido e seu material foi adotado como PMMA.

Figura 29. Objeto Simulador utilizado para o cálculo de deposição de dose quando inseridos mais de um material tecido equivalente. Nas simulações foram adotadas variações nas espessuras destes materiais $\Delta x=0,2$ ou $0,5 \mathrm{~cm}$. $O$ tracejado indica os limites da matriz que permitiu estabelecer as linhas de isodose como resposta para o tally utilizado. 64

Figura 30. Comparação dos valores da Função de Dose Radial da Semente de ${ }^{125}$ I. No gráfico está descrito o comportamento da função para a distância de 0 a 10,0 cm entre a fonte e o detector. A direita pode-se observar uma ampliação da mesma função no intervalo de 0 a $1,0 \mathrm{~cm}$ 68 Figura 31. Representação das curvas de isodose (em unidades de $\mathrm{MeV} \cdot \mathrm{g}^{-1}$ ) da semente simulada de ${ }^{125}$ I indicando os ângulos definidos para o cálculo de taxa de dose e explicitando o efeito da anisotropia. 69

Figura 32. Função de Anisotropia para Semente de ${ }^{125} \mathrm{I}$ explicitando o comportamento da função a $0,5 \mathrm{~cm}$, a $1 \mathrm{~cm}$, a $3 \mathrm{~cm}$ e a $5 \mathrm{~cm}$. 70

Figura 33. Valores médios dos TLDs em 4 ciclos de leitura e suas respectivas incertezas. 71

Figura 34. Histogramas das respostas dos TLDs-100 quando não aplicado (esquerda) e aplicado (direita) o fator de normalização. 71

Figura 35. Coeficiente de absorção de energia em massa do LiF para diferentes energias de fótons.

Figura 36. Comparação dos dados simulados neste estudo, de DAVIS et al, (2003) e de NUNN et al., (2008). para calculo da razão $D_{\text {Lif }} / K_{a r}$ obtidos de acordo com o a energia do feixe estudado 
normalizados para razão $D_{\text {Lif }} / K_{a r}$ obtidos no ${ }^{60} \mathrm{Co}$, denominado $\mathrm{R}_{\mathrm{MC}}$.

Figura 37. Dados simulados das razões de dose quando são mantidas fixas as densidades $(\rho=1.18$ $\mathrm{g} / \mathrm{cm}^{3}$ ) em cada um dos materiais heterogêneos. A Equação 17 exibe a fórmula utilizada para os cálculos. 75

Figura 38. Dados Simulados das razões de dose quando é mantida fixa a composição química do PMMA e adotam-se as densidades originais dos materiais heterogêneos. A Equação 18 exibe a fórmula utilizada para os cálculos. 76

Figura 39. Dados simulados e experimentais da atenuação do PMMA conforme variação da distância fonte-detector.. 79

Figura 40. Dados simulados e experimentais da atenuação no cilindro que possuía como material tecido equivalente o Fígado conforme variação da distância fonte-detector. 80

Figura 41. Dados simulados e experimentais da atenuação no cilindro que possuía como material tecido equivalente o Pulmão Exalado conforme variação da distância fonte-detector... 81

Figura 42. Dados simulados e experimentais da atenuação no cilindro que possuía como material tecido equivalente o Osso $1000 \mathrm{mg} / \mathrm{cm}^{3}$ HA conforme variação da distância fonte-detector. ...... 82 Figura 43. Fator de Conversão encontrado através da razão entre os parâmetros $D_{\mathrm{PMMA}, \mathrm{MTE}} \mathrm{e}$ $D_{\text {PMMA,PMMA }}$ previamente estabelecidos para os materiais tecido equivalentes fígado, pulmão exalado e osso $1000 \mathrm{mg} / \mathrm{cm}^{3} \mathrm{HA}$.

Figura 44. Matriz de cores explicitando as curvas de isodose obtidas em um objeto simulador contendo 3 distintos materiais tecidos equivalentes (representadas pelas letras a e c) e obtidas em um objeto simulador inteiriço de PMMA (letras b e d). As matrizes a) e b) apresentam a mesma dimensão, sendo as espessuras variáveis $(\Delta x)$ do objeto simulador fixadas em 2,0 mm. 0 mesmo ocorreu para as matrizes c) e d) porem sendo $\Delta x$ fixo em $5,0 \mathrm{~mm}$. Todos os gráficos apresentam como unidade de seu espectro de cores $\mathrm{MeV} / \mathrm{g}$. 86

Figura 45. Objeto Simulador utilizado para o cálculo de deposição de dose quando inseridos mais de um material tecido equivalente. Nas simulações foram adotadas variações nas espessuras destes materiais $\Delta x=0,2 \mathrm{~cm}$ ou $0,5 \mathrm{~cm}$. $O$ tracejado em preto indica os limites da matriz que permitiu estabelecer as linhas de isodose como resposta para o tally utilizado e a linha tracejada em verde denotam os dados que constituem os gráficos das Figuras 46 e 47.

Figura 46. Distribuição de doses ao longo do eixo mediano da semente de ${ }^{125}$ I comparando os dados obtidos com objetos simuladores que continham distintos materiais tecidos equivalentes com espessuras de $2,0 \mathrm{~mm}$.

Figura 47. Distribuição de doses ao longo do eixo mediano da semente de ${ }^{125}$ / comparando os dados obtidos com objetos simuladores que continham distintos materiais tecidos equivalentes com espessuras de $5,0 \mathrm{~mm}$.

Figura 48. Representação Esquemática das dimensões (em centímetros) e estruturas simuladas da Semente de ${ }^{125}$ I (Modelo Amersham 6711) utilizadas neste trabalho. Os quadrados azuis e círculos vermelhos correspondem, respectivamente, a numeração das superfícies e células descritas conforme os fragmentos do input (arquivo de entrada) do MCNP à esquerda. 99 


\section{LiSTA DE ABREVIATURAS E SiglaS}

AAPM - Associação Americana de Físicos em Medicina (American Association of Physics in Medicine).

$\mathrm{AgBr}$ - Fórmula química de brometo de prata.

Agl - Fórmula química de iodeto de prata.

MBDCA - Algoritmos de cálculo de dose baseados em modelos.

MCNP - Monte Carlo N-Particle Radiation Transport Code (código de Monte Carlo)

PMMA - Polimetil-metacrilato (Acrílico).

Tally - Cartão de Registro do Programa MCNP

TLD - Dosímetros Termoluminescentes (Thermoluminescent Dosimeter).

PSA - Antígeno Prostático Específico

PDP - Porcentagem de Dose em Profundidade 
CAPÍTULO 1

INTRODUÇÃO 


\section{INTRODUÇÃo}

\subsection{CÂNCER: DEFINIÇõES E INCIDÊNCIAS}

A palavra câncer se origina do grego Karkinos ou "caranguejo", e somente foi utilizada depois que Hipócrates (460-377 a.C.), considerado o pai da medicina, achou semelhanças entre um tumor e os vasos sanguíneos a seu redor e um caranguejo com as patas espalhadas na areia. Atualmente, o câncer pode ser definido como um grupo de doenças caracterizadas pelo crescimento incontrolado e desordenado de células que dão origem a uma neoplasia maligna (INCA, 2011). O estadiamento de neoplasias malignas consiste em verificar a extensão da doença no órgão de origem, nos órgãos e estruturas adjacentes e nos linfonodos regionais.

Neoplasias podem ser classificadas como benignas ou malignas. As neoplasias benignas ou tumores benignos têm seu crescimento de forma lenta, organizada e apresentam limites nítidos. Entretanto, apesar de não invadirem os tecidos vizinhos, podem comprimir os órgãos e tecidos adjacentes. As neoplasias malignas ou tumores malignos manifestam ampla autonomia e possuem a capacidade de invadir tecidos vizinhos e provocar metástases, podendo ser resistentes aos tratamentos e levar a óbito (INCA, 2011). A Figura 1 exibe as diferenças histológicas destas duas estruturas.

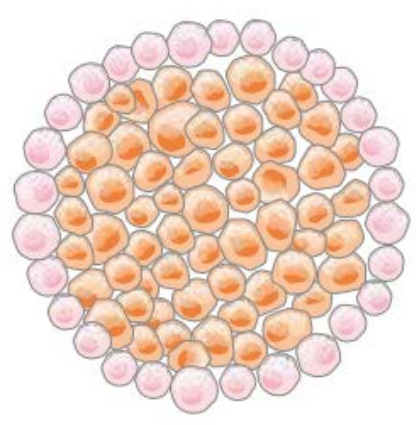

Tumor benigno

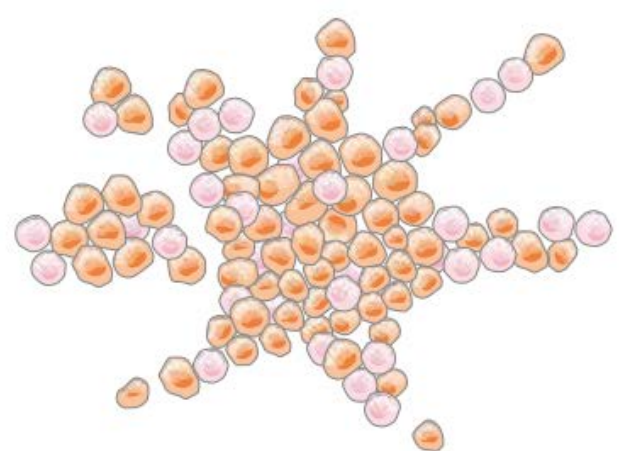

Tumor maligno

Figura 1. Diferenças histológicas entre tumores benignos e malignos.

Fonte: INCA, (2011) 
Mundialmente, uma em cada sete mortes ocorre como consequência do câncer, sendo este o responsável por mais mortes que doenças como malária, tuberculose e AIDS juntas. Segundo pesquisas realizadas pela Agência Internacional de Pesquisas em Câncer (IARC - International Agency for Research on Cancer) em 2012, foram estimados 14,1 milhões de novos casos de câncer no mundo e 8,2 milhões de mortes, sendo 2,9 milhões contabilizadas em países desenvolvidos e 5,3 milhões em países em desenvolvimento. Ainda no ano de 2012, os tipos de câncer com incidências mundiais predominantes foram: pulmão (1,8 milhão), mama (1,7 milhão), intestino (1,4 milhão) e próstata (1,1 milhão). Nos homens, os mais frequentes foram: pulmão $(16,7 \%)$, próstata $(15,0 \%)$ e intestino (10,0\%). Em mulheres, as maiores frequências encontradas foram: mama $(25,2 \%)$, intestino $(9,2 \%)$, pulmão $(8,7 \%)$ e colo do útero $(7,9 \%)$. O mapa apresentado na Figura 2 retrata o panorama mundial da incidência de cânceres conforme o sexo, países e sítios anatômicos. No ano de 2030 espera-se que a incidência de novos casos de câncer aumente para 21,7 milhões e o número de mortes para 13,0 milhões, devido principalmente a fatores como crescimento e envelhecimento da população (AMERICAN CANCER SOCIETY, 2015; FORMAN D et al., 2014).

Segundo o INCA (2016) para o biênio de 2016-2017 estima-se a ocorrência de cerca de 600 mil novos casos de câncer somente no Brasil (sendo 180 deles de câncer de pele não melanoma). Em homens, excetuando-se câncer de pele não melanoma, os tipos mais frequentes de cânceres serão próstata $(28,6 \%)$, pulmão $(8,1 \%)$ e intestino $(7,8 \%)$. Já nas mulheres, os cânceres de mama $(28,1 \%)$, intestino $(8,6 \%)$ e colo do útero $(7,9 \%)$ estarão entre os principais. A Figura 3 detalha a distribuição dos dez tipos de cânceres mais incidentes no Brasil estimados para 2016 e 2017 de acordo com o sexo (exceto câncer de pele não melanoma). 

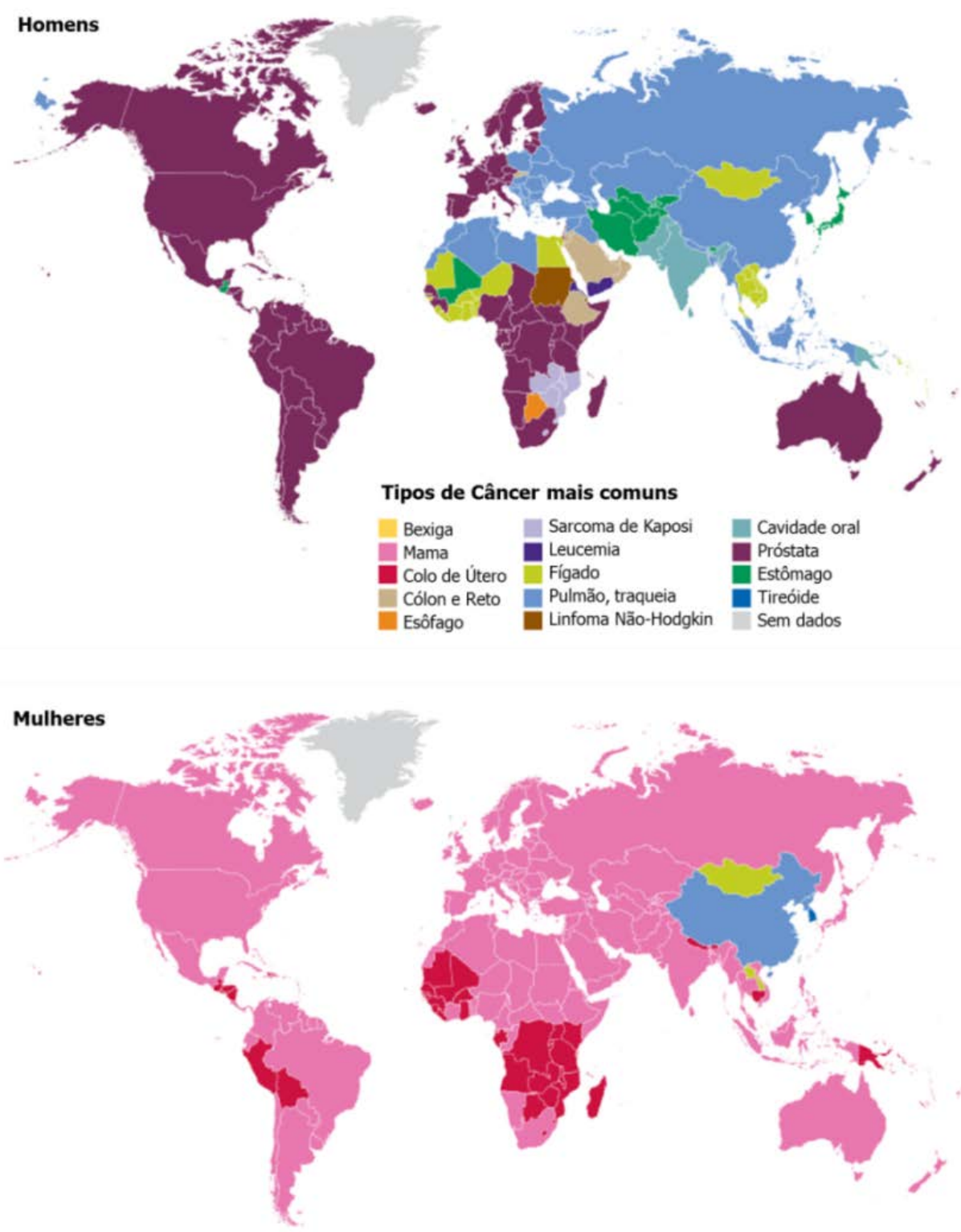

Figura 2. Sítios anatômicos mais comuns afetados por câncer conforme distribuição geográfica mundial e sexo (referente ao ano de 2012).

Fonte: (AMERICAN CANCER SOCIETY, 2015).

\begin{tabular}{|c|c|c|c|c|c|c|}
\hline $\begin{array}{l}\text { Localização primária } \\
\text { Próstata }\end{array}$ & $\begin{array}{c}\text { casos novos } \\
61.200\end{array}$ & $\begin{array}{r}\% \\
28,6 \%\end{array}$ & Homens & $\begin{array}{l}\text { Localização primária } \\
\text { Mama Feminina }\end{array}$ & $\begin{array}{l}\text { casos novos } \\
57.960\end{array}$ & $\begin{array}{l}\% \\
28,1 \%\end{array}$ \\
\hline Traqueia, Brônquio e Pulmão & 17.330 & $8,1 \%$ & Homens & Cólon e Reto & 17.620 & $8,6 \%$ \\
\hline Cólon e Reto & 16.660 & $7,8 \%$ & & Colo do Útero & 16.340 & $7,9 \%$ \\
\hline Estômago & 12.920 & $6,0 \%$ & & Traqueia, Brônquio e Pulmão & 10.890 & $5,3 \%$ \\
\hline Cavidade Oral & 11.140 & $5,2 \%$ & & Estômago & 7.600 & $3,7 \%$ \\
\hline Esôfago & 7.950 & $3,7 \%$ & & Corpo do Útero & 6.950 & $3,4 \%$ \\
\hline Bexiga & 7.200 & $3,4 \%$ & & Ovário & 6.150 & $3,0 \%$ \\
\hline Laringe & 6.360 & $3,0 \%$ & & Glândula Tireoide & 5.870 & $2,9 \%$ \\
\hline Leucemias & 5.540 & $2,6 \%$ & & Linfoma não Hodgkin & 5.030 & $2,4 \%$ \\
\hline Sistema Nervoso Central & 5.440 & $2,5 \%$ & & Sistema Nervoso Central & 4.830 & $2,3 \%$ \\
\hline
\end{tabular}

Figura 3. Estimativas para os anos de 2016 e 2017 da incidência de casos novos de câncer, segundo sexo e localização primária do tumor.

Fonte: (INCA, 2016) 
No Brasil, o número de incidências de câncer, sua histologia e sítio primário variam drasticamente conforme as diferenças regionais encontradas. A morbidade por câncer altera-se expressivamente de estado para estado e até para instituições de saúde (estando no mesmo estado ou na mesma cidade). Os fatores de risco como fumo, dieta, higiene, exposição à radiação, entre outros, acentuam significativamente a ocorrência dos tumores conforme as diferenças regionais (SALVAJOLI; SOUHAMI; FARIA, 2013). Este cenário evidencia a necessidade de investimentos no desenvolvimento de ações abrangentes para o controle do câncer, nos diferentes níveis de atuação, como na pesquisa, na gestão, na prevenção, no controle e no tratamento.

Por conseguinte a esta necessidade de aprimorar o tratamento do câncer, a dosimetria em radioterapia torna-se um importante objeto de estudo, sendo seu objetivo a verificação e a validação dos mais variados métodos dosimétricos a fim de estimar a dose de radiação efetivamente recebida pelo paciente em seu tratamento.

\subsection{RADIOTERAPIA}

Atualmente existem diversas modalidades para tratamento das mais de 100 doenças classificadas como câncer, sendo as principais, cirurgia, quimioterapia, radioterapia, terapia hormonal, imunoterapia e terapia alvo. Estes tratamentos podem ser utilizados sozinhos ou em combinação, dependendo do tipo celular do órgão de origem e do grau de invasão do tumor (AMERICAN CANCER SOCIETY, 2015). A Radioterapia caracteriza-se como tratamento que utiliza a radiação ionizante para destruir ou controlar o crescimento de células neoplásicas, permitindo o tratamento de diversas neoplasias, desde neoplasias cutâneas (cânceres de pele) a neoplasias mais internas (cânceres de próstata, colo de útero, pulmão, entre outros) (PODGORSAK, 2005).

Nos tratamentos radioterápicos destacam-se dois principais objetivos: entrega de dose de forma precisa e adequada, buscando erradicar todas as células tumorais, e a mínima deposição de energia no tecido circunvizinho saudável, a custa do qual se fará a regeneração da área irradiada. A eficiência do tratamento depende da dose depositada no volume alvo. Um desvio da dose prescrita ou mesmo do volume irradiado pode trazer 
consequências severas para o paciente, assim como negligenciar as limitações de dose estabelecidas para preservação dos tecidos sadios circunvizinhos.

Deste modo, se faz necessária a correta avaliação de variáveis do planejamento do tratamento, como: localização do tumor; seleção do feixe e dos campos de irradiação, determinação da dose e cálculo dos tempos de tratamento. Mesmo que as considerações anteriores sejam satisfatórias existem ainda limitações inerentes ao processo de entrega de dose, como por exemplo, a movimentação do paciente que pode afetar o tratamento. Nesse sentido, todos os procedimentos cabíveis devem ser adotados de forma que permitam a realização de um tratamento eficiente (INCA, 2011; MOURA, 2015; ZEITUNI, 2008).

As principais modalidades de radioterapia são a braquiterapia e a teleterapia. $\mathrm{Na}$ teleterapia, a fonte emissora é posicionada externamente ao paciente e o feixe de radiação ionizante percorre certa distância até o tumor, atingindo também todas as estruturas posicionadas entre este caminho. A braquiterapia utiliza uma ou várias fontes radioativas seladas a uma distância curta do tumor, ficando estas em contato ou próximas com a área a ser tratada, o que preserva os tecidos circunvizinhos sadios que não necessitam ser irradiados, sendo esta sua principal vantagem (KHAN, 2003).

\subsection{BRAQUITERAPIA}

Braquiterapia é uma modalidade de radioterapia no qual fontes radioativas seladas são usadas para irradiar, a curtas distancias, aplicações intersticiais, intracavitárias superficiais ou intraoperatórias, isto é, quando presentes tumores que permitam fácil acesso da fonte radioativa como, por exemplo, tumores de próstata e ginecológicos (KHAN, 2003; PODGORSAK, 2005).

Segundo a Agência Internacional de Energia Atômica, em um serviço típico de radioterapia cerca de $10 \%$ a $20 \%$ dos pacientes são tratados com braquiterapia (PODGORSAK, 2005). O tratamento pode ser realizado por meio de fontes com diversos formatos (agulhas, sementes, fios, etc.) e de diversos materiais $\left({ }^{125} \mathrm{I},{ }^{192} \mathrm{Ir},{ }^{198} \mathrm{Au}\right.$, etc.), além disso, a braquiterapia pode ser classificada por diferentes aspectos como posição da fonte (intersticial, superficial, intracavitária ou intraoperatorial), tempo em que 
permanece em contato com o paciente (implante temporário ou permanente) e conforme a taxa de dose liberada pela fonte (podendo ser alta taxa de dose - maior que $12 \mathrm{~Gy} / \mathrm{h}$, média taxa de dose - entre 2 e $12 \mathrm{~Gy} / \mathrm{h}$ ou baixa taxa de dose - entre 2,0 e 0,4 Gy/h) (SCAFF, 2010).

Atualmente, os tratamentos intersticiais de braquiterapia de alta taxa de dose (ATD) são mais comumente realizados com implantes temporários de ${ }^{192} \mathrm{Ir}$, e os de braquiterapia de baixa taxa de dose (BTD) utilizam implantes permanentes de sementes de ${ }^{125}$ I. O advento da tecnologia estimulou o estudo em áreas relacionadas a braquiterapia, através da introdução outros radioisótopos, equipamentos de afterloading que reduzem a exposição a radiação, entre outros que controlam a exposição à radiação de fontes com alta atividade (BALTAS; SAKELLIOU; ZAMBOGLOU, 2007; KHAN, 2003).

A escolha dos radionuclídeos a serem utilizados em braquiterapia é limitada de acordo com as propriedades desejáveis para uma fonte ideal. Entre estas propriedades, pode-se citar a meia vida, que determina a utilização de implantes temporários ou permanentes; a atividade específica da fonte, que influenciará na taxa de dose; a energia da radiação emitida, caracterizando as distribuições de dose no tecido e ditando os requisitos de radioproteção necessários durante o tratamento; e a geometria e composição da fonte, que permitirão a visibilidade radiográfica (localização) e caracterização da isotropia ou anisotropia da distribuição de dose (BALTAS; SAKELLIOU; ZAMBOGLOU, 2007).

\subsubsection{Modelos Dosimétricos Manuais}

Sistemas dosimétricos em braquiterapia podem ser definidos como o conjunto de regras que consideram a atividade das fontes, a grandeza kerma-ar, a geometria das fontes e o método da aplicação, para avaliar a distribuição de dose adequada nos volumes a serem tratados (SCAFF, 2010).

Nos últimos 50 anos, incontáveis sistemas de planejamento para dosimetria foram desenvolvidos. Entre eles, o sistema de Paterson-Parkes e o sistema Quimby possuíam um uso mais generalizado. Estes sistemas foram projetados numa época em que o advento dos computadores não era a realidade dos planejamentos do tratamento de rotina. 
Tabelas extensas e regras para distribuição das fontes foram concebidas para simplificar o planejamento braquiterápico manual. Estes sistemas diferenciavam-se entre si basicamente quanto às regras de distribuição do material radioativo, definição da uniformidade e especificação da dose de referência (FERNANDES, 2000; KHAN, 2003).

O sistema Quimby (1932) tem como característica a distribuição uniforme de fontes com a mesma atividade linear, que não apresentam distribuição uniforme da dose, sendo menor na periferia e aumentando no centro do volume. Este sistema também desenvolveu um cálculo dosimétrico para fontes lineares, que são muito úteis para certos tipos de aplicações braquiterápicas (FERNANDES, 2000; SCAFF, 2010).

O sistema de Paterson Parker ou Manchester (1934) tem como característica principal o intuito de homogeneizar uma dose em um plano ou volume, para isto a distribuição das fontes é feita de maneira não uniforme com atividades variáveis, de forma que o sistema tem regras de distribuição do material radioativo (KHAN, 2003; SCAFF, 2010).

Comparações entre os sistemas Quimby e Manchester apresentavam diferenças exacerbadas entre os dois de modo que as tabelas para cálculo do sistema Quimby não poderiam ser utilizadas com a do sistema Paterson-Parker (FERNANDES, 2000).

Posteriormente houve a introdução dos computadores para calcular distribuições de dose para pacientes individuais. Isto permitiu que o terapeuta pudesse desviar-se dos sistemas estabelecidos. O planejamento do tratamento realizado computacionalmente veio substituindo rapidamente os sistemas tradicionais (KHAN, 2003).

\subsubsection{Protocolos de Dosimetria Atuais}

No Update of Task Group 43 (TG-43U) (RIVARD et al., 2004), documento publicado pelo grupo de trabalho da AAPM (American Association of Physics in Medicine) estão descritas de forma detalhada as metodologias de cálculo de dose e medidas experimentais que envolvem fontes de braquiterapia em geral. Este protocolo define a água como o meio homogêneo onde é realizada a dosimetria. Deste modo, a deposição de energia é descrita em torno de uma única fonte posicionada no centro de uma esfera de água e toda a dosimetria é realizada considerando-se apenas este meio. Este método é 
rápido e prático na clínica. No entanto, a influência da heterogeneidade de tecidos e aplicadores, atenuação entre fontes radioativas, e as dimensões finitas do paciente são todos ignorados, fazendo-se necessários métodos de solução com maior acurácia.

Os algoritmos de cálculo de dose com base em modelos (MBDCAs) oferecem a possibilidade de não limitar o cálculo de dose apenas à água, permitindo o cálculo em outros meios (tecidos, aplicadores, interfaces ar-tecido), além de levar em conta geometrias complexas de modelagem para simulação do transporte de radiação. Tais modelos permitiram que correções de heterogeneidade fossem incorporadas em sistemas de planejamento em teleterapia (AHNESJÖ; ASPRADAKIS, 1999). Entretanto, em braquiterapia, diversos estudos estão sendo realizados atualmente para analisar os efeitos de heterogeneidade entre os diferentes tecidos e órgãos em situações clinicas e um grande esforço tem sido realizado no sentido de incorporar novas metodologias para estimar doses com maior acurácia. As diretrizes para implementação clínica deste novo modelo dosimétrico encontram-se descritas em detalhes no TG-186 (BEAULIEU et al., 2012).

Diante destas metodologias, faz-se relevante o estudo de deposição da dose considerando as heterogeneidades dos diferentes tecidos, resultando em modelos fisicamente muito mais acurados para a avaliação de dose efetivamente entregue ao paciente, estendendo sua aplicabilidade à verificação de sistemas de planejamento em braquiterapia que considerem as heterogeneidades dos diferentes tecidos humanos.

\subsubsection{HETEROGENEIDADES}

Aplicações de curvas de isodose padrões e tabelas de dose em profundidade assumem meios homogêneos. Em um paciente real, no entanto, o feixe pode atravessar camadas de gordura, osso, músculo, pulmão, entre outros tecidos. A presença destas heterogeneidades produzirá mudanças na distribuição da dose, dependendo da quantidade, do tipo de material presente e da qualidade de radiação (KHAN, 2003).

Os efeitos de heterogeneidade do tecido podem ser classificados sob duas perspectivas: alterações na absorção do feixe primário e padrão associado de fótons espalhados, e alterações da fluência de elétrons secundários. A importância atribuída a 
estes efeitos depende da região de interesse onde alterações na dose absorvida são consideradas. Nos pontos de interesse que se encontram relativamente longe da região de homogeneidade, o efeito predominante é a atenuação do feixe primário. Mudanças na distribuição de dose associadas aos fótons espalhados são mais explicitas próximas à heterogeneidade. Alterações na fluência de elétrons secundários, por outro lado, afetam os tecidos de dentro até os limites da heterogeneidade (KHAN, 2003).

A composição dos tecidos é um parâmetro essencial para estimar as distribuições de dose com acurácia, principalmente em procedimentos que utilizam fontes emissoras de fótons com baixas energias. Para estas energias o processo de interação com a matéria predominante é o efeito fotoelétrico, sendo a energia absorvida altamente dependente do número atômico (ATTIX, 2008).

O protocolo Task Group $43 U 1$ da AAPM (RIVARD et al., 2004) para dosimetria em braquiterapia, ainda bastante utilizado na rotina clínica, baseia-se na deposição de dose em simulador de água, o que pode superestimar o cálculo da dose efetivamente entregue a um paciente (TAYLOR, 2006). Múltiplos estudos demonstraram divergências significativas na dosimetria considerando a distribuição de dose absorvida em meios que consideram as heterogeneidades dos tecidos (MASHOUF et al., 2014; POON et al., 2008; SUTHERLAND; FURUTANI; THOMSON, 2013; YANG; RIVARD, 2011).

Taylor (2006) apresenta variações de aproximadamente $23 \%$ entre o cálculo de dose na água e no tecido mamário utilizando como fonte um raio-x, Intrabeam, com espectro de 30 a $50 \mathrm{kV}$. Neste mesmo estudo, diferenças de $10 \%$ foram contabilizadas quando comparadas as dosimetrias em água e no tecido prostático para fontes de ${ }^{125} \mathrm{I}$ e ${ }^{103} \mathrm{Pd}$. Landry et al. (2016) calcula diferenças de até 30\% entre a dose absorvida na água e no tecido mamário para fontes de baixas energias $\left({ }^{125} \mathrm{I},{ }^{103} \mathrm{Pd}\right.$ e $\left.{ }^{131} \mathrm{Cs}\right)$, enquanto que, para a próstata essa relação é de até $4 \%$.

O gráfico apresentado na Figura 4 exibe a razão entre coeficientes de absorção de energia em massa para diversos materiais e para água. Estes dados resultam em grandes diferenças nos cálculos de dose absorvida para algoritmos que realizam o transporte de radiação somente em água e os que consideram a presença de meios distintos, sobretudo a baixas energias. 


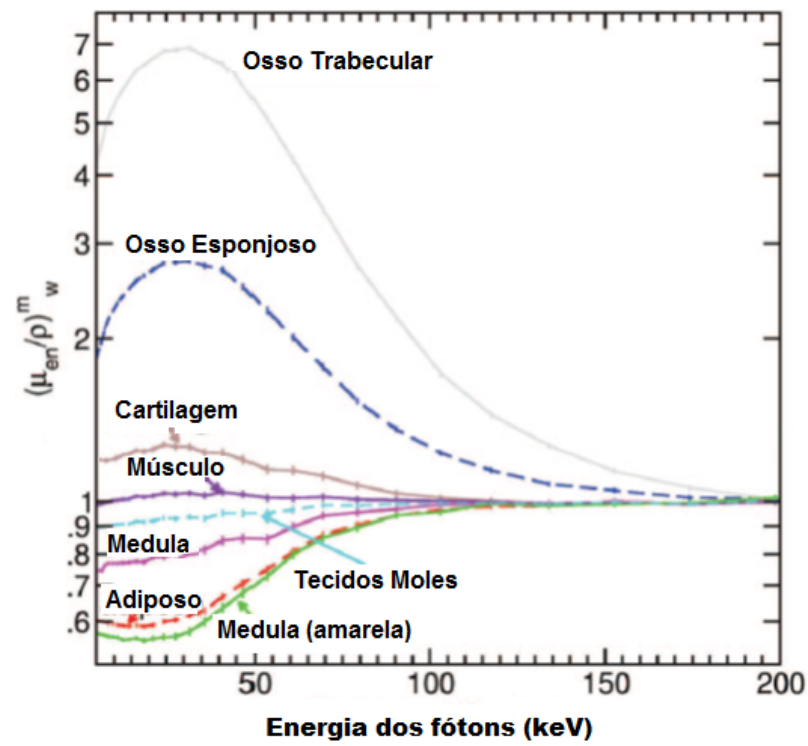

Figura 4. Coeficientes de absorção de energia em massa dos tecidos indicados normalizados pelo mesmo coeficiente calculado em água.

Fonte: Adaptado de BEAULIEU et al., (2012).

\subsection{SEMENTES DE IODO-125}

Allen Reid e Albert Keston descobriram o radionuclídeo ${ }^{125}$ I em 1946, mas decorreram 20 anos até que as fontes de ${ }^{125}$ I se tornassem clinicamente disponíveis para braquiterapia intersticial (BALTAS; SAKELLIOU; ZAMBOGLOU, 2007).

A utilização clinica pioneira de sementes de ${ }^{125}$ I foi realizada em 1970 no Memorial Hospital em Nova lorque por Whitmore e Hilaris (KHAN, 2003). A energia baixa dos fótons emitidos simplificou a radioproteção dos indivíduos ocupacionalmente expostos, mas introduziu complicações dosimétricas. A meia vida de aproximadamente 60 dias resultou em uma incerteza inicial radiobiológica e clínica dos implantes permanentes, já que a experiência era baseada no ${ }^{222} \mathrm{Rn}$ que possuía uma meia vida de 3,8 dias (MEURANT, 2012).

A técnica moderna de implantação de sementes de ${ }^{125} \mathrm{I}$ na próstata começou na década de 1980 e consiste na abordagem transperineal em que são inseridas as sementes com a orientação de ultrassonografia transretal. O procedimento é não cirúrgico e realizado em regime ambulatorial. O implante é feito em uma sala de operação onde o paciente recebe anestesia espinhal (KHAN, 2003). 
Nas diversas sementes de iodo, além de seu material radioativo, há materiais com alto número atômico (radiopacos) que tem a função de aumentar o grau de visualização em imagens de raios $X$, já que o invólucro de titânio possui espessuras micrométricas, de aproximadamente $50 \mu \mathrm{m}$. Estes materiais são denominados marcadores e o tipo de material a ser utilizado depende de cada modelo de semente de ${ }^{125} \mathrm{I}$. Todas as sementes são encapsuladas em titânio porque este elemento caracteriza um material inerte, isto é, não causa rejeição quando em contato direto com o tecido humano, sendo classificado como biocompatível. A Figura 5 ilustra alguns modelos de sementes de ${ }^{125}$ I (indicados na legenda) com sua distribuição geométrica interna.

a)

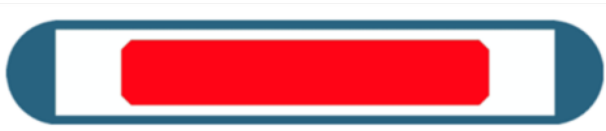

c)

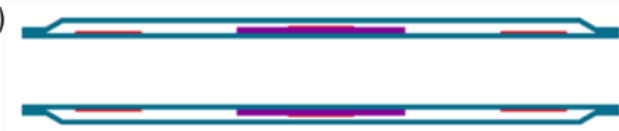

e)

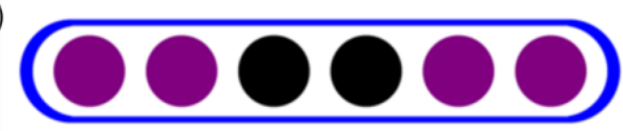

b)

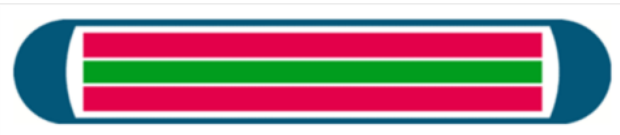

d)

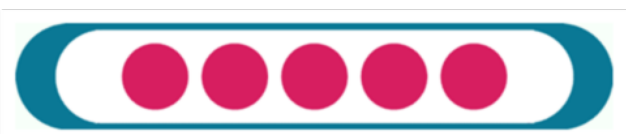

f)

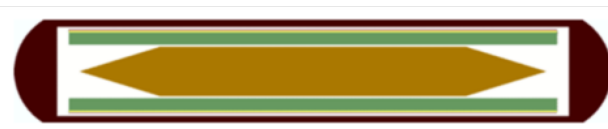

Figura 5. Ilustração de alguns modelos de semente de ${ }^{125} \mathrm{I}$ mostrando sua geometria interna ao invólucro de titânio, sendo a) Amersham, OncoSeed, 6711 b) BEBIG GmbH/ Theragenics Co., IsoSeed, I25.S06 c) IBt, InterSource, 1251L d) Mills Bio. Pharm., ProstaSeed, 125SL e) NASI, Prospera, Med3631 - ideal f) Implant Sciences, IPlant, 3500.

Fonte: Adaptado de TAYLOR; ROGERS, (2013).

Dentre os modelos de sementes de ${ }^{125}$ I detalhados anteriormente, este trabalho utilizou o modelo Amersham 6711 - OncoSeed - Oncura GE HealthCare (Figura 5a) de semente para experimentos e cálculos de distribuição de dose. Esta escolha justifica-se, pois este modelo de semente de ${ }^{125} \mathrm{I}$ tem características similares ao produzido no IPEN/CNEN contribuindo para o estudo e análise de seus parâmetros dosimétricos, além de ser amplamente utilizado em clínicas e hospitais brasileiros (ROSTELATO, 2005). 


\subsection{APLiCaÇões ClínICAS}

Sementes de ${ }^{125}$ I são comumente utilizadas para implantes temporários ou permanentes em aplicações intersticiais, intracavitárias ou superficiais. Elas também podem ser utilizadas como terapia primária, adjunta e para tratamento de recidiva de tumores. Há vastas descrições na literatura que demonstram as aplicações das sementes de ${ }^{125}$ I no tratamento de diversos tumores, como neoplasias oculares (SANCHEZ, 2006; STANNARD et al., 2002), câncer de fígado (ZHOU et al., 2007), carcinomas pancreáticos (MAAROUF et al., 2002) e principalmente no câncer de próstata (CHIBANI; WILLIAMSON; TODOR, 2005; LANDRY et al., 2012).

Para o biênio de 2016-2017 novos casos de câncer de próstata no Brasil caracterizarão este sítio anatômico como o de maior incidência, sendo também o mais frequentemente tratado utilizando sementes de iodo em braquiterapia. (INCA, 2016).

\subsubsection{CÂNCER DE Próstata}

O câncer de próstata é a neoplasia mais frequente em homens e sua incidência vem aumentando nas últimas décadas. As principais razões para isso são a elevação da expectativa de vida (que reflete no aumento da idade da população), a etnia, desenvolvimento de métodos diagnósticos mais apurados e a presença marcante do estilo de vida ocidental (sedentarismo e dieta altamente calórica) (SALVAJOLI; SOUHAMI; FARIA, 2013). Esta última pode estar associada às dietas ricas em gordura animal, carne vermelha, embutidos e cálcio, e pobre em vegetais, vitaminas D e E, licopeno e Ômega-3, assim como a obesidade e a presença da síndrome metabólica (MAGNABOSCO, 2014).

A próstata caracteriza-se por ser uma glândula exócrina que faz parte do sistema reprodutor masculino. Sua função é produzir e armazenar um fluido incolor e ligeiramente alcalino que constitui $10 \%$ a $30 \%$ do volume do liquido seminal, que juntamente com os espermatozoides constituem o sêmen. Estruturalmente, a próstata é envolta por uma cápsula de tecido conjuntivo e fibras musculares lisas da qual partem finas trabéculas que se dirigem para a profundidade do parênquima. Também é ocupada 
por células glandulares distribuídas em tubos ramificados, cuja secreção é drenada pelos ductos prostáticos que se abrem na superfície posterior do interior da uretra, um de cada lado do colículo seminal. É um órgão sólido que normalmente pesa cerca de 20 gramas (SALVAJOLI; SOUHAMI; FARIA, 2013).

A detecção do câncer de próstata ocorre mais comumente através do exame de toque retal e por meio de uma proteína eliminada pela glândula prostática, denominada Antígeno Prostático Específico, ou PSA (Prostate-Specific Antigen). O desenvolvimento do câncer de próstata aumenta proporcionalmente com aumento do nível do PSA. Como o PSA é produzido pelo corpo e pode ser usado para detectar doenças, é chamado de marcador biológico ou marcador tumoral. O PSA é encontrado principalmente no sêmen, mas uma pequena quantidade é também encontrada no sangue. Indivíduos saudáveis têm níveis de PSA menores de $4 \mathrm{ng} / \mathrm{ml}$ de sangue (INCA, 2002).

Clinicamente, combinam-se fatores para confirmar o estágio patológico do câncer de próstata e elaborar o pré-tratamento, como o valor do PSA sérico total, estágio clínico, e os níveis de Gleason. Esta abordagem dos fatores é conhecida como nomograma de Partin, e objetiva analisar estimativas de risco para a extensão prostática, invasão das vesículas seminais e metástases linfonodais (HUMPHREY, 2004).

O sistema de Gleason é inteiramente baseado no método de categorização de padrões histológicos de arranjo das células carcinogênicas em seç̧ões de tecido da próstata. Este sistema define cinco padrões básicos para gerar uma pontuação histológica, como mostrado na Figura 6. Os cinco níveis de Gleason são combinados por adição do padrão de grau primário e o padrão de grau secundário. O padrão primário é aquele que é predominante na área, por inspeção visual simples. O padrão secundário é o segundo padrão mais comum. Desta forma, o padrão de Gleason pode variar de 2 a 10. Se apenas um grau é observado na amostra de tecido, este é multiplicado por dois para obtenção da pontuação (HUMPHREY, 2004). 


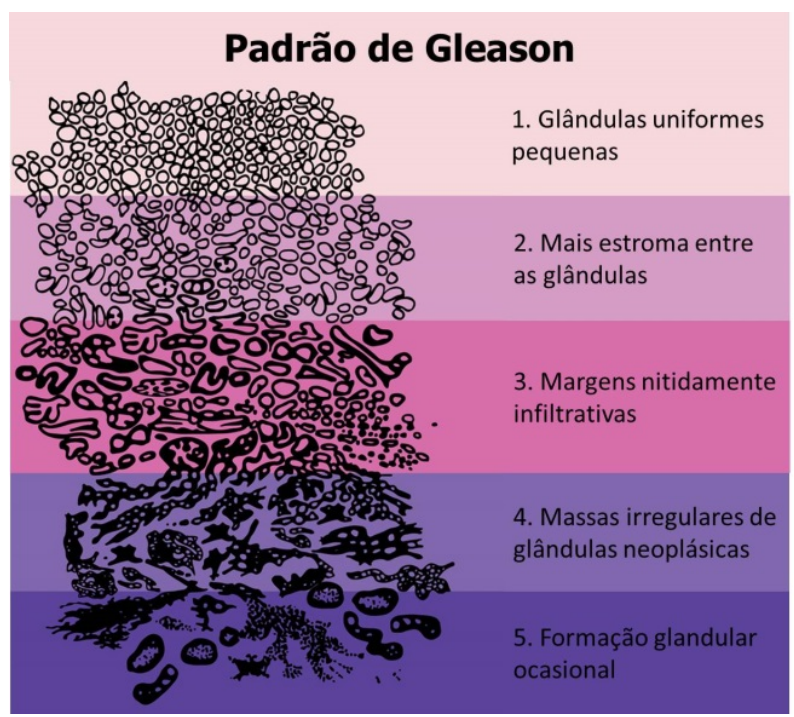

Figura 6. Padrão de Gleason ressaltando a diferença histológica dos diferentes níveis de acordo com o grau de indiferenciação celular.

Fonte: Adaptado de HUMPHREY, (2004)

Os estadiamentos característicos do câncer de próstata, que também compõem a análise pelo nomograma de Partin, estão ilustrados na Figura 7 e são caracterizados pelos seguintes aspectos:

Estágio I - O tumor ainda está confinado à próstata, sem comprometimento dos nódulos linfáticos e outros órgãos. Ele não é detectável pelo toque da próstata, bem como por imagens. Referencias do tumor podem ser somente percebidas com o aumento do nível de PSA (Antígeno Prostático Específico).

Estágio II - O tumor ainda está confinado a próstata, porém mais evoluído que no estagio I. Geralmente já pode ser identificado por exames de imagem e de toque. Neste estagio ainda não há sintomas para o paciente.

Estágio III - O tumor se espalha (pode atingir as vesículas seminais e o canal uretral), mas não alcançou os gânglios linfáticos ou outros órgãos. O sintoma mais frequente é a dificuldade ao urinar.

Estágio IV - Uma ou mais das seguintes condições estão presentes: O câncer se espalhou para tecidos próximos a próstata (além das vesículas seminais), como os músculos que agem no controle da urina, o reto ou a parede da pelve; O câncer atingiu os gânglios linfáticos ou o câncer disseminou-se para partes mais distantes do corpo, causando metástases (NATIONAL CANCER INSTITUTE, 2016). 

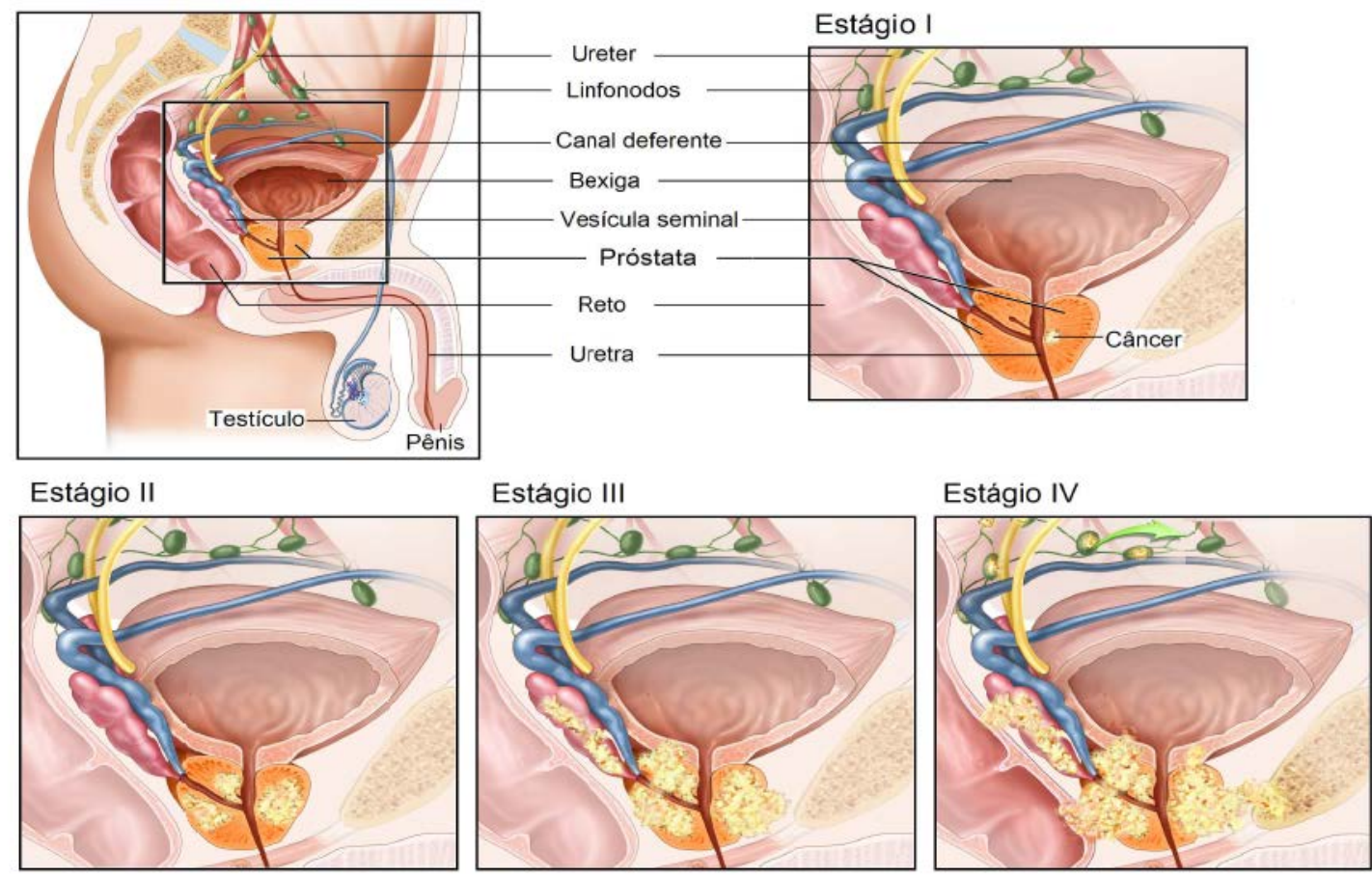

Figura 7. Anatomia dos sistemas reprodutivos e urinários masculinos, mostrando a próstata, os testículos, a bexiga, outros órgãos em corte coronal e estágios do câncer de próstata.

Fonte: Adaptado de NATIONAL CANCER INSTITUTE, (2016).

\subsection{Método de Monte Carlo}

Há muitos exemplos da utilização do método de Monte Carlo em diversas áreas, como fluxo de tráfego, o crescimento da população, finanças, genética, ciências de radiação, radioterapia e dosimetria de radiação (BIELAJEW, 2006). Em Física Médica, o método de Monte Carlo é uma ferramenta matemática que tem sido empregada para simular fontes de braquiterapia, aceleradores lineares, geometria de pacientes, dependência energética dos dosímetros, além de demais aplicações que possam ser representadas por processos estocásticos (FONSECA, 2015; YORIYAZ, 2009).

ROGERS (2006) publicou uma revisão sobre simulações que utilizaram o método de Monte Carlo na área de Física Médica. Em sua busca pelo termo "Monte Carlo" na base de dados PubMed ${ }^{1}$ foram obtidos 14.452 resultados, enquanto que a mesma pesquisa realizada neste trabalho em 2016 obteve 44.703 resultados. O aumento no uso de

\footnotetext{
${ }^{1}$ https://www.ncbi.nlm.nih.gov/pubmed/
} 
Códigos de Monte Carlo pode ser diretamente relacionado ao advento tecnológico do poder computacional que possibilitam diminuir os tempos de simulações devido à velocidade de processamento (FONSECA, 2015; YORIYAZ, 2009). O número de publicações por ano incluindo o termo "Monte Carlo" pode ser observado no gráfico exibido na Figura 8.

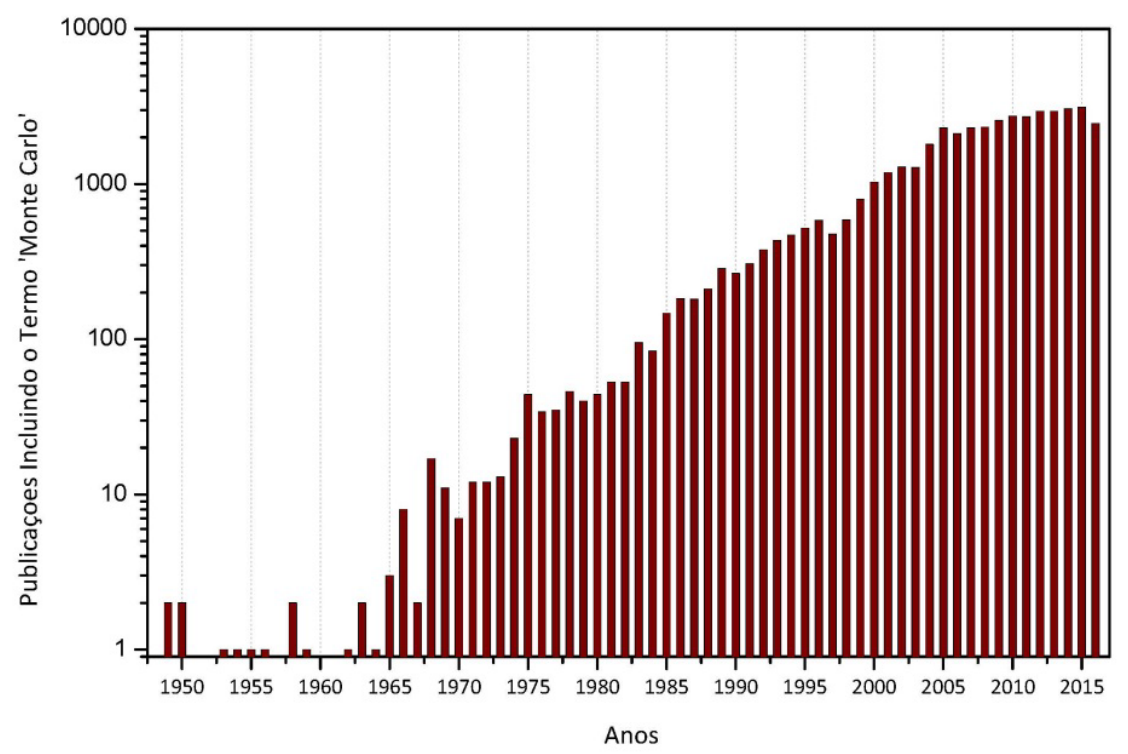

Figura 8. Número de Publicações incluindo o termo “Monte Carlo" nos anos de 1949 até 2016. Fonte: Adaptado de FONSECA, (2015)

O Método de Monte Carlo caracteriza-se por ser um método estatístico que utiliza técnicas de amostragem para obter uma solução desejada do problema físico. Sendo essencialmente simples na sua abordagem, este método busca uma solução para um sistema macroscópico através da simulação das suas interações microscópicas (BIELAJEW, 2006). Dentre as metodologias de cálculo que utilizam este método, destaca-se o código MCNP - Monte Carlo N-particle transport (BRIESMEISTER, 2000), que possui a alternativa do transporte de nêutrons, elétrons, prótons, fótons, pósitrons, além de partículas pesadas, em sistemas com alto detalhamento geométrico das fontes de radiação e do meio (JENKINS; NELSON; RINDI, 2012). Demais códigos de Monte Carlo também possuem amplas aplicações, como por exemplo GEANT4 - Geometry and Tracking (AGOSTINELLI et al., 2003), simula o transporte de uma ampla variedade de partículas (nêutrons, prótons, píons, etc.) e é utilizado em varias áreas de radioterapia; PENELOPE - Penetration and Energy Loss of Positrons and Electrons (BARO et al., 1995), simula o transporte de fótons, elétrons, e pósitrons, tendo uma abordagem detalhada de secções de choque para o 
transporte em baixas energias e um pacote de geometria flexível; e EGS que transporta fótons e elétrons e é o código mais utilizado para propósitos gerais na área de Física Médica (ROGERS, 2006).

Os códigos para transporte de radiação baseados neste método, possibilitam, desde que corretamente manipulados, uma ferramenta consagrada para os cálculos de distribuição de dose absorvida e outras grandezas relacionadas ao tratamento do câncer por radiação (YORIYAZ, 2009). O MCNP apresenta-se como ferramenta ideal para investigação dos diferentes processos de deposição de energia de acordo com a inserção de materiais tecido equivalentes que simulam o corpo humano, sendo deste modo, indispensável nas simulações dos fenômenos físicos envolvidos. 
CAPÍTULO 2

Objetivos 


\section{OBJETIVOS}

O objetivo principal deste trabalho consiste em contribuir nos estudos dosimétricos em braquiterapia com fonte de ${ }^{125} \mathrm{I}$, especificamente considerando os efeitos da heterogeneidade devido à presença de materiais com diferentes densidades e composições químicas, caracterizando objetos simuladores tecido equivalentes.

A metodologia descrita neste trabalho favorece o desenvolvimento de um sistema dosimétrico experimental, que avalie as interferências de materiais heterogêneos nas medidas de braquiterapia de baixa taxa de dose. Com isto, pretende-se melhorar a precisão do planejamento do tratamento braquiterápico e contribuir para o desenvolvimento deste campo. Para este propósito, foram adotados os seguintes objetivos específicos:

- Reprodução da metodologia de cálculo de deposição de dose, através de simulações de Monte Carlo, e de acordo com o TG-43U, para validação da geometria da semente utilizada.

- Estudo teórico da dependência energética dos dosímetros termoluminescentes utilizados para verificação de sua resposta conforme variação da energia.

- Simulações de Monte Carlo e medidas experimentais para cálculo de dose nos objetos simuladores confeccionados para validação dos dados, comparando os distintos materiais tecido equivalentes. 
CAPÍTULO 3

\section{FUNDAMENTOS}

TEÓRICOS 


\section{FUNDAMENTOS TEÓRICOS}

\subsection{Protocolo Task Group No. 43 DA AAPM}

Em 1995, baseado no modelo de cálculo proposto pelo INTERSTITIAL COLLABORATIVE WORKING GROUP (1990), um grupo composto pelo Radiation Therapy Committee da AAPM (American Association of Physicists in Medicine), publicou o protocolo intitulado Dosimetry of interstitial brachytherapy sources: recommendations of the AAPM Radiation Therapy Committee Task Group No. 43 (NATH et al., 1995), que continha recomendações sobre o formalismo dosimétrico e parâmetros dosimétricos para fontes intersticiais braquiterápicas. Mesmo considerando primariamente apenas fontes com baixas taxas de dose, o formalismo do TG-43 ainda tem sido amplamente utilizado e também praticamente aceito internacionalmente para altas taxas de dose (BALTAS et al., 2007).

Os formalismos de cálculos anteriores ao TG-43 não consideravam as diferenças nas estruturas internas das fontes distintas e nem o seu encapsulamento, os parâmetros para cálculo de dose dependem apenas do radionuclídeo. Além disto, os fatores utilizados referem-se à fluência de fótons em espaço livre e não em um meio espalhador. Em contraste com estes métodos, o formalismo do TG-43 incorporou de forma detalhada as metodologias de cálculo de dose e medidas experimentais que envolvem fontes de braquiterapia em geral (BALTAS et al., 2007). Este protocolo passou por atualizações nos anos de 2004 (RIVARD et al., 2004) e 2007 (RIVARD et al., 2007), sendo ainda vigente e referenciado na literatura como TG-43 ou TG-43U.

Em geral, o protocolo TG-43 resultou em melhoramentos significativos na padronização das metodologias para cálculo de dose, bem como as distribuições de taxas de dose usadas nas implementações clínicas em braquiterapia. Além deste protocolo definir as principais grandezas dosimétricas envolvidas, também define a água como o meio homogêneo onde é realizada a dosimetria, entretanto as aplicações clínicas requerem a distribuição de dose em um meio que simule, com maior acurácia, as configurações do paciente. 
No Task Group 43 da AAPM, as grandezas utilizadas para o cálculo da taxa de dose absorvida são medidas ou calculadas para um tipo específico de fonte e dependentes da estrutura desta fonte, além de seu espectro energético. Desta forma, a taxa de dose em um ponto com coordenadas $(r, \theta)$ pode ser expressa como sendo:

$$
\dot{D}(r, \theta)=S_{K} \cdot \Lambda \cdot \frac{\mathrm{G}_{\mathrm{L}}(\mathrm{r}, \theta)}{\mathrm{G}_{\mathrm{L}}\left(\mathrm{r}_{0}, \theta_{0}\right)} \cdot g_{L}(r) \cdot F(r, \theta)
$$

Onde $r$ é a distância radial do centro da fonte até o ponto de interesse; $r_{0}$ é a distância de referência especificada como sendo $1 \mathrm{~cm} ; \theta$ denota o angulo polar; $\theta_{0}$ define o ângulo de referência no plano transversal da fonte como sendo $90^{\circ} ; \dot{D}(r, \theta)$ é taxa de dose no ponto de interesse; $S_{K}$ é a Intensidade de kerma no ar (expressa em unidades de $\left.c G y \cdot c m^{2} \cdot h^{-1}\right) ; \wedge$ é a constante de taxa de dose $\left(c G y \cdot h^{-1} \cdot U^{-1}\right.$ ou $\left.\mathrm{cm}^{-2}\right) ; G_{L}(r, \theta)$ é a função de geometria $\left(\mathrm{cm}^{-2}\right) ; \mathrm{g}_{\mathrm{L}}(\mathrm{r})$ é a função de dose radial (adimensional) que caracteriza a distribuição de dose relativa no eixo transversal e $F(r, \theta)$ é a função de anisotropia (adimensional) que leva em conta a absorção e espalhamento dos fótons no em torno da fonte, conforme a variação angular.

Neste protocolo preconiza-se que os fatores e funções descritos, com exceção da função geometria e a intensidade de kerma no ar, sejam determinados por medidas ou cálculos realizados em objetos simuladores preenchidos por água. Para obtenção do valor da função geometria devem ser utilizados conceitos e cálculos de geometria plana e o valor de intensidade de kerma no ar deve ser medido com uma câmara de ionização ou calculado no vácuo (RIVARD et al., 2004).

A Figura 9 ilustra uma fonte de braquiterapia cilíndrica, exibindo a conformação geométrica das variáveis anteriormente descritas, onde o ponto onde será calculada a taxa de dose pode ser representado por meio de coordenadas polares $P(r, \theta)$ e o ponto de referencia é definido para $\theta_{0}=90^{\circ}$ e $r=1,0 \mathrm{~cm}$, sendo denotado por $P\left(r_{0}, \theta_{0}\right)$. 


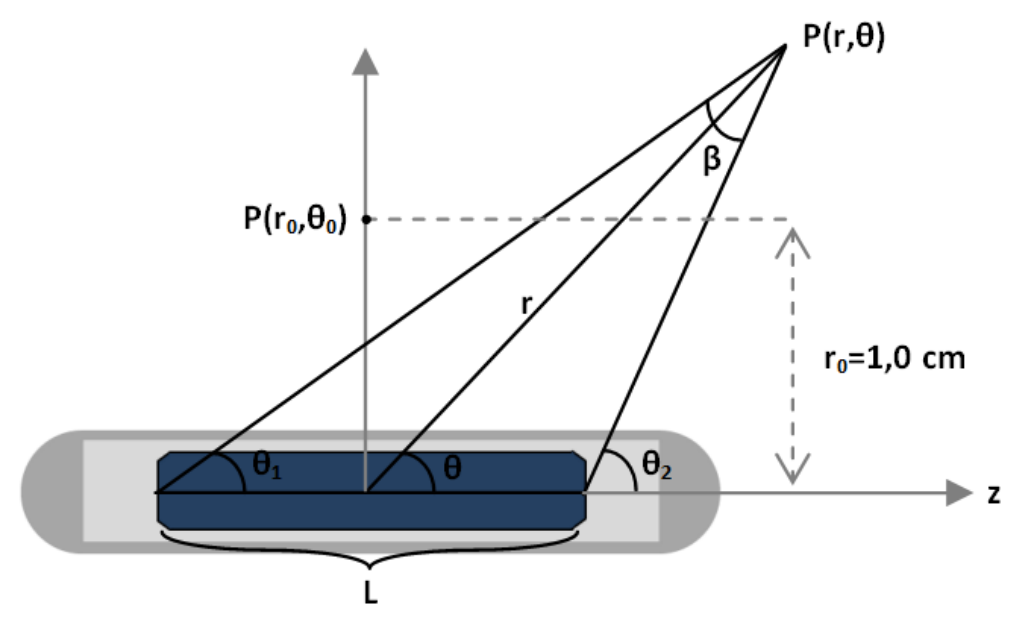

Figura 9. Representação esquemática do sistema de coordenadas introduzido pelo TG-43 e usado para cálculos dosimétricos em braquiterapia.

Fonte: Adaptado de RIVARD et al., (2004)

\subsubsection{INTENSIDADE Do KERMA No AR, $S_{K}$}

A intensidade de kerma no ar é a medida da intensidade da fonte de braquiterapia, sendo dependente de sua atividade, pois é especificada em termos de taxa de kerma no $\operatorname{ar} \dot{K}_{\delta}(d)$ em um ponto ao longo do eixo transverso da fonte, esta distância deve ser grande o suficiente para que a fonte seja tratada como pontual. A intensidade de kerma no ar é definida como sendo o produto da taxa de kerma no ar em uma calibração à distância d (medida "no vácuo", pois, as medições devem ser corrigidas para atenuação de fótons e espalhamento no ar e qualquer outro meio interposto entre a fonte e o detector), e o quadrado desta distância, que pode ser representada pela Equação 2, de modo que a unidade de $S_{\mathrm{K}}$ será $\mathrm{U}=1 \mu \mathrm{Gy} \cdot \mathrm{m}^{2} \cdot \mathrm{h}^{-1}=1 \mathrm{cGy} \cdot \mathrm{cm}^{2} \cdot \mathrm{h}^{-1}$.

$$
S_{K}=\dot{K}_{\delta}(d) \cdot d^{2}
$$

A fim de excluir os fótons de baixa energia que contribuiriam no aumento da intensidade de kerma-ar (porém seriam insignificantes no calculo de doses absorvidas para distâncias maiores que $0,1 \mathrm{~cm}$ ), o TG-43 sugere uma energia de corte ( $\delta=5 \mathrm{keV}$ ) para fótons. 
Experimentalmente, a determinação do valor de intensidade de kerma-ar demanda condições especiais somente fornecidas por laboratórios metrológicos de padronização primários ou secundários, por isto em 1999, o National Institute of Standards and Technology (NIST) introduziu um detector conhecido pelo termo WAFAC (Wide-Angle Free-Air Chamber), que permitiu filtrar contaminações de raios- $X$ de baixas energias (através de um filtro de Alumínio) com um maior volume sensível de modo que fontes individuais, posicionadas num rotor, pudessem ser medidas com precisão (SELTZER et al., 2003). A Figura 10 ilustra o desenho esquemático do funcionamento da câmara através de seu sistema de subtração de interferências causadas pela janela dos eletrodos.

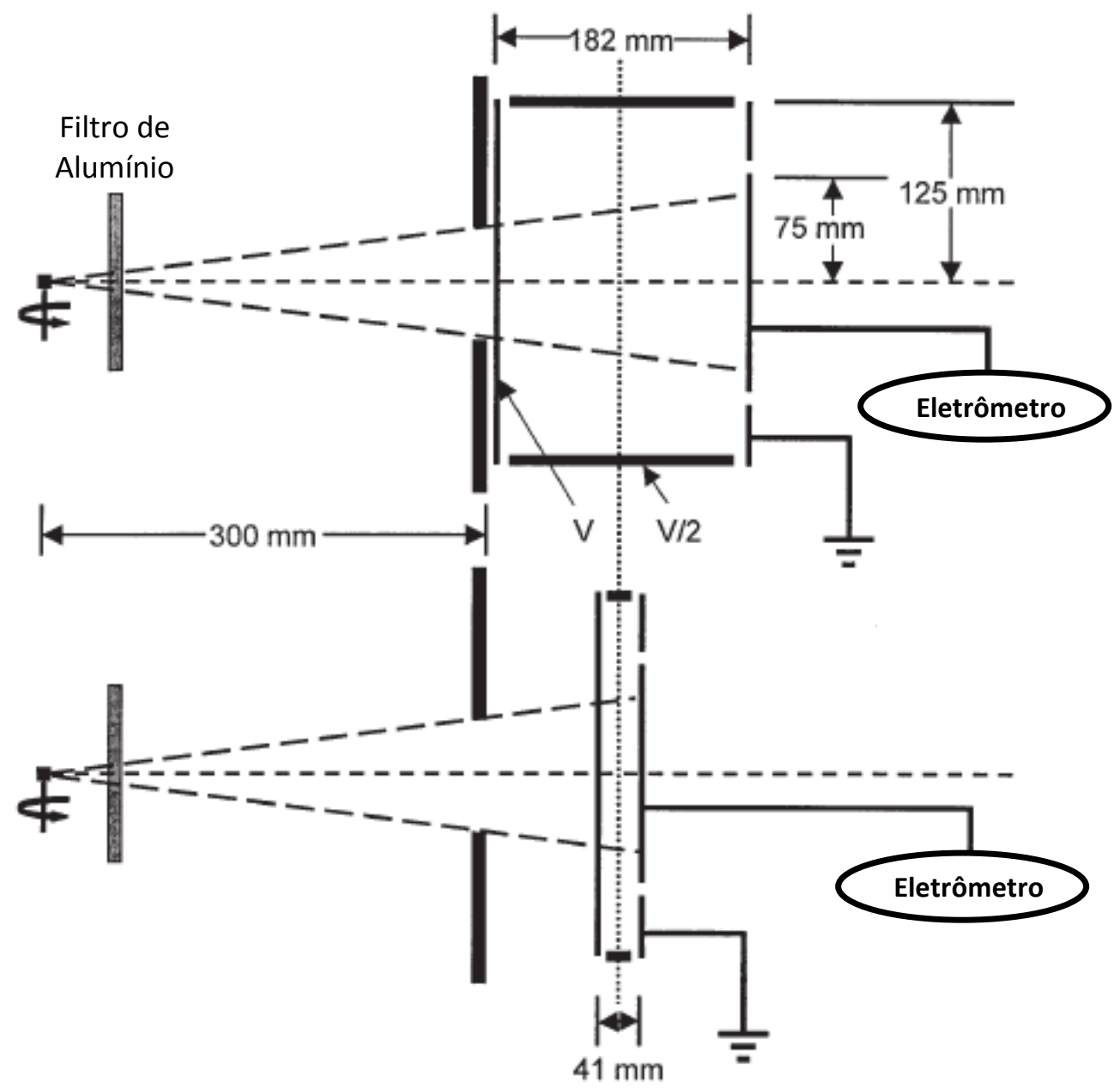

Figura 10. Sistema de medição da câmara WAFAC.

Fonte: SELTZER et al., (2003) 


\subsubsection{Constante De TaXa DE Dose, $\Lambda$}

O parâmetro constante de taxa de dose $(\Lambda)$ é inversamente proporcional a Intensidade de Kerma no Ar e portanto, influenciado por ela. A constante de taxa de dose é definida como sendo a razão entre taxa de dose calculada em um objeto simulador de água no ponto de referência $\left(r_{0}=1,0 \mathrm{~cm}\right.$ e $\left.\theta_{0}=90^{\circ}\right)$ e uma unidade da intensidade de kerma no ar da fonte. Matematicamente, a constante de taxa de dose pode ser representada pela Equação 3 e sua unidade será $\mathrm{cm}^{-2}$.

$$
\Lambda=\frac{\dot{D}\left(r_{0}, \theta_{0}\right)}{S_{K}}
$$

Analisando as variáveis que constituem a constante de taxa de dose verifica-se que nela incluem-se efeitos da geometria da fonte, seu encapsulamento e autofiltração, distribuição espacial do material radioativo dentro da fonte, além de valores referentes ao espalhamento na água ao redor da fonte.

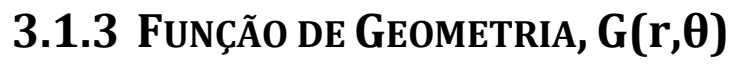

A função de geometria $G(r, \theta)$ fornece uma correção efetiva baseada na lei do inverso do quadrado da distância de acordo com o modelo aproximado de distribuição espacial de radioatividade no interior da fonte porém desconsidera o espalhamento e a atenuação dos fótons em sua estrutura (RIVARD et al., 2004). A Função de Geometria em 2D é utilizada quando a distribuição de radioatividade pode ser aproximada a uma fonte pontual ou a uma fonte linear de comprimento L, conforme esquematizado anteriormente na Figura 9 e descrito pelas Equações 4 e 5:

$$
\begin{gathered}
G_{p}(r, \theta)=r^{-2} \\
G_{L}(r, \theta)=\left\{\begin{array}{lc}
\frac{\beta}{L \cdot r \cdot \operatorname{sen} \theta} & \text { se } \theta \neq 0 \\
\left(r^{2}-\frac{L^{2}}{4}\right)^{-1} & \text { se } \theta=0^{\circ}
\end{array}\right.
\end{gathered}
$$


$G_{p}$ é utilizado para aproximação de fonte pontual e $G_{L}$ para aproximação de fonte linear onde $L$ é o comprimento da fonte e $\beta$ é o ângulo obtido em relação ao ponto $(r, \theta)$, ou seja $\beta=\theta_{2}-\theta_{1}$. Desenvolvendo os cálculos e conceitos de geometria plana, adota-se a expressão demonstrada na Equação 6 para o parâmetro $\beta$ (NATH; YUE, 2002).

$$
\beta=\tan ^{-1}\left(\frac{r \cdot \cos \theta+\frac{L}{2}}{r \cdot \sin \theta}\right)-\tan ^{-1}\left(\frac{r \cdot \cos \theta-\frac{L}{2}}{r \cdot \sin \theta}\right)
$$

No contexto de cálculos de dose em casos clínicos de braquiterapia, o efeito da função geometria seria fornecer aproximações simplistas que permitam obter uma precisão suficiente para realização do planejamento do tratamento, pois, os dados obtidos com esta função são uma interpolação entre os valores de taxa de dose tabulados em pontos definidos (RIVARD et al., 2004, 2007).

\subsubsection{FunÇÃo de Dose Radial, G(r)}

A função de dose radial $g(r)$ é caracterizada pela variação da taxa de dose causada pelos efeitos da absorção e espalhamento no meio ao longo do eixo transversal da fonte, sendo calculado somente com angulação adotada como referência $\left(\theta_{0}\right)$. Esta função é definida como:

$$
g(r)=\frac{\dot{D}\left(r, \theta_{0}\right) \cdot G\left(r_{0}, \theta_{0}\right)}{\dot{D}\left(r_{0}, \theta_{0}\right) \cdot G\left(r, \theta_{0}\right)}
$$

Por ser uma função normalizada, espera-se que no ponto de referência $g(r)=1$ e $\mathrm{g}(\mathrm{r})<1$ para pontos com maior raio, isto é, que haja um decréscimo da taxa de dose devido ao espalhamento e absorção do meio (objeto simulador contendo água). O material de encapsulamento da fonte também pode exercer uma autofiltração, atenuando os fótons gerados pela mesma e assim, influenciando nesta função. 


\subsubsection{FunÇÃo dE ANISOTROPIA, F(r, $\theta)$}

A função de anisotropia é calculada estabelecendo-se um raio fixo, de forma representar a anisotropia da distribuição da dose em torno da fonte devido a sua autofiltração, incluindo os efeitos de absorção e espalhamento no meio. A Equação 8 expressa as variáveis que compõem esta função.

$$
F(r, \theta)=\frac{\dot{D}(r, \theta) \cdot G\left(r, \theta_{0}\right)}{\dot{D}\left(r, \theta_{0}\right) \cdot G(r, \theta)}
$$

Deste modo, a função de anisotropia descreve a variação angular da taxa de dose sobre a fonte para cada uma das distâncias adotadas. $\mathrm{O}$ fator geométrico permite que a influência da lei do inverso do quadrado da distância seja suprimida na distribuição da dose ao redor da fonte.

\subsection{Protocolo Task Group 186}

O Protocolo Task Group 186 foi recentemente publicado no ano de 2012 e elaborado pelo grupo de trabalho da AAPM em parceria com o Grupo Europeu de Braquiterapia da Sociedade Europeia de Radioterapia e Oncologia (GEC-ESTRO), Sociedade Americana de Braquiterapia (ABS), e o Grupo Australiano de Braquiterapia (ABG) (BEAULIEU et al., 2012).

O TG-186 fornece orientações para introdução de Algoritmos de Cálculo de Dose Baseados em Modelos (MBDCAs) que permitem maior precisão na dosimetria em braquiterapia. A abordagem dos MBDCAs consiste em modelos que simulem explicitamente o transporte de radiações no meio real de forma que seja calculada a distribuição de dose volumétrica considerando as composições do meio, os fenômenos de espalhamento e seções de choque, além de necessitar de descrições geométricas mais precisas do paciente e dos aplicadores. As três metodologias atuais para o planejamento do tratamento de braquiterapia que envolvem MBDCAs são o Método por Convolução/Superposição de Cone Colapsado (Collapsed-Cone Convolution, Superposition 
Convolution), modelo baseado na solução da equação de Boltzman em grade (Grid-Based Boltzmann Solver - GBBS) e Método de Monte Carlo (MC) (BEAULIEU et al., 2012).

O protocolo TG-186 recomenda que a dose seja reportada de acordo com o meio de especificação de dose $(x)$ e a composição do meio utilizado para realizar o transporte de radiação $(y)$, sendo indicada por $D_{x, y}$. Em situações especificas as diferenças entre os cálculos de dose em braquiterapia seguindo o modelo do TG-43, para transporte e especificação da dose na água $\left(D_{w, w}\right)$ levaram a diferenças no cálculo de dose que excedem um fator de 10. O TG-186 recomenda que sejam realizados cálculos de dose transportados no meio e especificados no meio $D_{m, m}$, e de dose calculada em água e transportada no meio $D_{w, m}$, e também cita alguns estudos presentes na literatura que realizaram a comparação entre estes parâmetros (BEAULIEU et al., 2012).

\subsection{ESPECTRO DE EMISSÃO DO 125I}

O elemento ${ }^{125}$ I é um radionuclídeo filho do ${ }^{125}$ Xe que é usualmente criado em reatores nucleares a partir do ${ }^{124} \mathrm{Xe}$. O esquema de decaimento a seguir ilustra este processo.

$$
{ }^{124} \mathrm{Xe}(n, \gamma){ }^{125} \mathrm{Xe} \rightarrow{ }^{125} \mathrm{Xe}(E C, 16,9 h) \rightarrow{ }^{125} I
$$

A reação principal para a produção de ${ }^{125}$ I é a irradiação de ${ }^{124}$ Xe enriquecido em sua forma gasosa. Como a abundância natural de ${ }^{124}$ Xe é de apenas $0,1 \%$ o benefício de enriquecimento isotópico não ultrapassa os custos.

O ${ }^{124} \mathrm{Xe}$ resulta em ${ }^{125}$ I através da captura de nêutrons e posterior captura eletrônica. Embora sua produção ocorra mais comumente por meio de reatores nucleares, há como desvantagem a produção de ${ }^{126} \mathrm{I}$, um gás que não tem aplicação na área médica e é considerado um contaminante, não podendo ultrapassar $1 \%$ da amostra. 
O radionuclídeo ${ }^{125}$ I decai via captura eletrônica para o primeiro estado excitado de ${ }^{125}$ Te. A desexcitação para o estado estável do ${ }^{125}$ Te ocorre quase $7 \%$ por emissão de raios- $\gamma$ e a maioria de quase $93 \%$ ocorre via conversão interna, que resulta na emissão de raios-x característicos. A Figura 11 esquematiza o decaimento do ${ }^{125} \mathrm{I}$ em ${ }^{125} \mathrm{Te}$. Em média 1,476 fótons são emitidos por desintegração de ${ }^{125} \mathrm{I}$. As baixas energias emitidas podem ser facilmente filtradas pelas camadas do material que encapsula a fonte (BALTAS; SAKELLIOU; ZAMBOGLOU, 2007; RIVARD et al., 2004). A Tabela 1 denota as energias emitidas pelo ${ }^{125} \mathrm{I}$, assim como sua respectiva intensidade e tipo de emissão. Estes dados foram posteriormente utilizados para descrição da fonte nos arquivos de entrada (inputs) do MCNP.

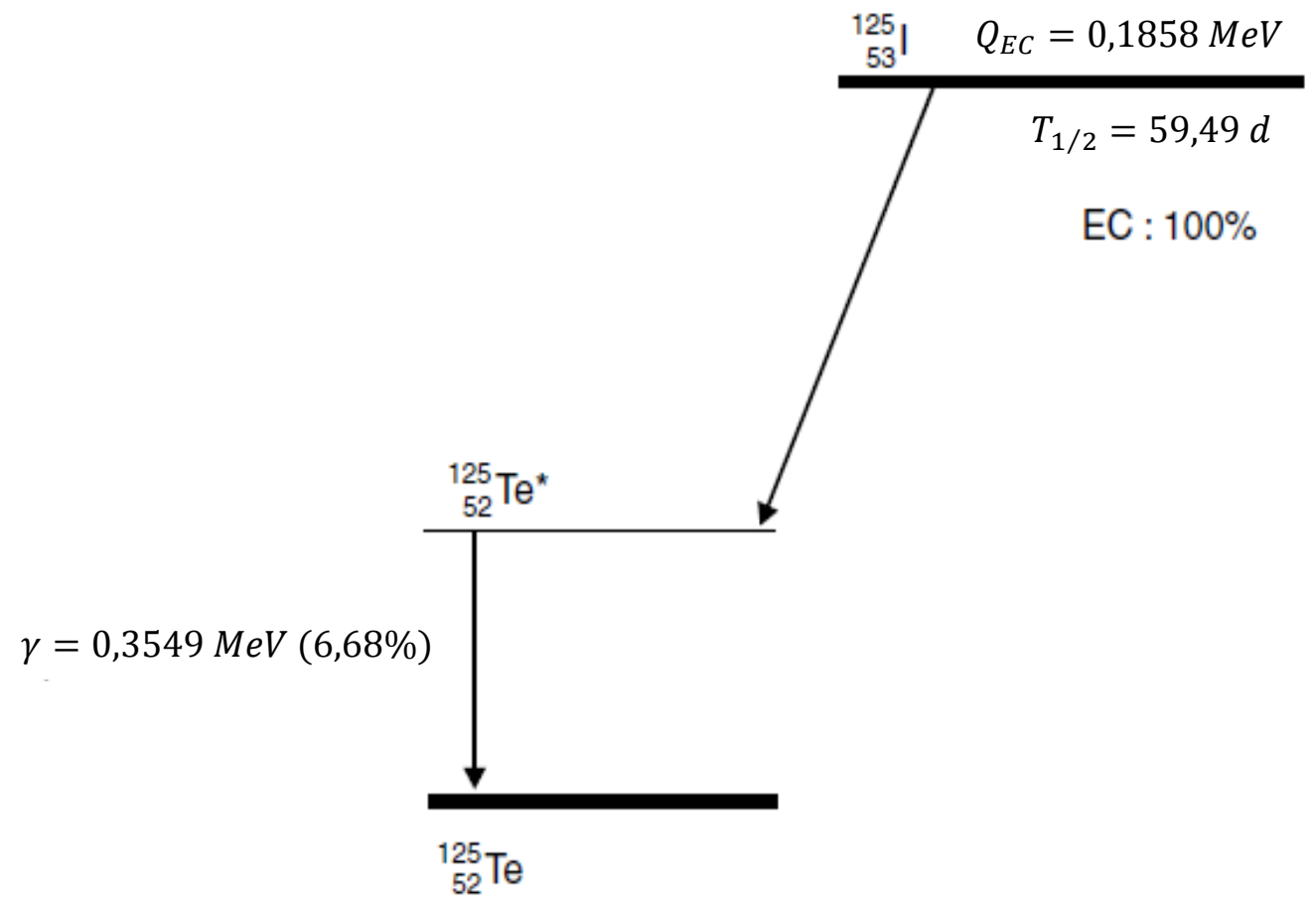

Figura 11. Diagrama Esquemático do decaimento do radioisótopo ${ }^{125} \mathrm{I}$ para o estado excitado e posteriormente para o estado estável de ${ }^{125} \mathrm{Te}$.

Fonte: (BALTAS; SAKELLIOU; ZAMBOGLOU, 2007) 
Tabela 1. Emissão de partículas resultantes do decaimento do isótopo ${ }^{125} \mathrm{I}$ em ${ }^{125} \mathrm{Te}$, sendo elas elétrons (auger e de conversão interna), raios-x característicos e raios $\gamma$.

\begin{tabular}{|c|c|c|}
\hline Energia & Tipo de Emissão & Intensidade \\
\hline (keV) & & $(\%)$ \\
\hline 3,19 & $\mathrm{e}^{-}$Auger & 156,500 \\
\hline 22,70 & $\mathrm{e}^{-}$Auger & 19,800 \\
\hline 3,68 & $\mathrm{e}^{-}$de Conversão Interna & 78,100 \\
\hline 30,55 & e- de Conversão Interna & 10,700 \\
\hline 34,49 & $\mathrm{e}^{-}$de Conversão Interna & 2,130 \\
\hline 35,32 & e- de Conversão Interna & 0,421 \\
\hline 35,49 & $\mathrm{e}^{-}$de Conversão Interna & 0,045 \\
\hline 3,77 & Raio-X Característico & 14,800 \\
\hline 27,20 & Raio-X Característico & 39,600 \\
\hline 27,47 & Raio-X Característico & 73,100 \\
\hline 30,94 & Raio-X Característico & 6,740 \\
\hline 31,00 & Raio-X Característico & 13,000 \\
\hline 31,70 & Raio-X Característico & 3,750 \\
\hline 35,49 & Emissão $\gamma$ & 6,680 \\
\hline
\end{tabular}

\subsection{DOSIMETRIA TERMOLUMINESCENTE}

Dosímetros termoluminescentes são cristais ou policristais dopados com quantidades adequadas de ativadores e caracterizam-se pela emissão de luz durante o aquecimento de seu material, previamente excitado através da incidência de radiação (OBERHOFER; SCHARMANN, 1981)

Materiais com propriedades termoluminescentes sofrem mudanças em sua rede cristalina conforme irradiados. Estas mudanças e os ativadores presentes fazem com que armadilhas sejam criadas na banda energética proibida, deste modo, ao migrar através das bandas energéticas, os elétrons podem ficar contidos nestas armadilhas. Desta forma, a radiação ionizante, ao interagir com os elétrons, cede energia para que os mesmo saiam da camada de valência e migrem para a camada de condução, podendo ficar armadilhados nesta camada graças a armadilhas criadas pelos ativadores.

Inicialmente, os elétrons devem receber energia da radiação incidente no cristal para que fiquem armadilhados. Diferentes tipos de radiações podem fornecer energia de inúmeras formas para sua estrutura eletrônica, como por exemplo, em uma irradiação com fótons na ordem de keVs, onde ocorrem efeitos fotoelétrico e Compton. 
Ao serem armadilhados, os elétrons deixam buracos de carga energética oposta em sua posição anterior na banda de valência. Após a irradiação, se o material for submetido a aquecimento ocorrerá a relaxação térmica, que é o mecanismo predominante em processos com dependência de temperatura. Com isto, o elétron pode escapar da armadilha e se recombinar com o buraco, emitindo luz no processo nos chamados centros de luminescência. A Figura 12 ilustra este processo.

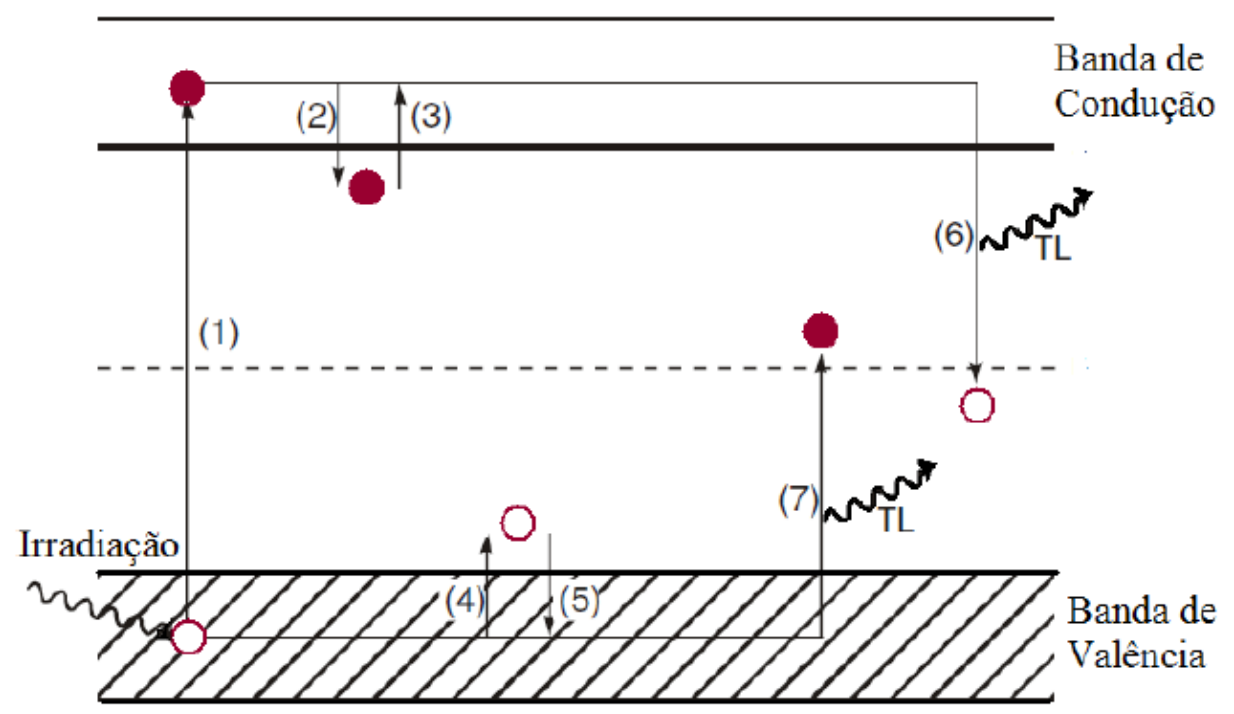

Figura 12. Modelos de bandas de energia mostrando as transições eletrônicas em um material termoluminescente. (1) Excitação de um elétron da Banda de Valência para a Banda de Condução. (2) e (4) Elétrons e buracos armadilhados, respectivamente. (3) e (5) Elétrons e buracos livres depois de receberem energia suficiente para serem liberados. (6) e (7) Elétrons e buracos recombinando com seus portadores de cargas opostas e liberando um fóton no processo.

Fonte: (MCKEEVER, 1988)

A sensibilidade dos dosímetros termoluminescentes relaciona diretamente a quantidade de luz liberada através do aquecimento e a dose de radiação absorvida. Os picos dosimétricos dos TLDs compõem a curva de emissão termoluminescente. Os picos estão associados a uma ou mais armadilhas, sendo proporcionais à taxa de desarmadilhamento dos elétrons. Os TLDs de diferentes composições apresentam diferentes formatos de picos e curvas TL. A Figura 13 mostra um exemplo de curva de emissão termoluminescente. 


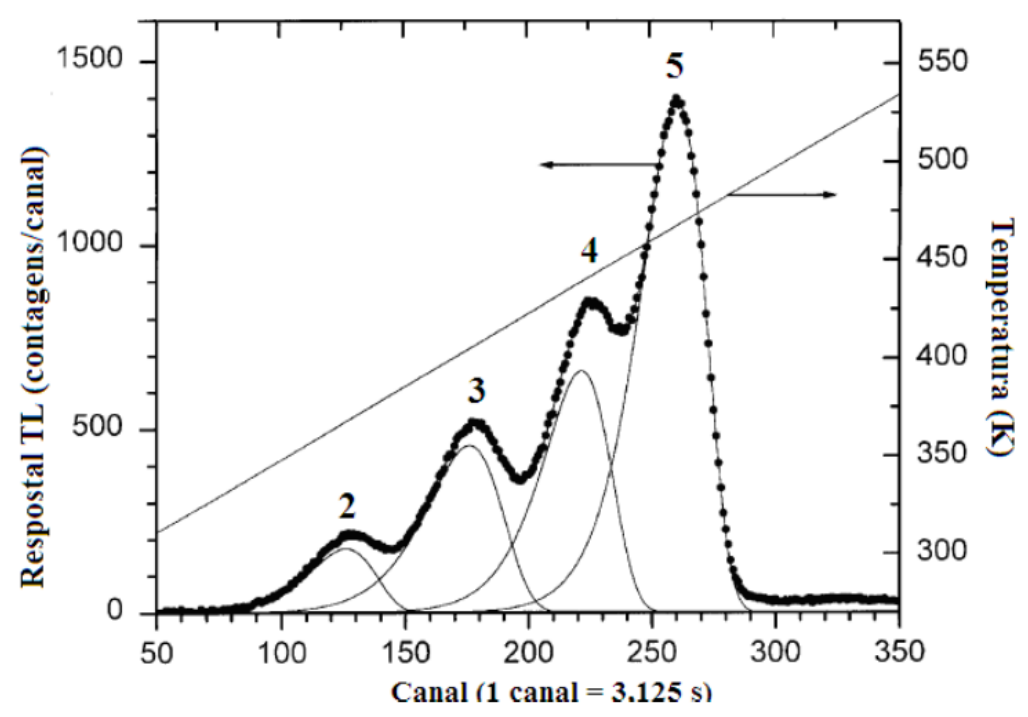

Figura 13. Curva de Emissão Termoluminescente do TLD-100 obtida através de irradiação com ${ }^{60} \mathrm{Co}$.

Fonte: (MCKEEVER, 1988)

$\mathrm{Na}$ Figura 13 é possível observar quatro picos de emissão TL, sendo eles convencionados como 2, 3, 4 e 5 . O pico de número 1 teve sua luminescência liberada de forma espontânea devido a sua meia vida pequena após a irradiação, este fenômeno é denominado de fading. Os picos que apresentam boa sensibilidade e estabilidade são selecionados para a realização das medidas e com isto recebem o nome de picos dosimétricos.

Os TLDs podem ser reutilizados, porém, para isto necessitam de tratamento térmico. O tratamento térmico consiste em deixar os TLDs dentro de muflas aquecidas em temperaturas determinadas por um período de tempo, e varia conforme cada tipo de TLD específico. Durante este tratamento, os elétrons ainda armadilhados na estrutura cristalina são liberados, resultando na eliminação das informações dosimétricas residuais.

Deste modo, a utilização dos dosímetros termoluminescentes compreende um ciclo de tratamento térmico, irradiação e leitura para a coleta de dados. Para minimizar as incertezas durante a aquisição dos sinais gerados pelos TLDs pode-se realizar um tratamento térmico pré-leitura, para minimizar a influência dos picos de baixa temperatura ou aguardar certo tempo até realizar a leitura, para que os picos menos estáveis percam sua luminescência. As etapas utilizadas nos ciclos do TLD devem ser mantidas para que não haja aumento das incertezas associadas às medidas, já que estes dosímetros são sensíveis a estas alterações. 


\subsection{O Código MCNP}

O Método de Monte Carlo foi desenvolvido durante o projeto Manhattan na Segunda Guerra Mundial. As técnicas de amostragem estatística aperfeiçoadas faziam alusão aos jogos de azar, onde a aleatoriedade seria estatisticamente resolvida através de probabilidades previsíveis. Deste modo, este método foi nomeado em referência à cidade de Mônaco, mundialmente famosa por ser a capital dos jogos de azar (BRIESMEISTER, 2000; YORIYAZ, 2009).

O transporte de radiação no código MCNP é realizado pela simulação de cada possível interação sofrida pela partícula durante sua trajetória, de modo que o conjunto de eventos se inicia no momento em que ela é emitida pela fonte e termina quando é absorvida ou escapa do sistema, sendo este conjunto denominado história da partícula. As simulações matemáticas para os eventos físicos de interação da radiação são geradas por meio de amostragens aleatórias de Funções Densidade de Probabilidade (PDF). Com o aumento do número de histórias da partícula há diminuição das incertezas estatísticas à medida que um número grande de amostragens é processado. Isto explicita a relação do aumento do uso dessa técnica concomitantemente ao avanço tecnológico computacional (ANTUNES, 2010; YORIYAZ, 2009).

Neste trabalho foram utilizadas as versões 5 e 6 do código MCNP (GOORLEY et al., 2012; X-5 MONTE CARLO TEAM, 2005) para descrições das grandezas geométricas simuladas analiticamente e cálculo da deposição de energia. Para realizar as simulações no MCNP se faz necessário elaborar um arquivo de entrada (input) que é composto por 3 blocos principais, sendo eles:

- BLoco I - Composto principalmente pela descrição geométrica das células que são intersecções e/ou uniões das superfícies declaradas no bloco II e caracterizam unidades de volume. Para cada uma das células deve-se explicitar o material e densidade que a compõe, assim como a importância para as partículas que irão interagir no meio delimitado.

- Bloco II - Destinado à descrição de cartões de superfícies geométricas que serão utilizadas no Bloco I. Estas superfícies são pré-estabelecidas pelo código, sendo compostas por mnemônicos que definem parâmetros matemáticos das equações que os representam. 
- BLoco III - São descritos os materiais a serem utilizados por cada célula; secções de choque; formato e distribuição das fontes; espectro energético, direção e sentido de propagação das partículas geradas na fonte; e os tallies que são cartões que descrevem o parâmetro físico a ser obtido.

Os resultados obtidos pelo MCNP, de acordo com os tallies específicos requisitados, são exibidos no arquivo de saída (output) gerado (SHULTIS; FAW, 2006). Nos arquivos de saída, o MCNP também cria automaticamente informações padrões que permitem uma melhor visão sobre a física do problema e a adequação da simulação de Monte Carlo, incluindo: o número de colisões em uma célula, o peso médio, caminho livre médio, a quantidade de interações da radiação com a matéria de acordo com os diferentes efeitos, eficiência da fonte, etc (X-5 MONTE CARLO TEAM, 2005).

Os tallies podem ser interpretados como cartões que permitem calcular parâmetros físicos específicos, como por exemplo, fluxo, corrente ou deposição de energia. Os valores apresentados como resultados dos tallies são valores médios da grandeza definida, normalizados por cada partícula emitida da fonte. Inerente a cada valor está associada uma incerteza estatística também representada no arquivo de saída.

O MCNP fornece sete tipos de tally padrão. Neste trabalho, os tallies foram utilizados para cálculo do kerma no ar e na água, assim como para contabilizar as doses depositadas nos TLDs dispostos nas distintas configurações de objetos simuladores.

O tally *F4 juntamente com os cartões auxiliares DE/DF e o coeficiente de absorção de energia em massa $\left(\mu_{\mathrm{en}} / \rho\right)$ foi utilizado para calcular a dose absorvida, de modo que os valores de $\mu_{\text {en }}$ fossem ponderados pela fluência energética dos fótons incidentes. 0 cartão *F4 considera uma partícula de peso $\mathrm{W}$ e energia $\mathrm{E}$ que realiza um caminho de comprimento $\mathrm{T}$ em um volume $\mathrm{V}$ estabelecido. Este segmento realiza uma contribuição WTE/V para a fluência energética na célula, sendo a soma destas contribuições reportada como o tally *F4 no arquivo de saída (SHULTIS; FAW, 2006). Deste modo, pode-se definir este tally através da equação:

$$
{ }^{*} F 4=\frac{1}{V} \int d E \int d t \int d V \int d \Omega E \psi(\vec{r}, \Omega, E, t)
$$


Onde,

${ }^{*} F 4$ = Fluência energética média na célula (partículas $. \mathrm{MeV} / \mathrm{cm}^{2}$ )

$V=$ Volume da célula $\left(\mathrm{cm}^{3}\right)$

$d E=$ Energia $(\mathrm{MeV})$

$d t=$ Tempo $(\mathrm{s})$

$d \Omega$ = ângulo $(\mathrm{sr})$

$\psi(\vec{r}, \Omega, E, t)=$ fluxo angular (partículas $\left./{\mathrm{sr} . \mathrm{cm}^{2}}^{2} \mathrm{MeV} . \mathrm{s}\right)$

Em adição ao tally padrão, o MCNP também apresenta o tally tipo 4 em forma de malha. Isto é, ele permite calcular a fluência (ou fluência energética) em um volume composto por malhas através do cartão FMESH4 (ou *FMESH4). O comprimento do traço é calculado sobre as células da malha de registro, e é normalizado por cada partícula emitida da fonte. Utilizando os cartões auxiliares DE/DF é possível obter o valor de dose absorvida em cada malha do volume especificado permitindo desta forma obter-se a distribuição espacial de dose no volume (SHULTIS; FAW, 2006; X-5 MONTE CARLO TEAM, 2005).

Os cálculos de kerma no ar e dose nas células de água foram realizados através do tally F6. Semelhantemente ao tally F4, este cartão consiste no cálculo de fluxo, porém, é multiplicado por uma função dependente da energia e pela seção de choque, de modo que a energia transferida para os elétrons é depositada localmente (X-5 MONTE CARLO TEAM, 2005). O tally F6 pode ser descrito pela equação:

$$
\mathrm{F} 6=\frac{\rho_{a}}{m} \int d E \int d t \int d V \int d \Omega \sigma_{t}(E) H(E) \psi(\vec{r}, \Omega, E, t)
$$

Onde,

F6 = Energia total depositada (MeV/g)

$\rho_{a}=$ Densidade atômica (átomos/barn-cm)

$m$ = massa da célula $(\mathrm{g})$

$d E=$ Energia $(\mathrm{MeV})$

$d t=$ Tempo $(\mathrm{s})$

$d V=$ Volume da célula $\left(\mathrm{cm}^{3}\right)$ 


$$
\begin{aligned}
& d \Omega=\text { Ângulo }(\mathrm{sr}) \\
& \sigma_{t}(E)=\text { Seção de choque microscópica total (barn) } \\
& H(E)=\text { Energia transferida por colisão (MeV/colisão) } \\
& \psi(\vec{r}, \Omega, E, t)=\text { Fluxo angular (partículas/sr.cm².MeV.s) }
\end{aligned}
$$

A energia depositada nos TLDs e no PMMA, quando presentes nos objetos simuladores elaborados, foi contabilizada através do tally *F8 (MeV/g). Neste tally, o calculo é realizado através da intensidade dos pulsos produzidos pela interação da radiação com a matéria, isto é, pela diferença de energia de uma partícula ao entrar e sair do volume de interesse, semelhante ao que ocorre nos detectores reais (FONSECA, 2010; X-5 MONTE CARLO TEAM, 2005).

O resultado apresentado pelo MCNP, no arquivo de saída, especifica o tally utilizado pelo usuário e exibe a média dos resultados obtidos na simulação de $\mathrm{N}$ histórias de partículas e seu erro relativo, sendo:

$$
Y=\bar{x} \pm R
$$

Onde,

$\mathrm{Y}=$ Resultado do tally para a célula de interesse.

$\bar{x}=$ Média aritmética simples dos resultados das interações.

$R=$ Erro Relativo definido como a razão entre desvio padrão da média e a média simples.

O aumento do tempo computacional de simulação está relacionado com o número de histórias simuladas e é inversamente proporcional ao erro relativo fornecido pelo MCNP. Seu manual orienta que valores com erros superiores a 0,5 não devem ser considerados e acima de 0,1 podem ser questionáveis (SHULTIS; FAW, 2006; X-5 MONTE CARLO TEAM, 2005). 
CAPÍTULO 4

Materiais e MÉTOdos 


\section{MATERIAIS E MÉTODOS}

A metodologia descrita foi estruturada conforme os elementos em comum utilizados nos estudos dos objetos simuladores abordados, como o tipo de fonte e os dosímetros. Os objetivos específicos anteriormente descritos adequam-se a análise destes elementos, sendo introduzidos no decorrer de suas elucidações. As seções abordadas também se associam aos resultados que serão posteriormente apresentados e discutidos.

Inicialmente foram analisados aspectos dosimétricos simulados que evidenciaram a caracterização da semente de ${ }^{125}$ I (seção 4.1), através da reprodução e comparação de parâmetros estabelecidos no Task Group-43 da AAPM (seção 4.1.1), além do estudo da resposta dos dosímetros termoluminescentes (seção 4.2) através dos dados teóricos de dependência energética (seção 4.2.5). Influências na dose devido à inserção de materiais tecido equivalentes, que simulam tecidos humanos distintos, foram observadas através de comparações entre resultados experimentais e simulados (seção 4.3). A dosimetria realizada experimentalmente com sementes de ${ }^{125}$ I apresentou certa complexidade devido ao alto gradiente de taxa de dose presente a distâncias próximas a fonte (menores que $5,0 \mathrm{~mm}$ ), além de incertezas associadas aos dosímetros termoluminescentes. As simulações foram realizadas de forma fiel aos experimentos, de forma a minimizar as incertezas e assim permitirem a validação dos cálculos.

A seguir são apresentados aspectos para caracterização dos elementos gerais que compõem os objetos simuladores, além de descrições sobre configurações distintas dos mesmos e demais materiais adotados para cada um dos estudos realizados.

\subsection{SEMENTES DE ${ }^{125}$ I}

Como fontes de radiação ionizante, foram utilizadas sementes de ${ }^{125}$ I (modelo Amersham 6711). Este radioisótopo apresenta meia vida de 59,408 dias e seu decaimento acompanha emissões de fótons com energia média de 29,0 keV (com distribuição de energias conforme exibido anteriormente na Tabela 1) (KATAKURA, 2011; MOURA, 2011; ZEITUNI, 2008). 
As simulações realizadas com o código MCNP utilizaram a biblioteca de dados de interação de elétrons (el03) e de fótons (mcnplib84), seguindo as recomendações do TG43 para utilização de bibliotecas modernas referentes às secções de choque. Para representação geométrica das sementes nas simulações foram utilizados os dados descritos na literatura (DOLAN et al., 2006; TAYLOR et al., 2008). As composições e densidades dos materiais utilizados nas simulações da semente de ${ }^{125}$ I foram provenientes do artigo de DOLAN et al (2006) e do banco de dados X-COM do NIST (BERGER et al., 1998) A Figura 14 ilustra a composição e as superfícies utilizadas para sua especificação no arquivo de entrada do MCNP, informações adicionais como dimensões, superfícies e células utilizadas neste trabalho estão detalhadamente evidenciadas na Figura 48 do Apêndice A.

a)

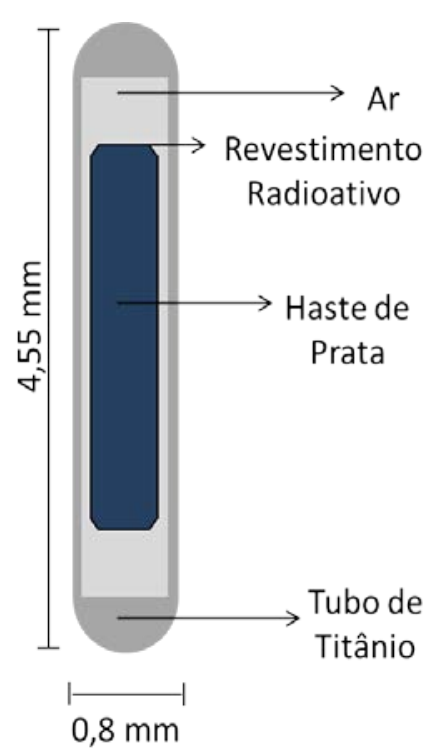

b)

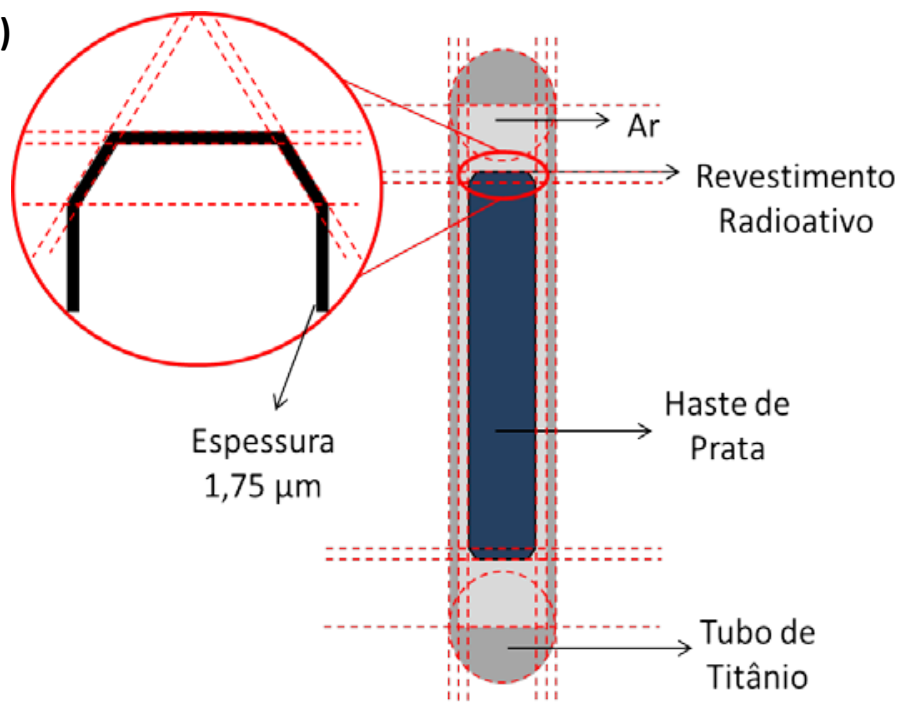

Figura 14. Representação Esquemática da Semente de ${ }^{125}$ I (Modelo Amersham 6711) seccionada longitudinalmente, sendo destacadas a composição de sua estrutura geométrica em a) e genericamente as superfícies utilizadas para sua representação com o código em b).

Fonte: Elaborado pela Autora.

A semente de ${ }^{125}$ I tem como composição um revestimento radioativo de $\mathrm{Agl} \mathrm{e} \mathrm{AgBr}$ (proporção molecular de 2,5:1 de Agl:AgBr e densidade de 6,2 g.cm $\mathrm{cm}^{-3}$ ) depositado em uma haste de prata cujas extremidades formam cones biselados em $45^{\circ}$, e as faces das extremidades da haste tem raio de $0,175 \mathrm{~mm}$. O revestimento radioativo possui espessura de 1,75 $\mu \mathrm{m}$ e está adsorvido sobre toda a superfície da haste. Um tubo de 
titânio encapsula estes materiais, sendo formado por paredes de 0,07 $\mathrm{mm}$ e estruturas semiesféricas soldadas nas extremidades (TAYLOR; ROGERS, 2008).

A haste de prata, juntamente com o material radioativo, apresenta liberdade para mover-se devido à cavidade de ar que a contém, como evidenciado no trabalho de Dolan et al. (2006) e representado na Figura 15.

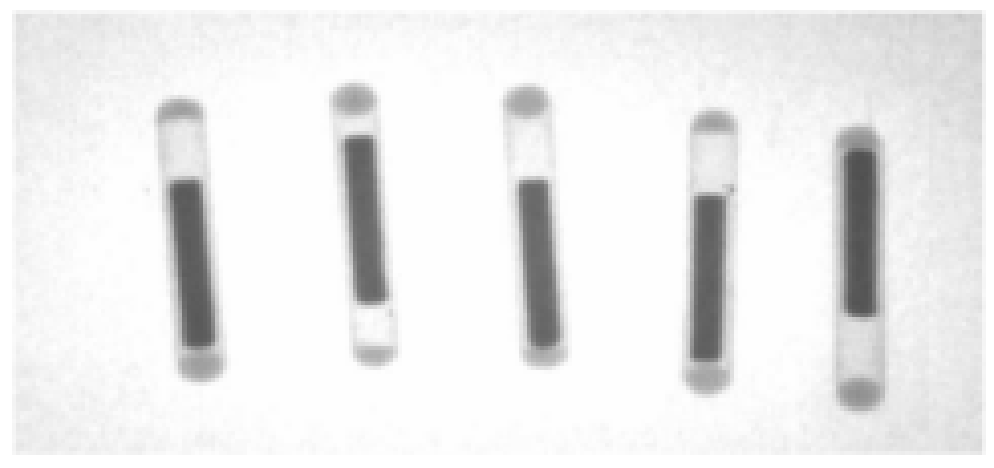

Figura 15. Radiografia de cinco sementes mostrando a variação na posição da haste de prata e do material radioativo.

Fonte: Dolan et al. (2006).

O deslocamento da haste de prata e do material radioativo contribui no aumento das incertezas nas medidas experimentais. Como alternativa para minimizar as incertezas dos objetos simuladores, utilizados em procedimentos experimentais (seção 4.3), foram usinadas quatro cavidades para conter as quatro sementes dispostas de maneira simétrica nas placas de PMMA, conforme representado na Figura 16, desta forma, o deslocamento ocorreu de forma aleatória.

Para validação da geometria simulada da semente de ${ }^{125} \mathrm{I}$, foi realizada a reprodução da metodologia de cálculo presente no TG-43 da AAPM. As configurações reproduzidas para avaliação dos parâmetros são descritas a seguir. 


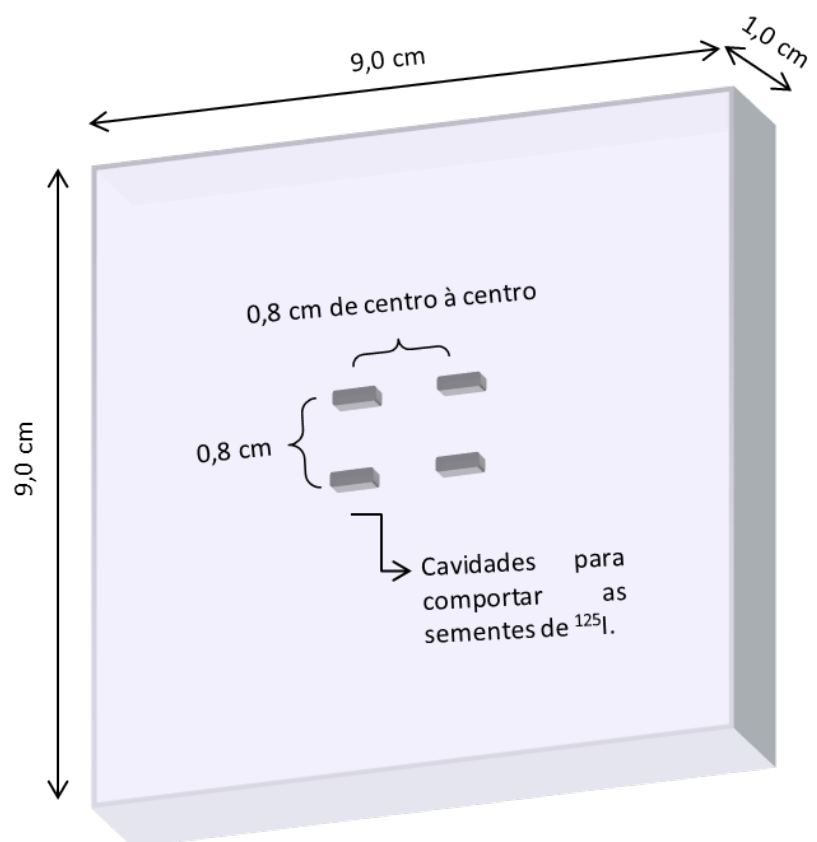

Figura 16. Representação esquemática da disposição das sementes de ${ }^{125} \mathrm{I}$ em uma placa de PMMA com dimensões de $9.0 \times 9.0 \times 1.0 \mathrm{~cm}^{3}$.

Fonte: Elaborado pela Autora.

\subsubsection{Validação da Geometria da SEmente}

Seguindo as recomendações descritas no protocolo TG-43U (RIVARD et al., 2004), nas simulações para validação da geometria da semente foram adotados objetos simuladores cúbicos com dimensões de $30,0 \times 30,0 \times 30,0 \mathrm{~cm}^{3}$ contendo uma semente de ${ }^{125}$ I posicionada no centro.

O cálculo do parâmetro de Intensidade do Kerma no $\operatorname{Ar}(\mathrm{Sk})$ foi realizado no vácuo e o objeto simulador continha duas células, simulando detectores, localizadas a $10,0 \mathrm{~cm}$ da fonte, com dimensões de 0,10 $\times 0,10 \times 0,05 \mathrm{~cm}^{3}$ (denominado método point) e 2,70 2,70 $\times 0,05 \mathrm{~cm}^{3}$ (método WAFAC), dispostas paralelamente à fonte e com angulação de $180^{\circ}$ um do outro. A Figura 17 esquematiza a geometria simulada para obtenção da Intensidade de Kerma no Ar. 


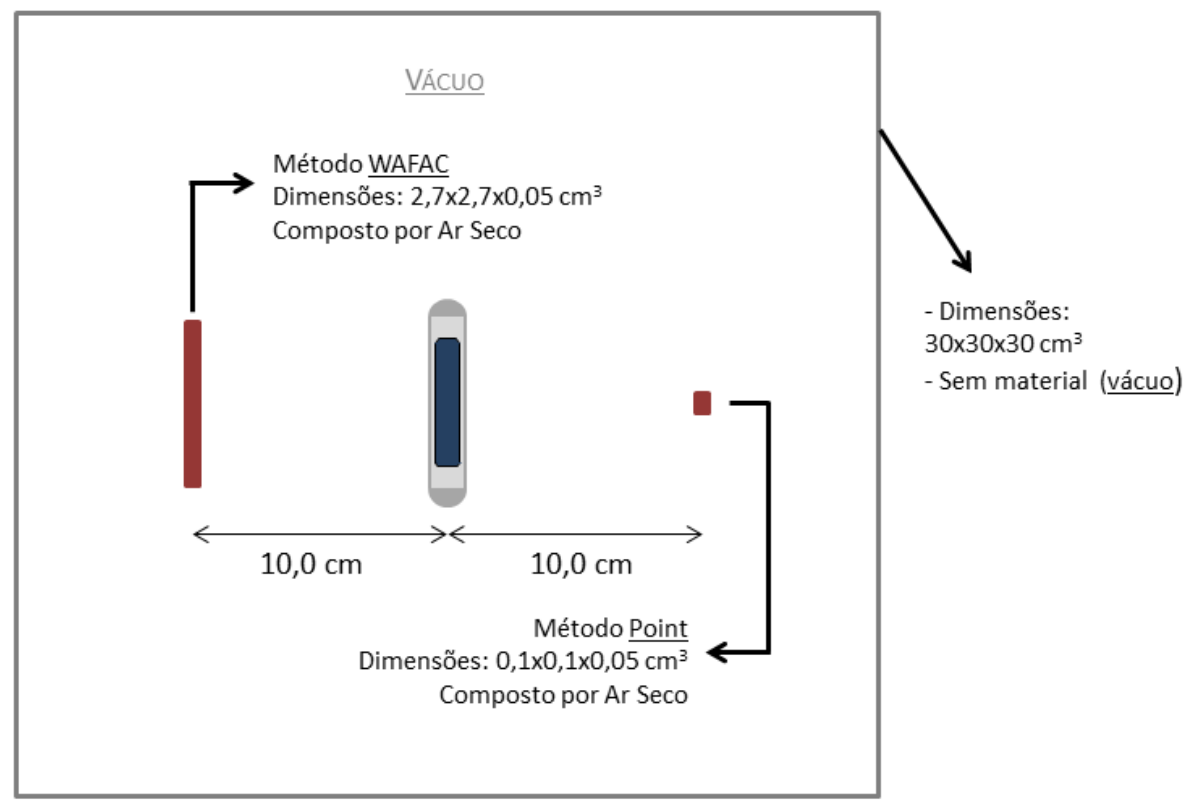

Figura 17. Representação esquemática da geometria simulada para obtenção da Intensidade de Kerma no Ar - Sk (Figura fora de escala).

Fonte: Elaborado pela Autora.

O tally utilizado para obtenção do cálculo de Intensidade de Kerma no Ar (Sk) nestas células (simulando detectores) foi *F4 juntamente com os cartões auxiliares DE/DF e o coeficiente de absorção de energia em massa $\left(\mu_{\mathrm{en}} / \rho\right)$ do ar seco. A escolha deste tally permitiu calcular o kerma de modo que os valores de $\mu_{e n} / \rho$ fossem ponderados pela fluência energética dos fótons incidentes. Para interações envolvendo fótons incidentes de baixa energia e materiais com baixo número atômico $\left(Z_{\text {eff }}\right.$ ar seco $\left.=7,36\right)$ nas quais os elétrons secundários gerados irão perder energia quase inteiramente por colisões, a energia emitida por bremsstralung será desprezível, de modo que, o coeficiente de transferência de energia em massa poderá ser aproximado ao coeficiente de absorção de energia em massa $\left(\mu_{t r}=\mu_{e n}\right)($ KHAN, 2003), o que permitiu estimar o valor do kerma. $\mathrm{A}$ Tabela 2 demonstra que esta aproximação é possível através dos valores de stopping power de colisão, de radiação e total, em função da energia para o ar seco, que evidenciam a perda mínima de energia pelos elétrons secundários ao gerarem raio-x por bremsstralung e, a significativa perda de energia dos elétrons ao sofrerem colisões. 
Tabela 2. Stopping power de colisão, de radiação e total variando com a energia para o meio ar seco, além de suas contribuições em porcentagem que compõem o valor do stopping power total .

\begin{tabular}{|c|c|c|c|c|c|}
\hline $\begin{array}{l}\text { Energia } \\
\text { Cinética }\end{array}$ & $\begin{array}{l}\text { Stopping } \\
\text { Power de } \\
\text { Colisão }\end{array}$ & $\begin{array}{l}\text { Stopping } \\
\text { Power de } \\
\text { Radiação }\end{array}$ & $\begin{array}{c}\text { Stopping } \\
\text { Power Total }\end{array}$ & $\begin{array}{l}\text { Stopping } \\
\text { Power de } \\
\text { Colisão em } \\
\text { relação ao } \\
\text { Total }\end{array}$ & $\begin{array}{c}\text { Stopping } \\
\text { Power de } \\
\text { Radiação em } \\
\text { relação ao } \\
\text { Total }\end{array}$ \\
\hline$(\mathrm{MeV})$ & $\left(\mathrm{MeV} \cdot \mathrm{cm}^{2} \cdot \mathrm{g}^{-1}\right)$ & $\left(\mathrm{MeV} . \mathrm{cm}^{2} \cdot \mathrm{g}^{-1}\right)$ & $\left(\mathrm{MeV} \cdot \mathrm{cm}^{2} \cdot \mathrm{g}^{-1}\right)$ & (\%) & (\%) \\
\hline $1,00 \cdot 10^{-2}$ & 19,750 & $3,897 \cdot 10^{-3}$ & 19,754 & 99,980 & 0,020 \\
\hline $1,25 \cdot 10^{-2}$ & 16,630 & $3,921 \cdot 10^{-3}$ & 16,634 & 99,976 & 0,024 \\
\hline $1,50 \cdot 10^{-2}$ & 14,440 & $3,937 \cdot 10^{-3}$ & 14,444 & 99,973 & 0,027 \\
\hline $1,75 \cdot 10^{-2}$ & 12,820 & $3,946 \cdot 10^{-3}$ & 12,824 & 99,969 & 0,031 \\
\hline $2,00 \cdot 10^{-2}$ & 11,570 & $3,954 \cdot 10^{-3}$ & 11,574 & 99,966 & 0,034 \\
\hline $2,50 \cdot 10^{-2}$ & 9,753 & $3,966 \cdot 10^{-3}$ & 9,757 & 99,959 & 0,041 \\
\hline $3,00 \cdot 10^{-2}$ & 8,491 & $3,976 \cdot 10^{-3}$ & 8,495 & 99,953 & 0,047 \\
\hline $3,50 \cdot 10^{-2}$ & 7,562 & $3,986 \cdot 10^{-3}$ & 7,566 & 99,947 & 0,053 \\
\hline $4,00 \cdot 10^{-2}$ & 6,848 & $3,998 \cdot 10^{-3}$ & 6,852 & 99,942 & 0,058 \\
\hline $4,50 \cdot 10^{-2}$ & 6,280 & $4,011 \cdot 10^{-3}$ & 6,284 & 99,936 & 0,064 \\
\hline $5,00 \cdot 10^{-2}$ & 5,818 & $4,025 \cdot 10^{-3}$ & 5,822 & 99,931 & 0,069 \\
\hline $5,50 \cdot 10^{-2}$ & 5,434 & $4,040 \cdot 10^{-3}$ & 5,438 & 99,926 & 0,074 \\
\hline $6,00 \cdot 10^{-2}$ & 5,110 & $4,057 \cdot 10^{-3}$ & 5,114 & 99,921 & 0,079 \\
\hline $7,00 \cdot 10^{-2}$ & 4,593 & $4,093 \cdot 10^{-3}$ & 4,597 & 99,911 & 0,089 \\
\hline $8,00 \cdot 10^{-2}$ & 4,197 & $4,133 \cdot 10^{-3}$ & 4,201 & 99,902 & 0,098 \\
\hline $9,00 \cdot 10^{-2}$ & 3,885 & $4,175 \cdot 10^{-3}$ & 3,889 & 99,893 & 0,107 \\
\hline $1,00 \cdot 10^{-1}$ & 3,633 & $4,222 \cdot 10^{-3}$ & 3,637 & 99,884 & 0,116 \\
\hline
\end{tabular}

Fonte: BERGER et al., (2005).

Para o cálculo de taxa de dose $(\dot{D}(r, \theta))$ nos pontos recomendados, o objeto simulador foi preenchido com água. A distância (raio) e ângulo da fonte ao detector foram variados conforme o parâmetro e pontos analisados. Para avaliar as distribuições

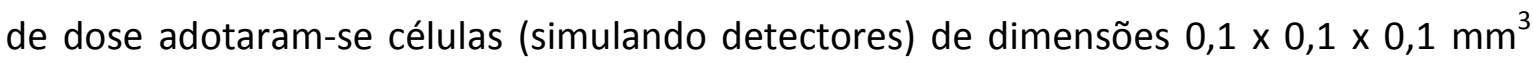

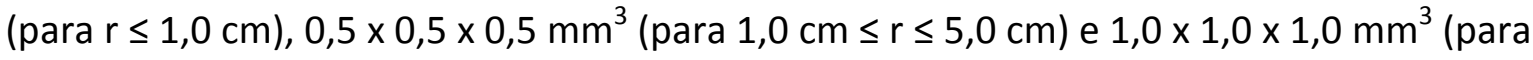
$r \geq 5,0 \mathrm{~cm}$ ) (DOLAN et al., 2006) e foi utilizado o tally F6.

A Figura 18 esquematiza a geometria simulada para obtenção da taxa de dose posteriormente utilizada para o cálculo dos parâmetros das funções de Constante de Taxa de Dose $(\Lambda)$, Função de Dose Radial $g(r)$ e Função de Anisotropia $F(r, \theta)$. É importante ressaltar que nas simulações, as células adotadas para cálculo da taxa de dose foram distribuídas em todo entorno da fonte, com variação angular de $0^{\circ}$ a $360^{\circ}$. Isto pode ser realizado graças à distribuição de dose simétrica no plano axial da fonte (como demonstrado posteriormente na Figura 31 - Seção 5.1.3), permitindo que as células não 
atinjam o espaço geométrico umas das outras e aumentando a presença de pontos para cálculo da taxa de dose.

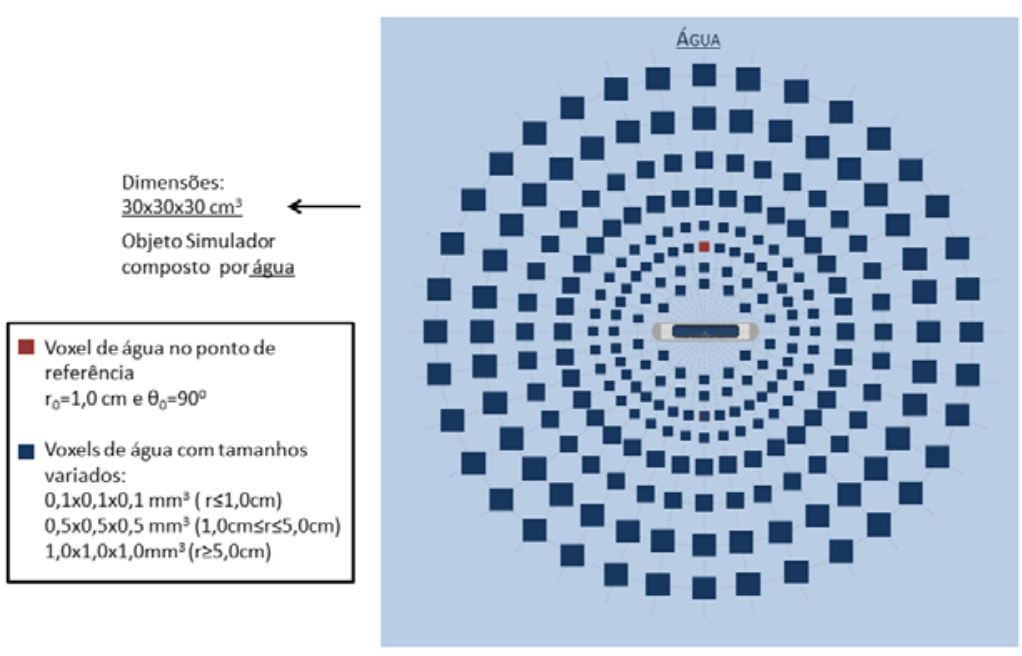

Figura 18. Representação esquemática da geometria simulada para obtenção da taxa de dose $D(r, \theta)$. (Figura fora de escala)

Fonte: Elaborado pela Autora.

\subsection{DOSÍMETROS TERMOLUMINESCENTES}

Os detectores utilizados neste trabalho foram dosímetros termoluminescentes (TLDs) do tipo LiF - 100 na forma de microcubos (com dimensões de 0,1 x 0,1 x 0,1 $\mathrm{cm}^{3}$ ), constituídos por fluoreto de lítio dopado com magnésio e titânio (LiF:Mg,Ti) e produzidos pela empresa Thermo Fisher Scientific (Harshaw como antecessora). As propriedades descritas pelo fabricante para este dosímetro estão especificadas na Tabela 3.

Tabela 3. Propriedades dos TLDs-100 microcubos utilizados neste trabalho.

\begin{tabular}{cc} 
& Especificações \\
\hline Descrição & \\
Material & TLD-100 microcubo \\
Fluoreto de Lítio \\
Número atômico efetivo & 8,2 \\
Espectro de emissão & \\
termoluminescente & 3500 a $6000 \AA$ (máximo a $4000 \AA$ ) \\
Temperatura do pico dosimétrico & $195^{\circ} \mathrm{C}$ \\
Resposta de energia (30 keV / $\left.{ }^{60} \mathrm{Co}\right)$ & 1,25 \\
Faixa de kerma no ar mensurável & $10 \mu \mathrm{Gy}-10 \mathrm{~Gy}$ \\
Desvanecimento otimizado a $20^{\circ} \mathrm{C}$ & $5 \%$ por ano \\
\hline Fonte: Adaptado de (HARSHAW TLD, [s.d.])
\end{tabular}


A escolha deste tipo de dosímetro se deve pelo seu fácil manuseio, seu tamanho que permite a utilização em medidas com altos gradientes de dose, sua sensibilidade a elétrons e a fótons, a vasta faixa de dose mensurável e a sua característica de ser reutilizável.

Para a obtenção de resultados experimentais reprodutíveis destes dosímetros foram realizados ciclos com processos de tratamento térmico, irradiação e leitura, seguindo as recomendações do fabricante e com intervalo de tempo de $24 \mathrm{~h}$ entre eles. As metodologias adotadas em cada procedimento, assim como os materiais utilizados, serão ressaltadas nas seções seguintes.

\subsubsection{TRATAMENTo TÉRMico}

Dosímetros termoluminescentes requerem tratamento térmico antes de serem reutilizados, a fim de eliminar os elétrons que ainda continuam aprisionados nas armadilhas após a realização da leitura.

No tratamento térmico, os dosímetros foram colocados em uma mufla durante $1 \mathrm{~h}$ a $400^{\circ} \mathrm{C}$, e imediatamente após foram colocados em outra mufla por $2 \mathrm{~h}$ a $100^{\circ} \mathrm{C}$, conforme recomendações do fabricante. Ao final do tratamento, os dosímetros foram retirados da mufla e ocorreu seu resfriamento até a temperatura ambiente. Aproximadamente $24 \mathrm{~h}$ depois foram irradiados conforme o experimento de interesse.

A Figura 19 exibe as muflas utilizadas pelo grupo de Física Médica do Centro de Engenharia Nuclear (CEN-IPEN) para tratamento térmico dos TLDs.
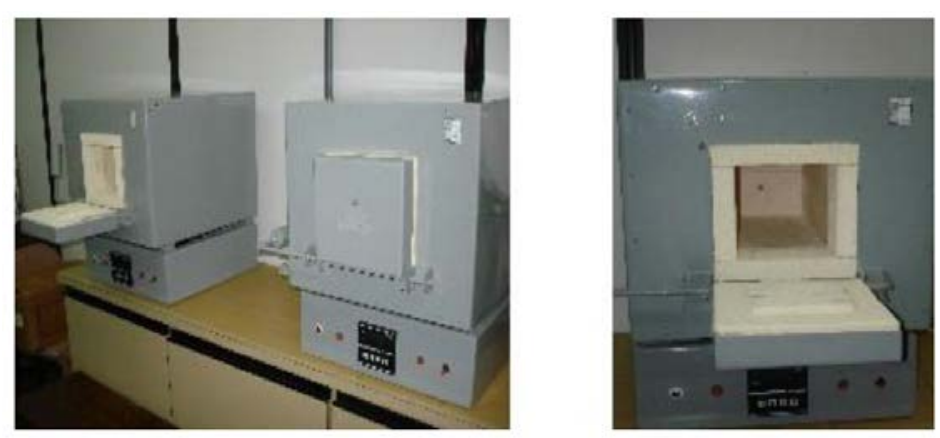

Figura 19. Muflas do grupo CEN/IPEN utilizadas no tratamento térmico dos dosímetros termoluminescentes.

Fonte: CAVALIERI, (2013). 


\subsubsection{IRRADIAÇõES}

Este trabalho utilizou duas fontes distintas de radiação para obtenção dos resultados experimentais contabilizados nos TLDs. Inicialmente, 90 TLDs foram irradiados com um feixe de ${ }^{137}$ Cs, nas instalações do Grupo de Metrologia das Radiações (GMR/IPEN) conforme exibido na Figura 20 , para que os dosímetros com menor variação em sua resposta pudessem ser selecionados e posteriormente utilizados em medidas com objetos simuladores usinados, contribuindo para a diminuição das incertezas. 0 selecionamento dos dosímetros será introduzido com mais detalhes na seção 4.2.4.

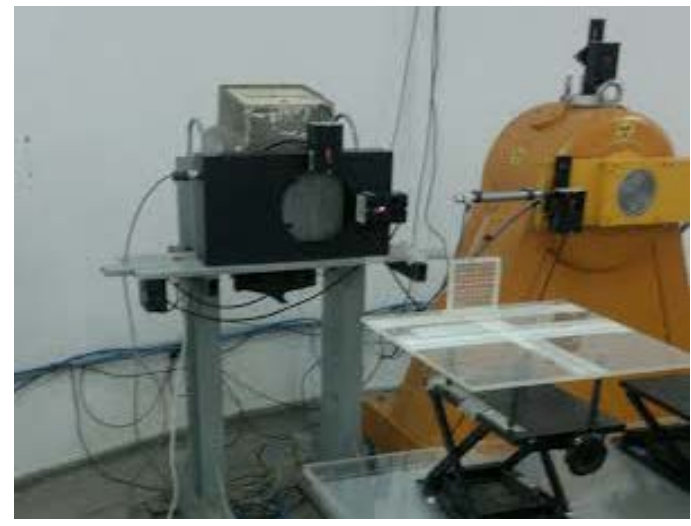

Figura 20. Irradiação dos TLDs com ${ }^{137}$ Cs para o processo de selecionamento dos dosímetros termoluminescentes.

Fonte: Autoria Própria.

Os TLDs selecionados foram utilizados em diversas medidas com sementes de ${ }^{125}$ I como fonte de radiação. Diversas configurações de objetos simuladores foram elaboradas para o estudo da deposição de dose quando presentes heterogeneidades que simulam diferentes tecidos humanos. Estas configurações e os demais detalhes dos experimentos estão descritos na seção 4.3 .

\subsubsection{LEITORA TLD}

Ao final do ciclo de utilização dos TLDs, eles eram lidos através de leitoras de TLD. A leitora utilizada nestes procedimentos é do modelo Harshaw 3500, conforme exibido na Figura 21. 


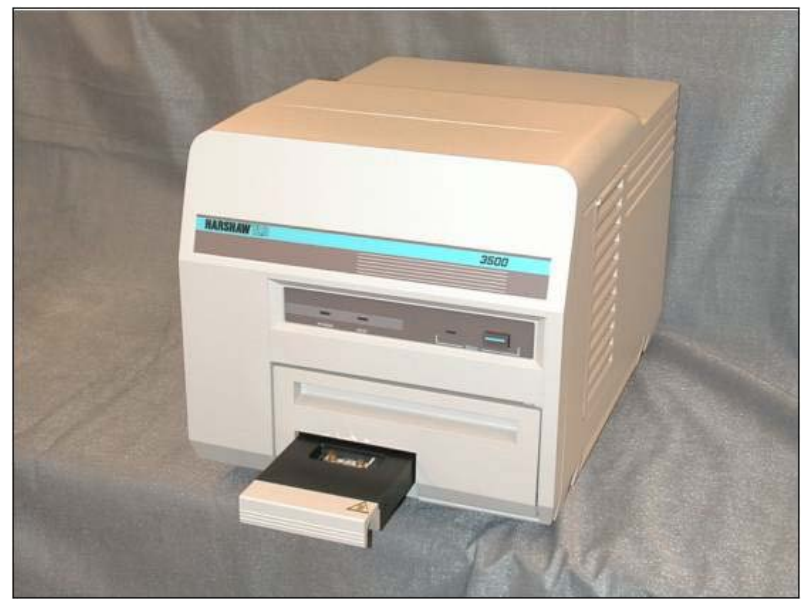

Figura 21. Leitora Harshaw, modelo 3500.

Fonte: THERMO ELECTRON CORPORATION, (2005)

Inicialmente, os TLDs são posicionados manualmente e a leitura ocorre em uma prancheta gradualmente aquecida, permitindo que os TLDs liberem elétrons armadilhados, os quais emitem fótons ao retornarem a banda de valência. Estes fótons emitidos geram sinais elétricos ao incidir sobre uma fotomultiplicadora, e então são enviados para o sistema de aquisição e análise dos dados obtidos. O sistema utilizado para esta análise foi o WinRens (THERMO ELECTRON CORPORATION, 2005) da Harshaw, nele, era possível observar a curva de resposta termoluminescente (Figura 13) do TLD em função da temperatura na prancheta de aquecimento. Os parâmetros utilizados pela leitora Harshaw para a realização das leituras são apresentados na Tabela 4.

Tabela 4. Parâmetros de operação da leitora Harshaw 3500 para leitura dos TLDs-100 na forma de microcubos.

\begin{tabular}{|c|c|}
\hline \multicolumn{2}{|l|}{ Especificações } \\
\hline Temperatura Inicial & $60^{\circ} \mathrm{C}$ \\
\hline Taxa de Aquecimento & $10{ }^{\circ} \mathrm{C} / \mathrm{s}$ \\
\hline Temperatura Final & $400^{\circ} \mathrm{C}$ \\
\hline Tempo de Aquisição & $45 s$ \\
\hline
\end{tabular}

Ao término da leitura dos TLDs, o ciclo era repetido conforme a necessidade e número de experimentos realizados. A repetição dos experimentos visava diminuir as incertezas encontradas. 
Além dos ciclos em que eram submetidos a tratamento térmico, irradiação e leitura, os TLDs foram submetidos a processos de selecionamento. Posteriormente foi realizado também um estudo teórico de sua dependência energética. Estas metodologias são elucidadas a seguir.

\subsubsection{SELECIONAMENTo dos Dosímetros TermoluminesCEnTES}

A grande dispersão nas respostas de leitura dos dosímetros termoluminescentes faz com que o processo de selecionamento seja necessário. Isto pode ocorrer devido a fatores como defeitos na estrutura do dosímetro, diferença de massa, dopagem, entre outros. A fim de minimizar as incertezas atribuídas aos TLDs foi feita uma seleção dos dosímetros que apresentam as menores dispersões entre as determinadas leituras e, posteriormente, foi atribuído a cada dosímetro já selecionado, um fator de normalização segundo a reprodutibilidade de suas respostas em relação à média. Pode-se expressar o fator de normalização atribuído através da seguinte fórmula:

$$
\bar{F}_{i}=\frac{1}{N} \cdot \sum_{n}^{N} F_{i, n}
$$

Onde:

$$
\begin{gathered}
F_{i, n}=\frac{\left(\frac{1}{M} \cdot \sum_{i}^{M} R_{i, n}\right)}{R_{i, n}} \\
\sigma_{i}=\sqrt{\frac{\left(F_{i}-\overline{F_{l}}\right)^{2}}{N-1}}
\end{gathered}
$$

Sendo $i$ o índice associado ao número de identificação do TLD; $n$ o índice associado a irradiação realizada; $F_{i, n}$ o fator de normalização do TLD $i$ na irradiação $n ; \bar{F}_{i}$ a média dos fatores de normalização de um mesmo TLD em cada irradiação; $R_{i, n}$ sendo a resposta de determinado TLD $i$ na irradiação $n ; M$ o número de TLDs contabilizados numa 
determinada leitura $n$; $N$ o número total de irradiações e leituras realizadas; $\sigma_{i}$ o desvio padrão destes fatores de normalização.

Para realização do selecionamento 90 dosímetros foram irradiados a 1,0 m, no feixe de ${ }^{137}$ Cs e com Kerma de 584,0 mGy, mantendo-se sempre a mesma posição e suporte fixador.

Os dosímetros irradiados eram parte de um mesmo lote, os quais foram colocados em uma placa composta inteiramente por PMMA com dimensões de $9,0 \times 9,0 \times 0,5 \mathrm{~cm}^{3}$, e com 100 furos para que fossem alojados. À frente dos dosímetros foi colocada outra placa de PMMA com 5,0 mm de espessura a fim de garantir as condições de equilíbrio eletrônico (região de build-up). A Figura 22 ilustra a disposição das configurações de irradiação com o ${ }^{137}$ Cs, também mostrada anteriormente na Figura 20.

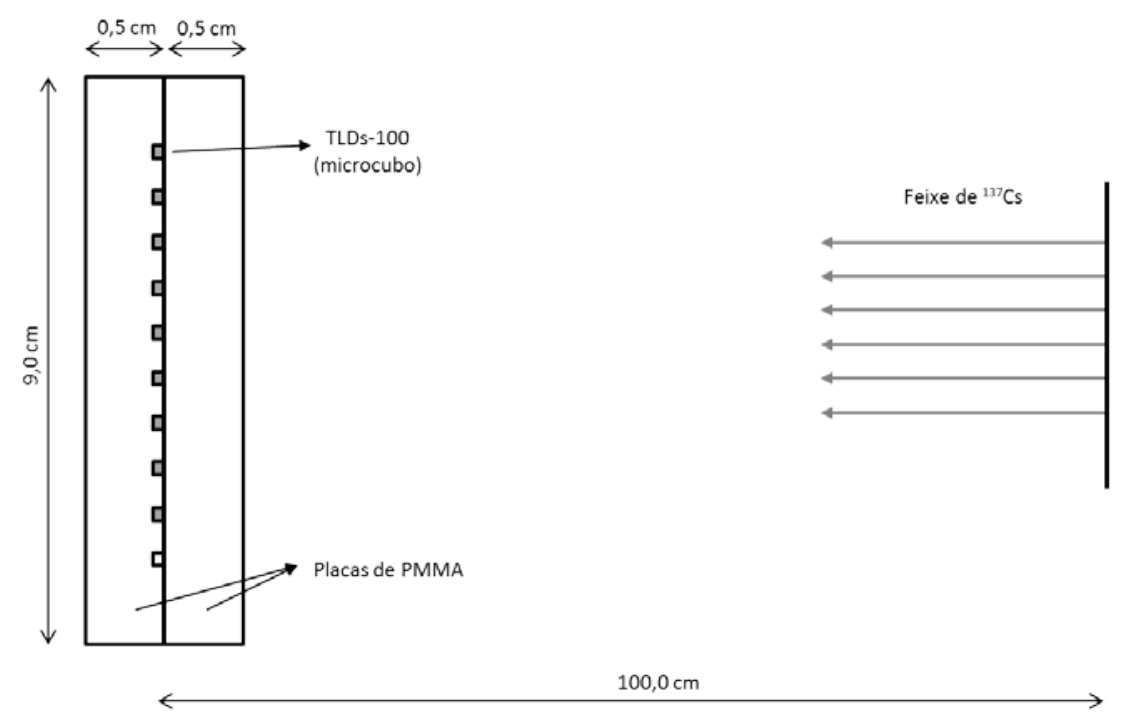

Figura 22. Representação esquemática da configuração do objeto simulador para irradiações com feixe de ${ }^{137} \mathrm{Cs}$ - vista lateral (Figura fora de escala).

Fonte: Elaborado pela Autora.

Posteriormente a 4 ciclos de selecionamento, 68 dosímetros foram escolhidos de acordo com o desvio padrão dos coeficientes de normalização apresentados em cada uma das leituras para o mesmo TLD, de forma que, somente os dosímetros com desvios abaixo de $3 \%$ fossem designados para medidas experimentais. 


\subsubsection{DEPENDÊNCIA ENERGÉTICA}

Os dosímetros de fluoreto de lítio (LiF) são os mais utilizados para analisar as distribuições de dose absorvida na água em torno de fontes radioativas utilizadas para braquiterapia. Dosímetros termoluminescentes são classificados como dosímetros relativos pois dependem de calibrações com valores de dose absorvida conhecidas para que sua resposta possa ser convertida em unidades de dose absorvida. Para realizar estas medições, a calibração dos dosímetros é frequentemente feita feixes de fótons com altas energias onde se pode assegurar a rastreabilidade aos padrões primários de dose absorvida na água (TEDGREN et al., 2011).

Correções referentes à diferença de qualidade do feixe de calibração e a medição podem ser feitas no sentido de estimar a dose absorvida em água devido a energias menores utilizadas em procedimentos braquiterápicos. Neste trabalho, os feixes simulados foram comparados com o emitido pelo ${ }^{60} \mathrm{Co}$.

As análises referentes à dependência energética foram realizadas através de simulações de Monte Carlo com o código MCNP. As análises possibilitaram a observação e comparação das simulações envolvendo dosímetros termoluminescentes com dados simulados de outros autores. Este estudo utilizou fundamentos teóricos para comparações das análises de dados provenientes de artigos publicados anteriormente (DAVIS et al., 2003; NUNN et al., 2008) que estudam a dependência energética a partir da comparação da razão entre a dose absorvida no TLD e a resposta kerma no ar, simulada para feixes de energias de interesse, normalizadas pela mesma razão calculada para o feixe de ${ }^{60} \mathrm{Co}$, de acordo com a equação:

$$
R_{M C}=\frac{\frac{D_{L i F, Q}}{K_{a r, Q}}}{\frac{D_{L i F, Q o}}{K_{a r, Q o}}}
$$

Sendo $D_{L i F}$ a dose calculada no TLD; $K_{a r}$ Kerma do ar calculado na posição do TLD (a 1,0 m); $Q$ a qualidade do feixe de interesse (a ser analisado) e $Q o$ a qualidade do feixe de referência adotado (neste trabalho ${ }^{60} \mathrm{Co}$ ). 
Para obtenção dos resultados de resposta do TLD simulado normalizado pelo Kerma descrito anteriormente, foram utilizados 6 espectros de fótons diferentes referentes às fontes de interesse, onde três eram provenientes de raios $X$, representados na Figura 23, e os outros eram ${ }^{137} \mathrm{Cs},{ }^{60} \mathrm{Co}$ para os quais somente as energias médias exibidas Tabela 5 foram adotadas nas simulações. Para as simulações com ${ }^{125} \mathrm{I}$ foi adotado o espectro previamente referido na Tabela 1 , considerando somente emissões de fótons (raio-X característico e $\gamma)$.

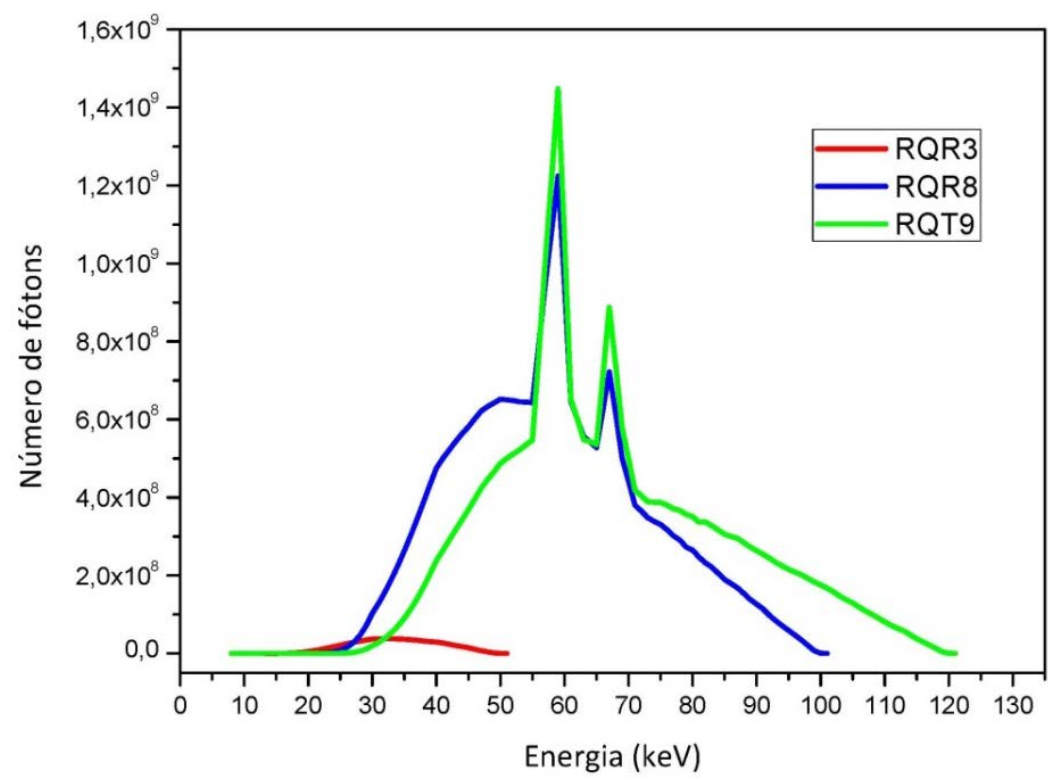

Figura 23. Espectros de Raios-X das qualidades RQR3, RQR8 e RQT9.

Fonte: (SIEMENS HEALTHINEERS, [s.d.]).

Tabela 5. Parâmetros principais dos espectros utilizados nas simulações referentes à dependência energética dos TLDs.

\begin{tabular}{cccc}
$\begin{array}{c}\text { Qualidade do } \\
\text { Feixe }\end{array}$ & $\mathbf{k V}$ & $\mathbf{m A}$ & $\begin{array}{c}\text { Energia Média } \\
{[\mathrm{keV}]}\end{array}$ \\
${ }^{60} \mathrm{Co}$ & - & - & 1250 \\
${ }^{137} \mathrm{Cs}$ & - & - & 661,6 \\
${ }^{125} \mathrm{I}$ & - & - & 29,0 \\
RQR3 & 50 & 10 & 33,7 \\
RQR8 & 100 & 10 & 52,5 \\
RQT9 & 120 & 10 & 67,0 \\
\hline
\end{tabular}

Para a realização das simulações nos feixes de ${ }^{137}$ Cs e ${ }^{60}$ Co, os dosímetros termoluminescentes foram inseridos em uma placa de PMMA com espessura de 5,0 mm atrás e 5,0 mm na frente semelhante às configurações da Figura 22 anteriormente 
explicitada. Já para simulações realizadas com raio-X $\mathrm{e}^{125} \mathrm{I}$, o suporte utilizado foi alterado, de forma que se retirou a placa da frente, utilizando somente placa de 5,0 $\mathrm{mm}$ na parte de trás. Em todas as irradiações, a distância fonte-detector foi mantida a 1,0 m.

Os resultados obtidos com o cálculo do parâmetro de $R_{M c}$ nas simulações foram comparados com o de DAVIS et al., (2003) e com NUNN et al., (2008). As energias utilizadas nas simulações de DAVIS et al., (2003) diferiram das utilizadas neste trabalho, e são descritas na Tabela 6. O autor menciona ainda que os espectros de ${ }^{60} \mathrm{Co}$ e ${ }^{137} \mathrm{Cs}$ foram retirados de ROGERS; KAWRAKOW, (2000). A Tabela 7 apresenta as energias utilizadas por NUNN et al., (2008). Para comparação dos dados e cálculo das diferenças relativas, os resultados foram interpolados através do software MATLAB, versão 8.0.

Tabela 6. Feixes de Energia utilizados nas simulações referentes à dependência energética dos TLDs no artigo de DAVIS et al., (2003).

\begin{tabular}{|cc|}
\hline $\begin{array}{c}\text { Identificador } \\
\text { (Feixes de Raio-X) }\end{array}$ & $\begin{array}{c}\text { Energia Média } \\
{[\mathrm{keV}]}\end{array}$ \\
\hline $\mathrm{N}-30$ & 24,2 \\
$\mathrm{~N}-40$ & 32,5 \\
$\mathrm{~N}-60$ & 47,3 \\
$\mathrm{~N}-80$ & 64,5 \\
$\mathrm{~N}-100$ & 82,6 \\
$\mathrm{~N}-150$ & 117 \\
$\mathrm{~N}-200$ & 164 \\
\hline $\mathrm{N}-250$ & 207 \\
\hline Fonte: DAVIS et al., (2003).
\end{tabular}

Tabela 7. Feixes de Energia utilizados nas simulações referentes a dependência energética dos TLDs no artigo de NUNN et al., (2008).

\begin{tabular}{|cc|}
\hline $\begin{array}{c}\text { Identificador } \\
\text { (Feixes) }\end{array}$ & $\begin{array}{c}\text { Energia Média } \\
{[\mathrm{keV}]}\end{array}$ \\
\hline M20 & 11,5 \\
\hline M30 & 15,5 \\
\hline M40 & 19,8 \\
\hline M50 & 22,4 \\
\hline L100 & 32,7 \\
\hline M100 & 42,1 \\
\hline M120 & 49,9 \\
\hline M150 & 67,0 \\
\hline H100 & 88,6 \\
\hline M200 & 99,8 \\
\hline M250 & 145,0 \\
\hline${ }^{137}$ Cs & 662,0 \\
\hline${ }^{60}$ Co & 1250,0 \\
\hline Fonte: NUNN et al., (2008).
\end{tabular}




\subsection{Objetos Simuladores Contendo Material Tecido EQUIVALENTE}

Os objetos simuladores utilizados neste trabalho continham além das sementes de

${ }^{125}$ I e dosímetros termoluminescentes, cilindros de materiais tecido equivalentes que possuem propriedades como densidade e composição (apresentadas na Tabela 8) semelhantes aos dos distintos tecidos humanos (CIRS TISSUE SIMULATION \& PHANTOM TECHNOLOGY, 2013a). Os cilindros de material tecido equivalente apresentavam espessura de $42 \mathrm{~mm}$ e diâmetro de $30 \mathrm{~mm}$ quando mantidas suas dimensões originais (conforme exibido na Figura 24), porém, alguns materiais já se encontravam previamente usinados, e estavam disponíveis em espessuras de 2,0 mm, 3,0 mm e 5,0 mm, conservando o diâmetro. Na realização dos experimentos, estas estruturas ficaram contidas em placas de PMMA adquiridas pelo Centro de Engenharia Nuclear (CEN) do IPEN, que para tal propósito foram usinadas na Divisão de Oficinas (IEO) do mesmo instituto.

Tabela 8. Composição dos materiais tecido equivalentes utilizados nas simulações e experimentos.

\begin{tabular}{|c|c|c|c|c|c|c|c|c|c|c|}
\hline \multirow{2}{*}{ Material } & \multicolumn{9}{|c|}{ Composição (\% em peso) } & \multirow{2}{*}{$\rho\left(\mathrm{g} / \mathrm{cm}^{3}\right.$} \\
\hline & C & 0 & $\mathrm{H}$ & $\mathbf{N}$ & $\mathrm{Ca}$ & $P$ & $\mathrm{Cl}$ & $S$ & $\mathrm{Ba}$ & \\
\hline $\begin{array}{c}\text { Mama } \\
50 / 50\end{array}$ & 70,3 & 17,0 & 9,6 & 1,9 & 0,9 & 0 & 0,2 & 0 & 0 & 0,991 \\
\hline Tecido Adiposo & 71,3 & 16,4 & 10,0 & 1,8 & 0,3 & 0 & 0,2 & 0 & 0 & 0,960 \\
\hline Fígado & 69,4 & 17,1 & 9,0 & 2,1 & 2,2 & 0 & 0,1 & 0 & 0 & 1,072 \\
\hline Pulmão exalado & 66,0 & 20,4 & 8,9 & 2,4 & 1,7 & 0 & 0,6 & 0 & 0 & 0,510 \\
\hline Pulmão Inalado & 67,5 & 18,6 & 8,8 & 3,5 & 0 & 0 & 1,6 & 0 & 0 & 0,195 \\
\hline Músculo & 69,7 & 16,8 & 9,1 & 2,1 & 2,2 & 0 & 0,1 & 0 & 0 & 1,062 \\
\hline $\begin{array}{c}\text { Osso } \\
1000 \mathrm{mg} / \mathrm{cm}^{3} \mathrm{HA}\end{array}$ & 35,4 & 29,4 & 4,5 & 1,2 & 19,9 & 9,2 & 0,04 & 0,08 & 0,33 & 1,660 \\
\hline $\begin{array}{c}\text { Osso } \\
800 \mathrm{mg} / \mathrm{cm}^{3} \mathrm{HA}\end{array}$ & 40,8 & 25,9 & 5,7 & 1,0 & 17,9 & 8,3 & 0,03 & 0,07 & 0,28 & 1,530 \\
\hline
\end{tabular}

Fonte: CIRS TISSUE SIMULATION \& PHANTOM TECHNOLOGY, (2013a) 


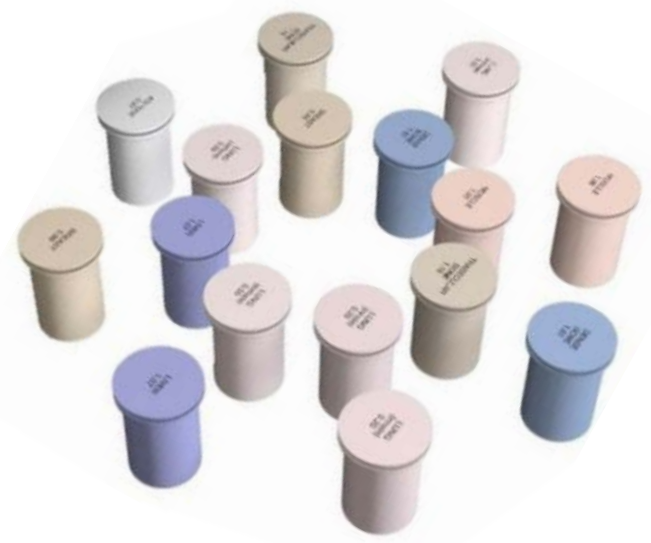

Figura 24. Exemplificação dos cilindros de materiais tecido equivalentes utilizados neste trabalho. Para realização dos experimentos foi retirada a tampa com identificação dos materiais, resultando em dimensões de $42 \mathrm{~mm}$ de altura e $30 \mathrm{~mm}$ de diâmetro.

Fonte: (CIRS TISSUE SIMULATION \& PHANTOM TECHNOLOGY, 2013b)

O material tecido equivalente mamário foi referenciado como Mama 50/50 (Em inglês Breast 50/50) por possuir em sua composição 50\% de material que simula o tecido adiposo e outros $50 \%$ que simulam tecido glandular. Embora a proporção destes tecidos varie entre a população (AFSHARPOUR et al., 2010; YAFFE et al., 2009), este material é amplamente utilizado para controle de qualidade em radiodiagnóstico e estudo de sistemas dosimétricos, sendo sua utilização irrestrita também para a área de braquiterapia (MOURA, 2015; POLETTI et al., 2004).

Os ossos apresentam em sua descrição determinada densidade de HA, esta sigla faz referência ao composto hidroxiapatita, que compõe cerca de $95 \%$ de sua porção inorgânica. Materiais inorgânicos, orgânicos e impurezas constituem os ossos, sendo atribuídos a estes materiais, respectivamente, pesos de $70 \%, 5-8 \%$ e cerca de $5 \%$ restantes. Desta forma, a hidroxiapatita caracteriza-se como componente fundamental na histologia óssea (BONNICK, 2009).

Os resultados obtidos com objetos simuladores contendo materiais tecido equivalentes foram provenientes tanto de medidas experimentais bem como simulações com o código MCNP.

O estudo experimental da distribuição de dose nos objetos simuladores usinados dispôs de 44 sementes de ${ }^{125}$ I de dois lotes diferentes, ambos do modelo 6711 da Amersham Oncura - GE Healthcare, importados através do Centro de Tecnologia das 
Radiações (CTR) no IPEN. As sementes de lodo possuíam atividade aparente inicial de 0,676 mCi (primeiro lote com 20 sementes) e 1,409 mCi (segundo lote com 22 sementes). Para todos os experimentos, o tempo de exposição foi definido de forma que a dose de kerma no ar da semente fosse de 1,0 mGy (a $100 \mathrm{~cm}$ ).

Para composição do objeto simulador foram utilizadas placas de PMMA com dimensões de $9,0 \times 9,0 \mathrm{~cm}^{2}$, duas delas com espessura de $1,0 \mathrm{~cm}$ e outras com espessura variável. As placas de PMMA em que os cilindros poderiam ser inseridos estavam disponíveis nas espessuras de $0,20 \mathrm{~cm}, 0,30 \mathrm{~cm}, 0,50 \mathrm{~cm}$ e 1,0 cm, de modo que elas foram sobrepostas para obter diferentes espessuras de $0,8 \mathrm{~cm}$ e 1,3 cm. A espessura total das placas, mesmo para os casos em que foram utilizadas placas sobrepostas, foi referida neste trabalho como $\Delta x$. Nas simulações e medidas experimentais, os cilindros de material tecido equivalente, quando presentes, possuíam a mesma espessura total das placas localizadas entre a fonte e o detector $(\Delta x)$.

No objeto simulador, representado pela Figura 25, a primeira placa de PMMA com dimensões de $9,0 \times 9,0 \times 1,0 \mathrm{~cm}^{3}$ continha quatro cavidades preenchidas pelas sementes de ${ }^{125} \mathrm{I}$ dispostas de maneira simétrica (previamente explicitada pela Figura 16), de modo que as sementes ficassem rentes ao material tecido equivalente. A seguir foram posicionadas as placas com espessura variável que possuíam uma abertura circular vazada no seu centro, na qual houve a inserção e alternância entre cilindros de material tecido equivalente com diâmetro de $3,0 \mathrm{~cm}$ e espessura total $\Delta x$. Também junto à placa com espessura $\Delta x$ e o cilindro, porém em sua parte inferior, foi colocada uma última placa de PMMA com dimensões de $9,0 \times 9,0 \times 1,0 \mathrm{~cm}^{3}$, a qual continha quatro cavidades preenchidas por quarto dosímetros termoluminescentes, posicionados nos eixos coincidentes com o centro da semente de ${ }^{125} \mathrm{I}$, deste modo a distância centro a centro dos dosímetros também foi de $0,8 \mathrm{~cm}$ e sua disposição em forma de uma matriz $2 \times 2$. As Figuras 25 e 26 apresentam a disposição das estruturas utilizadas na composição dos objetos simuladores, bem como suas dimensões. 

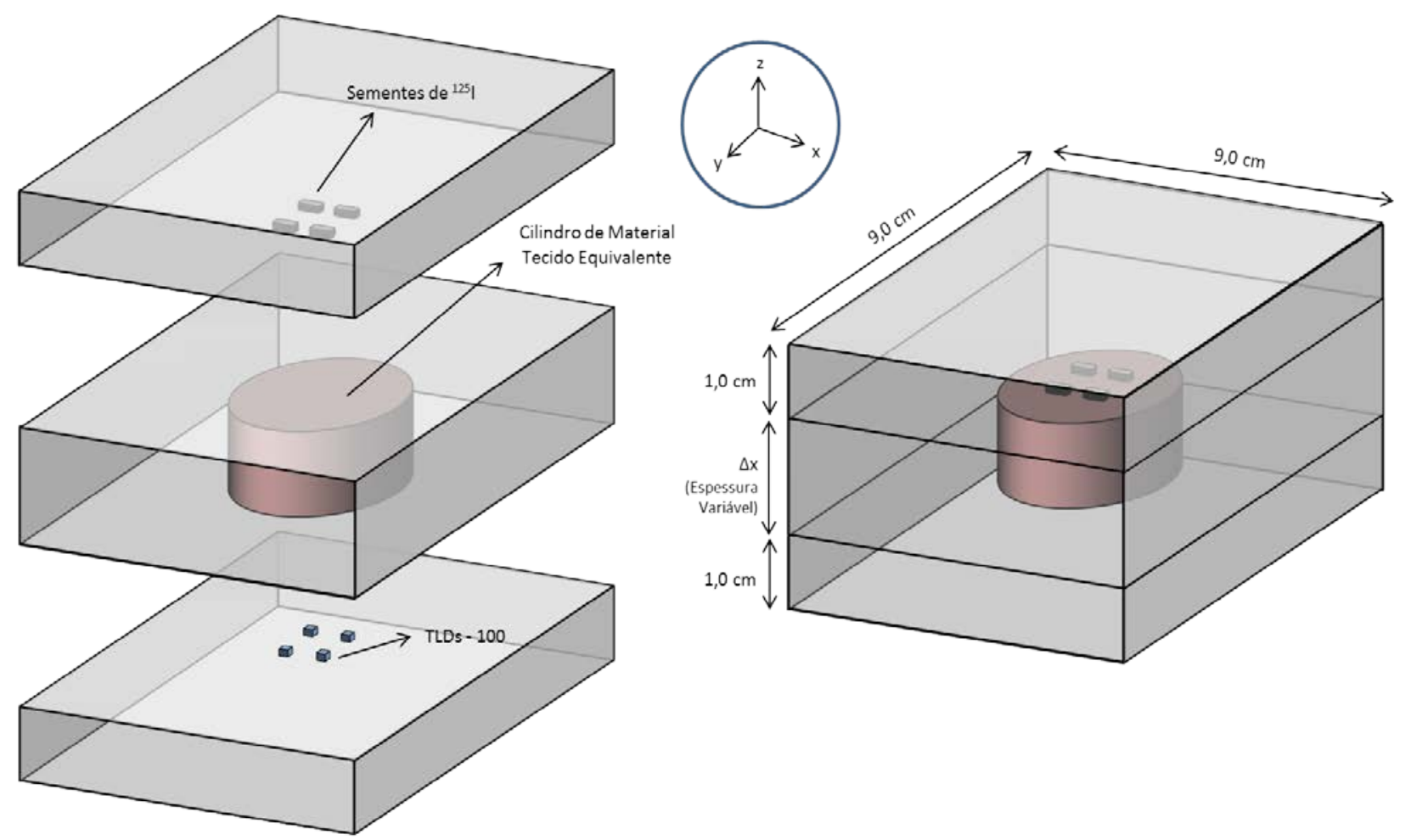

Figura 25. Representação esquemática da configuração do objeto simulador para irradiações com semente de ${ }^{125} \mathrm{I}$ a fim de observar a distribuição de dose conforme a inserção de materiais tecido equivalentes. A esquerda observam-se as estruturas presentes em cada uma das placas de PMMA, e a direita o objeto simulador com estas placas sobrepostas demonstrando sua conformação real reproduzida nas simulações e experimentos. As coordenadas cartesianas adotadas também são representadas na parte central da imagem.

Fonte: Elaborado pela autora.

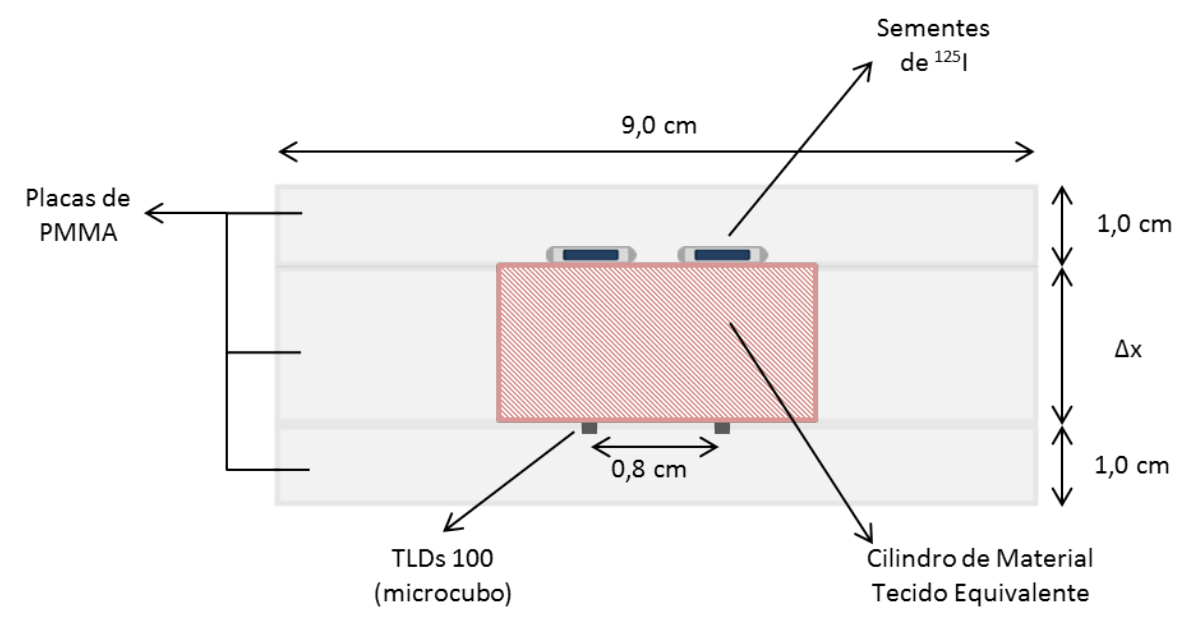

Figura 26. Representação esquemática do plano $x z$ no ponto $y=0,4 \mathrm{~cm}$ (segundo coordenadas estabelecidas na Figura 25 e nas simulações deste trabalho) da configuração do objeto simulador, contendo material tecido equivalente, para irradiações com semente de ${ }^{125}$ I.

Fonte: Elaborado pela autora. 
Diversas configurações de objetos simuladores foram adotadas para complementação das análises realizadas a partir das simulações e medidas experimentais. Em alguns dos estudos, cujas metodologias serão introduzidas a seguir, foram realizados cálculos para distribuição de dose relativa, de forma que os valores contabilizados nos TLDs-100 foram obtidos com geometria semelhante aos objetos simuladores previamente descritos exceto pela ausência da heterogeneidade, sendo o objeto simulador composto inteiramente por PMMA. A Figura 27 ilustra esta nova condição, ao passo que mantém a geometria da Figura 26.

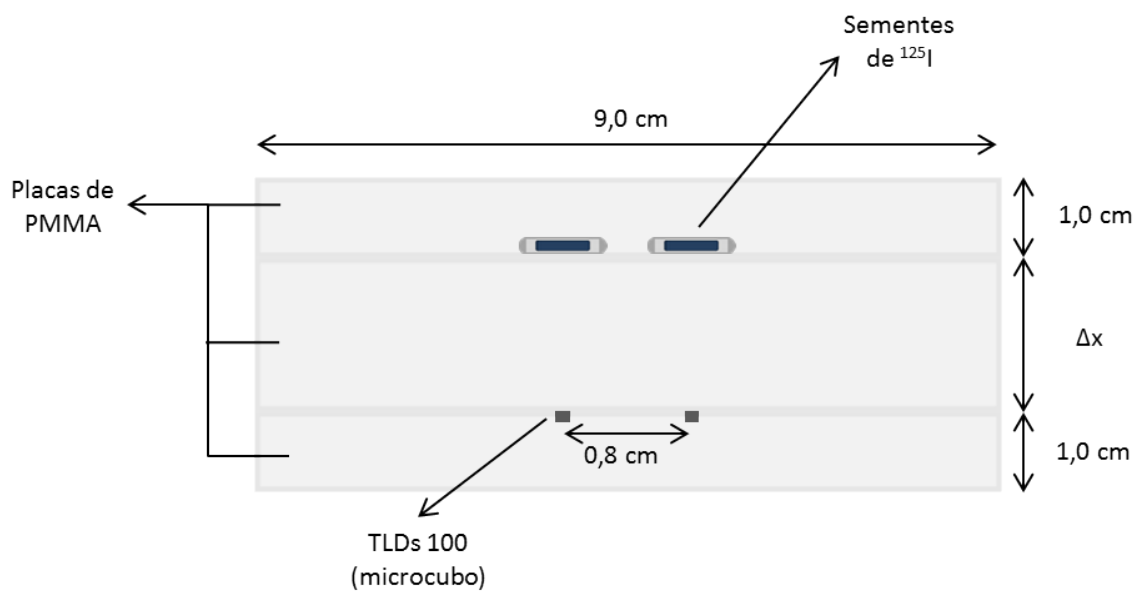

Figura 27. Representação esquemática do plano xz no ponto $y=0,4 \mathrm{~cm}$ (segundo coordenadas estabelecidas na Figura 25 e nas simulações deste trabalho) da configuração do objeto simulador para irradiações com semente de ${ }^{125} \mathrm{I}$, porém, sem a presença de material tecido equivalente, sendo a placa de espessura variável constituída inteiramente por PMMA.

Fonte: Elaborado pela autora.

A fim de observar a influência da presença dos TLDs nas medidas, também foram simulados objetos simuladores em que os TLDs estavam ausentes, isto é, nas células onde eles eram definidos, seu material foi trocado por PMMA, assumindo a densidade e composição deste material. Isto permitiu que as doses fossem comparadas pois o cálculo foi realizado num mesmo volume $\left(0,1 \times 0,1 \times 0,1 \mathrm{~cm}^{3}\right)$. Deste modo, a geometria dos objetos simuladores permaneceu idêntica à introduzida nas Figuras 26 e 27, exceto pelo material onde foi calculada a deposição de dose. A Figura 28 ilustra esta nova configuração. 

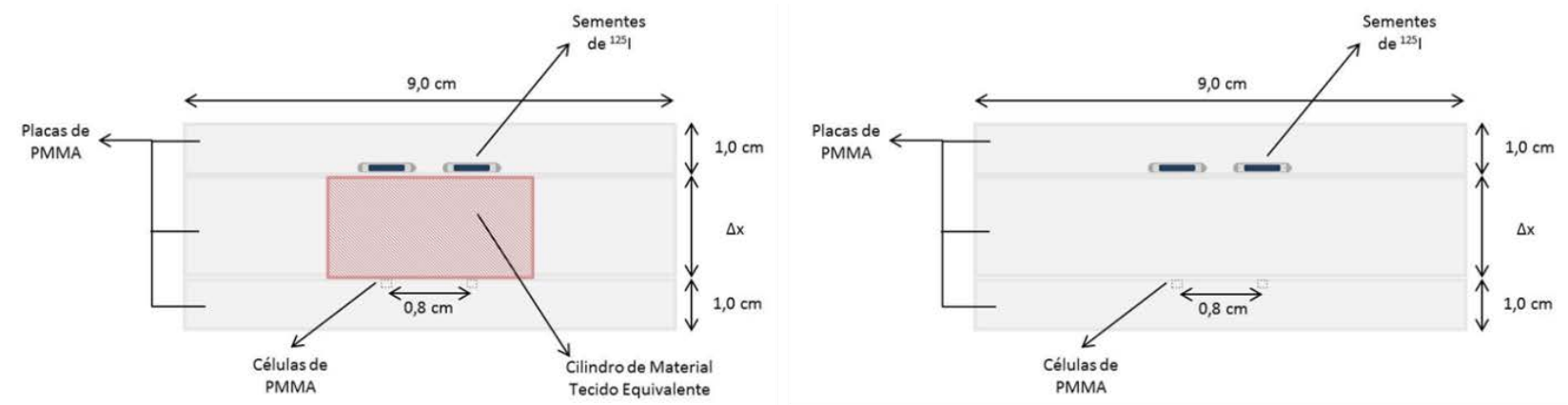

Figura 28. Representação esquemática do plano $x z$ no ponto $y=0,4 \mathrm{~cm}$ (segundo coordenadas estabelecidas na Figura 25 e nas simulações deste trabalho) da configuração do objeto simulador contendo material tecido equivalente (à esquerda), e da configuração do objeto simulador constituído inteiramente por PMMA (à direita). Em ambas situações, as irradiações foram realizadas com semente de ${ }^{125}$ I e com a ausência do TLD, porém, o volume de sua célula foi mantido e seu material foi adotado como PMMA.

Fonte: Elaborado pela autora.

A nomenclatura adotada para diferenciar as configurações de objetos simuladores previamente citadas serão referentes ao meio onde é calculada a dose e ao meio onde ela é transportada. De modo que a configuração demonstrada na Figura 26 seja evidenciada por $D_{T L D ; M T E}$, onde a dose é calculada em uma célula preenchida com o material do TLD (LiF) e transportada em um meio com a presença de material tecido equivalente (MTE). De forma semelhante, a configuração exibida na Figura 27 será representada por $D_{T L D ; P M M A}$ os objetos simuladores representados na Figura 28 serão denotados por $D_{P M M A ; M T E}$ (disposto a esquerda) e $D_{P M M A ; P M M A}$ (disposto a direita).

\subsubsection{INFLUÊNCIA DA DENSIDADE E CoMPoSIÇÃo}

Inicialmente, a análise dos efeitos da composição e densidade dos materiais tecido equivalentes foi realizada através de simulações com o código MCNP, a fim de observar o quanto estes dois parâmetros influenciavam a distribuição de dose relativa nos objetos simuladores.

Neste estudo, foram simulados objetos simuladores contendo materiais tecido equivalente com espessuras $(\Delta x)$ variando de milímetro a milímetro até uma espessura total entre 2,0 a 10,0 mm (geometria representada na Figura 26), além de objetos simuladores compostos inteiramente por PMMA, com TLDs presentes, que variaram a espessura da mesma maneira (Figura 27). As simulações dividiram-se em 2 grupos, no 
primeiro, foi atribuído a todos os materiais heterogêneos a mesma densidade do PMMA $\left(\rho=1,18 \mathrm{~g} . \mathrm{cm}^{-3}\right)$ mantendo suas composições químicas originais. E em seguida, foram realizadas simulações com as densidades originais dos materiais heterogêneos e composição química do PMMA para todos os casos. As doses obtidas em ambos os grupos foram normalizadas pela dose obtida no objeto simulador composto inteiramente por PMMA com sua composição e densidade original. Em todas as simulações descritas neste estudo, a deposição de dose foi calculada nos TLDs. As Equações 17 e 18 mostram as relações obtidas conforme o efeito estudado.

$$
\begin{aligned}
D_{\text {Dens Fixa }} & =\left(\frac{D_{T L D, M T E} \rho-P M M A}{D_{T L D, \text { PMMA }}}\right)_{\Delta x} \\
D_{\text {Comp Fixa }} & =\left(\frac{D_{T L D, \text { РMMA } \rho-M T E}}{D_{T L D, \text { РMMA }}}\right)_{\Delta x}
\end{aligned}
$$

Onde $D_{\text {Dens Fixa }}$ é a dose relativa para uma distância $\Delta \mathrm{x}$, sendo a dose calculada com a presença de material tecido equivalente com sua respectiva composição, mas, ao

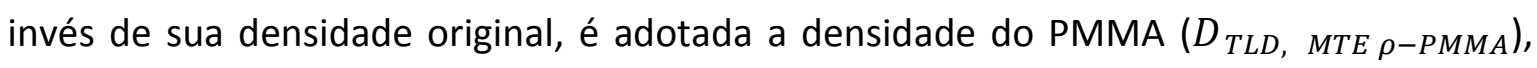
normalizada pela dose calculada em um meio constituído inteiramente por PMMA (com as respectivas composição e densidade $\left.D_{T L D, P M M A}\right)$. A definição de $D_{\text {Comp Fixa é }}$ semelhante a relação anterior, porém neste caso, a composição é mantida fixa sendo adotada como igual a do PMMA e a densidade varia de acordo com o material tecido equivalente estudado.

\subsubsection{Dose Relativa POR Profundidade}

O estudo de porcentagem de dose por profundidade comparou dados obtidos com as simulações e medidas experimentais. A análise principal consistiu em observar a distribuição de dose conforme variação da espessura $\Delta x$. Para a obtenção da dose relativa referente à porcentagem de dose por profundidade, a normalização ocorreu entre materiais idênticos em espessuras diferentes. Inicialmente foram comparados os 
dados dos objetos simuladores contendo a placa de espessura variável constituída inteiramente por PMMA. A Equação 19 introduz a razão analisada.

$$
P D P_{T L D, ~} \text { PMMA }=\frac{\left(D_{T L D, P M M A}\right)_{\Delta x}}{\left(D_{T L D, P M M A}\right)_{\Delta x=2,0 \mathrm{~mm}}}
$$

Onde $\left(D_{T L D,} \text { PMMA }\right)_{\triangle x}$ é a dose transportada em um objeto simulador constituído por PMMA, com uma espessura $\Delta \mathrm{x}$ na placa intermediária, e calculada no TLD (conforme a Figura 27); $\left(D_{T L D, ~ P M M A}\right)_{\triangle x=2,0 \mathrm{~mm}}$ é a dose transportada em um objeto simulador também constituído por PMMA e com TLD presente, porém com espessura $\Delta x$ fixa em 2,0mm, sendo esta adotada como profundidade de referência. $P D P_{T L D,} P M M A$ é a razão entre estes dois parâmetros analisados previamente.

A análise da variação da dose por profundidade também foi simulada para objetos simuladores cujo cálculo e transporte de radiação foi realizado no meio de PMMA $\left(D_{P M M A}\right.$, PMMA $)$, a fim de observar a influência da presença dos TLDs nas simulações. A Equação 20 denota esta razão.

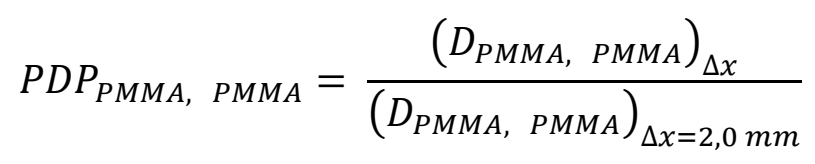

Onde $\left(D_{P M M A, ~ P M M A}\right)_{\triangle x}$ é a dose transportada em um objeto simulador constituído por PMMA, com uma espessura $\Delta \mathrm{x}$ na placa intermediária, e calculada no mesmo meio em um volume de $1,0 \mathrm{~mm}^{3}$ (conforme a Figura 28 - direita); $\left(D_{P M M A, P M M A}\right)_{\triangle x=2,0 \mathrm{~mm}}$ é a dose transportada e calculada em um objeto simulador também constituído por PMMA, porém com espessura $\Delta \mathrm{x}$ fixa em 2,0mm. $P D P_{P M M A}, P M M A$ é a razão entre estes dois parâmetros analisados previamente.

Posteriormente as mesmas razões de dose relativa por profundidade descritas pelas Equações 19 e 20 foram simuladas para objetos simuladores contendo materiais tecido equivalentes, sendo eles Fígado, Pulmão Exalado e Osso (1000 mg/cm $\left.{ }^{3} \mathrm{HA}\right)$, a normalização manteve-se entre materiais idênticos em espessuras diferentes, sendo $\Delta x$ também fixo a 2,0 mm no denominador da função. Nestas análises, os resultados 
simulados foram comparados com as medidas experimentais realizadas com o uso de dosímetros termoluminescentes. As equações a seguir elucidam os parâmetros utilizados nas simulações.

$$
\begin{gathered}
P D P_{T L D, M T E}=\frac{\left(D_{T L D, M T E}\right)_{\Delta x}}{\left(D_{T L D, M T E}\right)_{\Delta x=2,0 \mathrm{~mm}}} \\
P D P_{P M M A, M T E}=\frac{\left(D_{P M M A}, M T E\right)_{\Delta x}}{\left(D_{P M M A, M T E}\right)_{\Delta x=2,0 \mathrm{~mm}}}
\end{gathered}
$$

Onde $\left(D_{T L D, M T E}\right)_{\triangle x}$ é a dose transportada em um objeto simulador constituído por material tecido equivalente, com uma espessura $\Delta x$ na placa intermediária, e calculada no TLD (conforme a Figura 26); $\left(D_{T L D, M T E}\right)_{\triangle x=2,0 \mathrm{~mm}}$ é a dose transportada em um objeto simulador também constituído por material tecido equivalente e com TLD presente, porém com espessura $\Delta \mathrm{x}$ fixa em 2,0mm. $P D P_{T L D}, M T E$ é a razão entre estes dois parâmetros analisados previamente. A $P D P_{P M M A}, \quad M T E$ apresenta uma razão semelhante a anteriormente descrita, porém a dose ao invés de calculada no TLD, é calculada no PMMA, em um volume de $1,0 \mathrm{~mm}^{3}$ (conforme a Figura 28 - esquerda), estabelecendo uma relação entre os parâmetros $\left(D_{P M M A}, M T E\right)_{\Delta x}$ calculada para uma espessura de

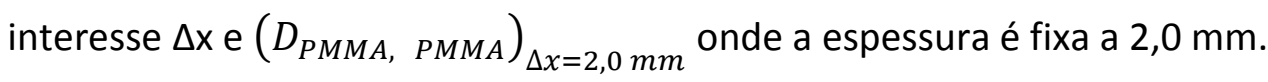

A partir das simulações foi possível a obtenção de parâmetros referentes ao cálculo da distribuição da dose transportada em meios constituídos por material tecido equivalente ou PMMA e calculada em volumes contendo LiF (TLDs) ou PMMA. Isto é, foi possível a obtenção de parâmetros relacionados como $D_{T L D, M T E}, D_{T L D, ~ P M M A}$, $D_{P M M A, ~ M T E}$ e $D_{P M M A}$, PMMA que possibilitaram a determinação de uma razão que proporciona um fator de conversão entre a dose calculada/medida no PMMA com o uso de TLDs, bem como, quando o transporte de radiação é feito no PMMA e em material tecido equivalente. O desenvolvimento das Equações 23 e 24 mostram as variáveis deste fator. 


$$
\begin{gathered}
\mathrm{D}_{T L D, M T E}=D_{T L D, P M M A} \cdot\left(\frac{\mathrm{D}_{P M M A, M T E}}{D_{P M M A, P M M A}}\right) \\
F_{C}=\frac{\mathrm{D}_{P M M A, M T E}}{D_{P M M A, P M M A}}
\end{gathered}
$$

A razão estabelecida pelo Fator de Conversão $F_{C}$ permite para a rotina clinica, por exemplo, estimar a dose de atenuação de um tecido humano a partir da distribuição de dose obtida num objeto simulador de PMMA através da leitura de TLDs-100 de LiF. Como o fator $F_{C}$ é influenciado pela espessura do material entre a fonte e o detector, foram definidas funções para estimar o seu valor para cada um dos materiais estudados (Fígado, Pulmão Exalado e Osso $1000 \mathrm{mg} \cdot \mathrm{cm}^{-3}$ ).

\subsubsection{Objetos Simuladores com Variados Materiais Tecidos EQUIVALENTES}

O estudo preliminar de porcentagem de dose por profundidade foi estendido a inserção de cilindros contendo materiais tecido equivalentes distintos através de simulações para o cálculo de deposição de dose realizado com o tally *FMESH4. Os objetos simuladores tiveram sua geometria modificada neste estudo, sendo esta exibida na Figura 29. Aspectos da geometria dos objetos simuladores contendo somente um material equivalente foram mantidos, como por exemplo, a disposição das 4 sementes de ${ }^{125} \mathrm{I}$, além das dimensões da placa que as continham como exibido anteriormente na Figura 25. É importante ressaltar que, inicialmente, não foram inseridos dosímetros nas simulações, sendo calculados os perfis de dose na extensão (área pontilhada na Figura 29) do objeto simulador. 


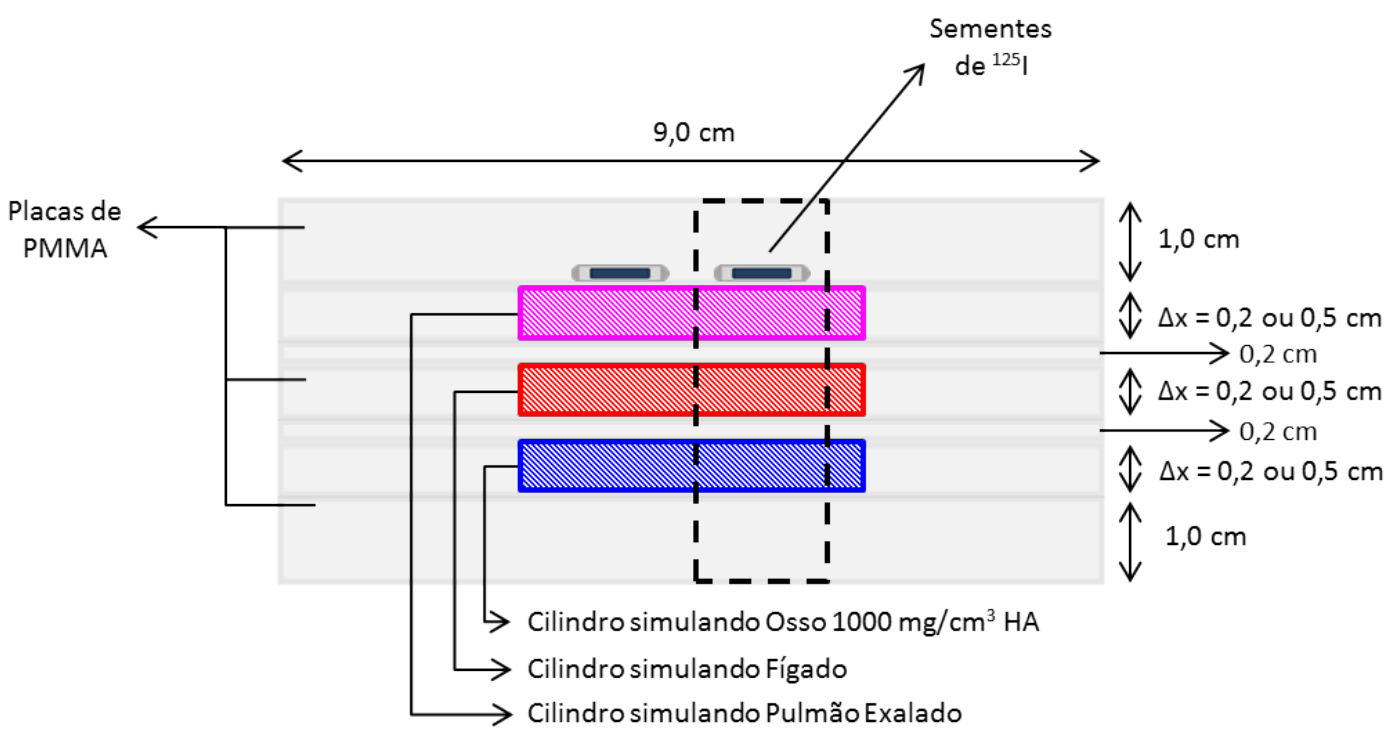

Figura 29. Objeto Simulador utilizado para o cálculo de deposição de dose quando inseridos mais de um material tecido equivalente. Nas simulações foram adotadas variações nas espessuras destes materiais $\Delta x=0,2$ ou $0,5 \mathrm{~cm}$. O tracejado indica os limites da matriz que permitiu estabelecer as linhas de isodose como resposta para o tally utilizado.

Fonte: Elaborado pela autora.

Nos objetos simuladores, a disposição dos distintos materiais equivalentes seguiu sempre a demonstrada na Figura 29 , de modo que a espessura destes materiais $(\Delta x)$ variava igualmente (ora todas com $\Delta x=2,0 \mathrm{~mm}$ e ora com $\Delta x=0,5 \mathrm{~mm}$ ). A área pontilhada na Figura 29 denota a área da matriz onde foi realizado o cálculo de dose absorvida e a partir da qual foi possível traçar linhas de isodose para melhor visualização e compreensão do experimento. Devido as variações de $\Delta x$, as matrizes geradas através do tally utilizado quando $\Delta \mathrm{x}=2,0 \mathrm{~mm}$ possuíam tamanho de $10 \mathrm{x} 64$, e as matrizes com $\Delta x=5,0 \mathrm{~mm}, 10 \times 82$, de modo que cada voxel de ambas apresentavam dimensões de $0,05 \mathrm{~cm}^{3}$.

Os cálculos com o tally FMESH4 também foram utilizados para observar a distribuição de dose nas mesmas condições do objeto simulador representado na Figura 29, exceto pela presença dos materiais tecido equivalentes, sendo este constituído inteiramente por PMMA. Posteriormente foi realizada a comparação entre a distribuição de dose com a atenuação dos diferentes materiais tecido equivalentes e a distribuição de dose observada no objeto simulador constituído inteiramente por PMMA. 
CAPÍTULO 5

\section{RESUltados E} DISCUSSÕES 


\section{Resultados E Discussões}

Visando a melhor compreensão e estruturação dos dados obtidos, os resultados experimentais e simulados abordados por este trabalho referentes às distribuições de dose, foram diferenciados conforme os objetivos específicos anteriormente descritos. Os tópicos relacionados a seguir fazem alusão à metodologia empregada, sendo uma extensão de seus detalhamentos.

\subsection{ANÁLISE dos PARÂMETROS Do TG-43U}

\subsubsection{Constante DE TAXa DE Dose, $\Lambda$}

As metodologias presentes no protocolo TG-43 foram seguidas a fim de validar a geometria da semente de ${ }^{125} \mathrm{I}$ construída. Os dados de Intensidade do Kerma no $\operatorname{Ar}\left(\mathrm{S}_{\mathrm{K}}\right)$ obtidos para as células simulando detectores WAFAC e POINT foram 0,705 $\mathrm{cGycm}^{2} \mathrm{~h}^{-1} \mathrm{mCi}^{-}$ ${ }^{1}$ e $0,732 \mathrm{cGycm}^{2} \mathrm{~h}^{-1} \mathrm{mCi}^{-1}$ respectivamente. Os dados de Constante de Taxa de Dose $(\Lambda)$ obtidos neste trabalho e de outros autores estão apresentados na Tabela 9.

Tabela 9. Comparação dos valores de Constante de Taxa de Dose $(\Lambda)$ da semente de ${ }^{125} \mathrm{I}$, modelo Amersham 6711.

\begin{tabular}{ccc}
\hline Autor & Metodologia & $\boldsymbol{\Lambda}\left(\mathbf{c G y h}^{-1} \mathbf{U}^{-1}\right)$ \\
\hline Este trabalho & MCNP - WAFAC & $0,968 \pm 0,013$ \\
Este trabalho & MCNP - POINT & $0,933 \pm 0,017$ \\
\hline TAYLOR; ROGERS, (2008) & EGSnr - WAFAC & $0,924 \pm 0,002$ \\
\hline TAYLOR; ROGERS, (2008) & EGSnr - POINT & $0,942 \pm 0,003$ \\
DOLAN et al. (2006) & WAFAC (PTRAN) & $0,942 \pm 0,017$ \\
\hline RIVARD et al. (2004) & TG-43 Consensus & $0,965 \pm 0,028$ \\
\hline
\end{tabular}

Fonte: Elaborado pela Autora.

As incertezas apresentadas por TAYLOR; ROGERS (2008) referem-se às incertezas estatísticas intrínsecas ao Método de Monte Carlo utilizado através do código EGSnrc, enquanto as deste e dos demais autores, referem-se à propagação de incertezas. 
A avaliação das incertezas atribuídas à Constante de Taxa de Dose $(\Lambda)$ neste trabalho foi realizada considerando as incertezas do Tipo $A$, referentes à análise estatística, e Tipo B, sistemáticas. Como incertezas sistemáticas foram consideradas as incertezas da biblioteca da seção de choque, do espectro energético e geometria da semente. A Tabela 10 exibe os valores de incertezas para cada componente.

Tabela 10. Incertezas referentes à Constante de Taxa de Dose $(\Lambda)$ para o método WAFAC da semente de ${ }^{125}$, modelo Amersham 6711.

\begin{tabular}{|c|c|c|}
\hline Autor & Tipo A & Tipo B \\
\hline Estatística MC & $0,08 \%$ & \\
\hline $\begin{array}{l}\text { Seção de Choque } \\
\text { (CULLEN et al., 1997) }\end{array}$ & & $1,20 \%$ \\
\hline $\begin{array}{c}\text { Geometria } \\
\text { (DOLAN; LIA; WILLIAMSON, } \\
\text { 2006) }\end{array}$ & & $0,75 \%$ \\
\hline $\begin{array}{l}\text { Espectro Energético } \\
\text { (RIVARD et al., 2004) }\end{array}$ & & $0,10 \%$ \\
\hline Incerteza Combinada & $0,08 \%$ & $1,42 \%$ \\
\hline Incerteza Total (k=1) & & \\
\hline
\end{tabular}

Fonte: Elaborado pela Autora.

As diferenças nos valores de TAYLOR; ROGERS, (2008) e DOLAN et al, (2006) ocorreram devido a pequenas diferenças nas geometrias adotadas na descrição da semente, além da utilização de diferentes códigos.

Neste estudo, a constante de taxa de dose diferiu 0,31\% em comparação à apresentada pelo TG-43U1, quando considerada a deposição de energia na célula que simulou a câmara WAFAC.

\subsubsection{Função de Dose Radial, G(r)}

A obtenção e análise de parâmetros como a função de dose radial, $g(r)$, e função de anisotropia, $F(r, \theta)$, foi realizada através do cálculo de taxa de dose nos pontos recomendados, $\dot{D}(r, \theta)$, e cálculo da função geométrica para fonte linear $\left(\mathrm{G}_{\mathrm{L}}\right)$ descritos previamente.

Os cálculos das funções de dose radial e anisotropia permitiram analisar a deposição de energia causada pela semente de ${ }^{125} \mathrm{I}$, calculando-a no eixo transversal, 
somente para pontos com um ângulo $\theta_{0}=90^{\circ}$, e ao redor da fonte, para um raio fixo e $\theta$ variável, respectivamente. A Figura 30 denota o comportamento da função de dose radial (representada na Equação 7) neste e em demais estudos presentes na literatura.

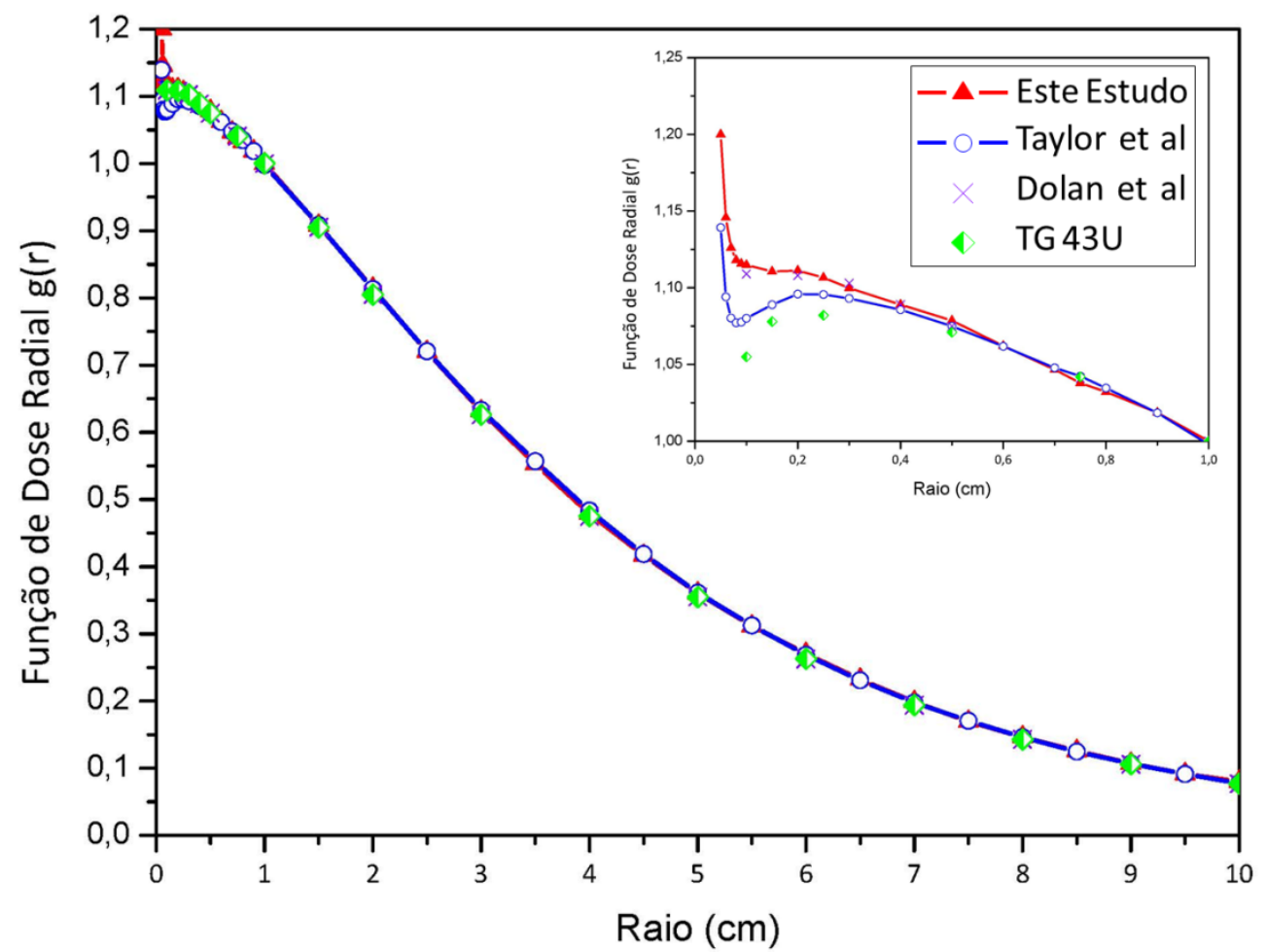

Figura 30. Comparação dos valores da Função de Dose Radial da Semente de ${ }^{125} \mathrm{I}$. No gráfico está descrito o comportamento da função para a distância de 0 a 10,0 cm entre a fonte e o detector. A direita pode-se observar uma ampliação da mesma função no intervalo de 0 a $1,0 \mathrm{~cm}$.

Fonte: Elaborado pela Autora.

Os gráficos ressaltam a concordância do presente estudo com os dados encontrados na literatura. Para poucos milímetros as diferenças relativas encontradas, em relação aos dados de TAYLOR; ROGERS, (2013), foram em torno de 5\%, chegando a $2 \%$ com $0,2 \mathrm{~cm}$ de distância fonte-detector, o que se deve provavelmente à diferença de códigos de Monte Carlo utilizados. As maiores diferenças relativas encontradas foram em comparação ao TG-43U1, sendo 7,5\% para distâncias em torno de 0,1 cm. As maiores semelhanças no comportamento da Função de Dose Radial se dão quando comparados os dados deste estudo e de DOLAN et al., (2006), isto pode ser explicado pelo detalhamento da geometria utilizada e pela correspondência nas bibliotecas de dados utilizadas, já que a biblioteca MCPLIB84 utilizada neste trabalho foi baseada na biblioteca EPDL97 (HUGHES; JAMES, 2014) . 


\subsubsection{FunÇÃo dE ANISOTROPIA, F(r, $\theta)$}

Na função anisotropia, a medida que a variação angular tende a $0^{\circ}$ ou a $180^{\circ}$ seu valor decresce, isto ocorre principalmente devido a filtração da energia dos fótons primários e ao aumento da espessura de seu encapsulamento e é mais evidente para curtas distâncias fonte-detector. A Figura 31 apresenta as curvas de isodose obtidas para uma semente de ${ }^{125} \mathrm{I}$, exaltando a autofiltração da fonte a $0^{\circ}$ e a $180^{\circ}$.

Os dados obtidos através da função de anisotropia, representada na Figura 32, explicitam que para o eixo transverso $\left(\theta=90^{\circ}\right)$ seu valor é próximo a 1 , não exercendo grande influência sobre a distribuição de dose. As diferenças relativas mais acentuadas podem ser observadas em comparação ao TG-43U1, sendo de 37\% quando assumidos valores de raio $=0,5 \mathrm{~cm}$ e angulação $0^{0}$.

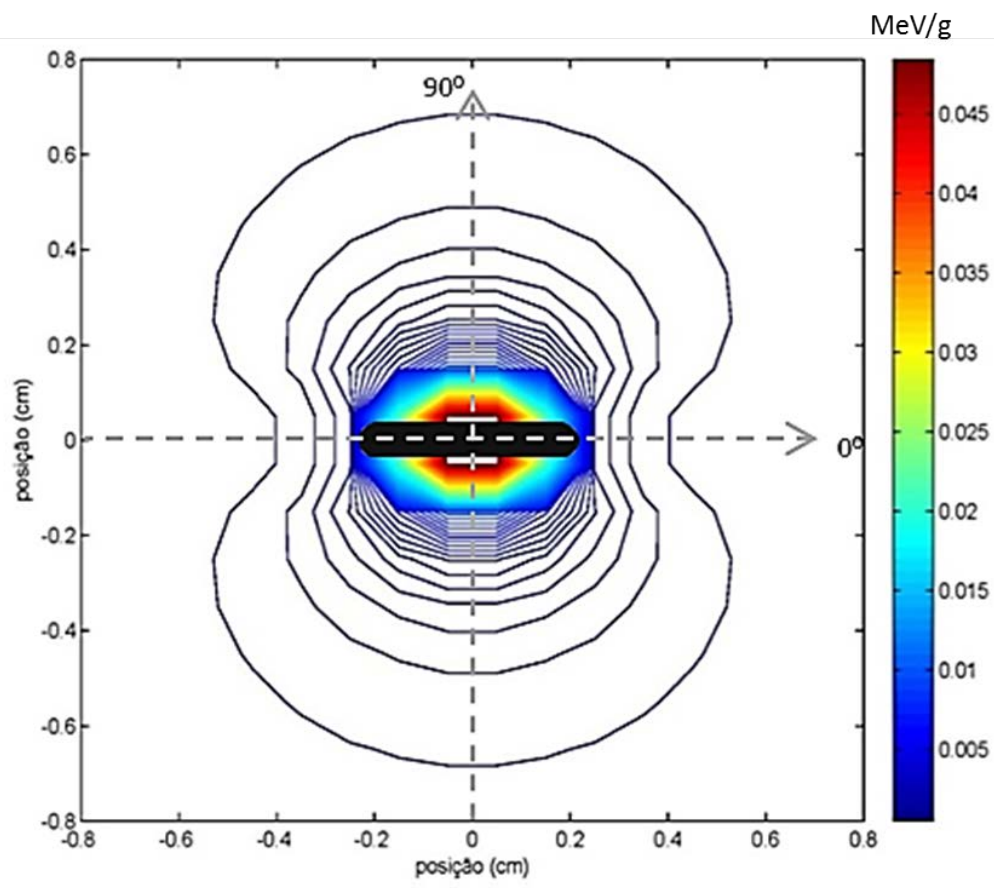

Figura 31. Representação das curvas de isodose (em unidades de $\mathrm{MeV} \cdot \mathrm{g}^{-1}$ ) da semente simulada de ${ }^{125}$ I indicando os ângulos definidos para o cálculo de taxa de dose e explicitando o efeito da anisotropia.

Fonte: Elaborado pela Autora. 

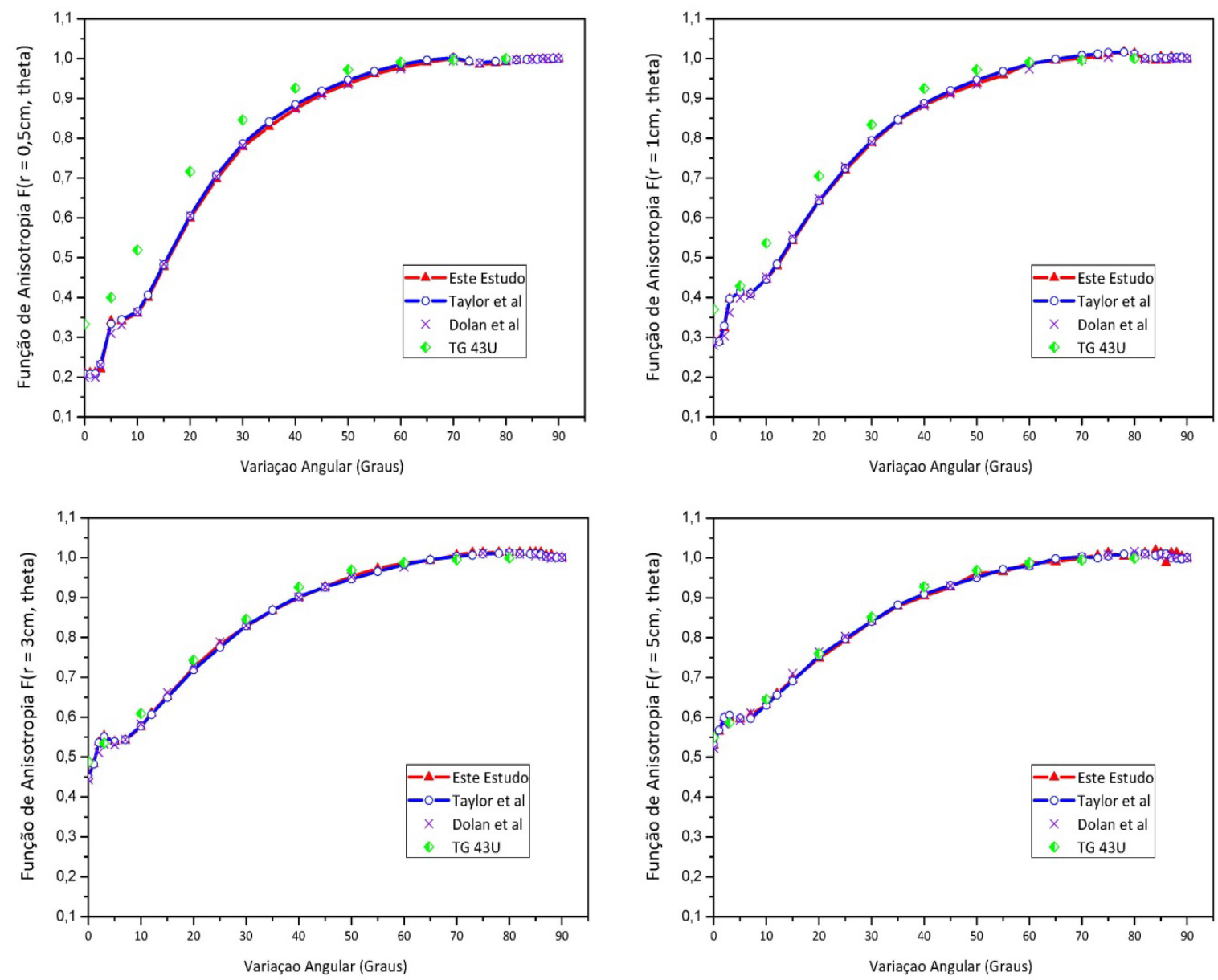

Figura 32. Função de Anisotropia para Semente de ${ }^{125} \mathrm{I}$ explicitando o comportamento da função a $0,5 \mathrm{~cm}, \mathrm{a}$ $1 \mathrm{~cm}$, a $3 \mathrm{~cm}$ e a $5 \mathrm{~cm}$.

Fonte: Elaborado pela Autora.

\subsection{SELECIONAMENTO dos DosímETROS TERMOLUMINESCENTES}

A média das respostas das leituras TL, obtidas com a realização de 4 ciclos de selecionamento dos dosímetros, assim como a representação de sua dispersão são expostos na Figura 33 abaixo. 


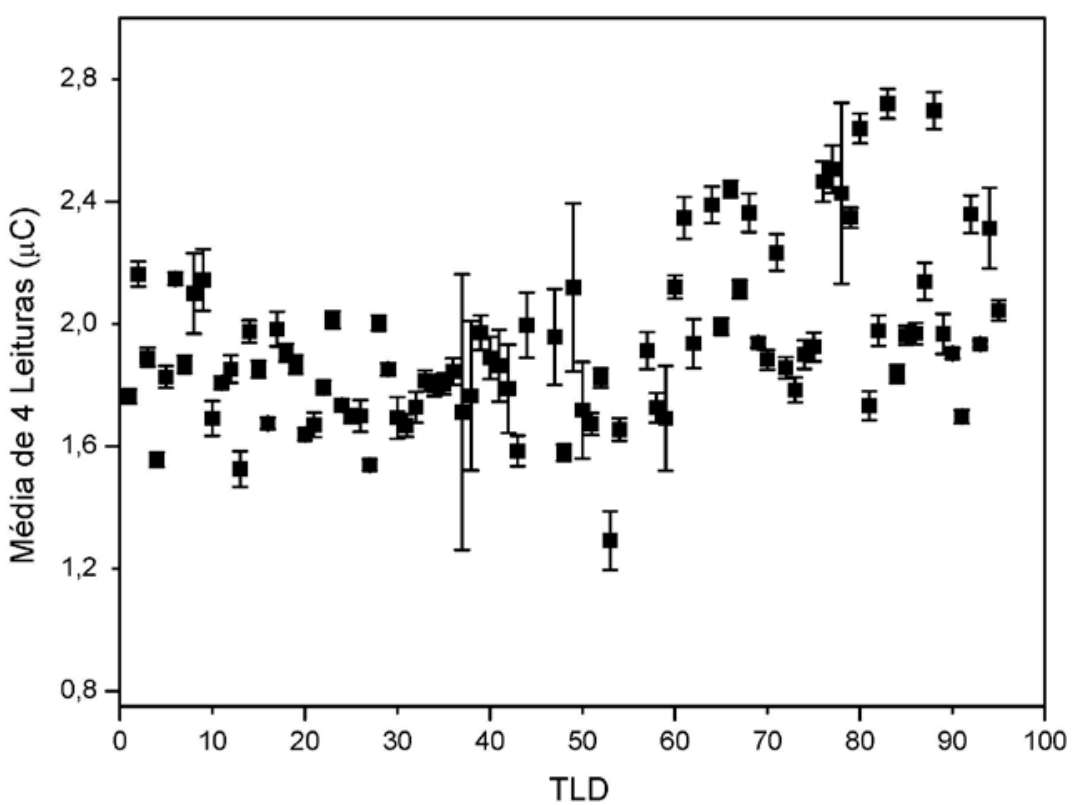

Figura 33. Valores médios dos TLDs em 4 ciclos de leitura e suas respectivas incertezas.

Fonte: Elaborado pela autora.

A fim de minimizar as incertezas dos TLDs foi atribuído a cada dosímetro já selecionado, um fator de normalização. Na Figura 34 são apresentados os histogramas das respostas destes TLDs com e sem a presença do fator de normalização influenciando nas leituras, assim como a curva normal obtida a partir destes dados.
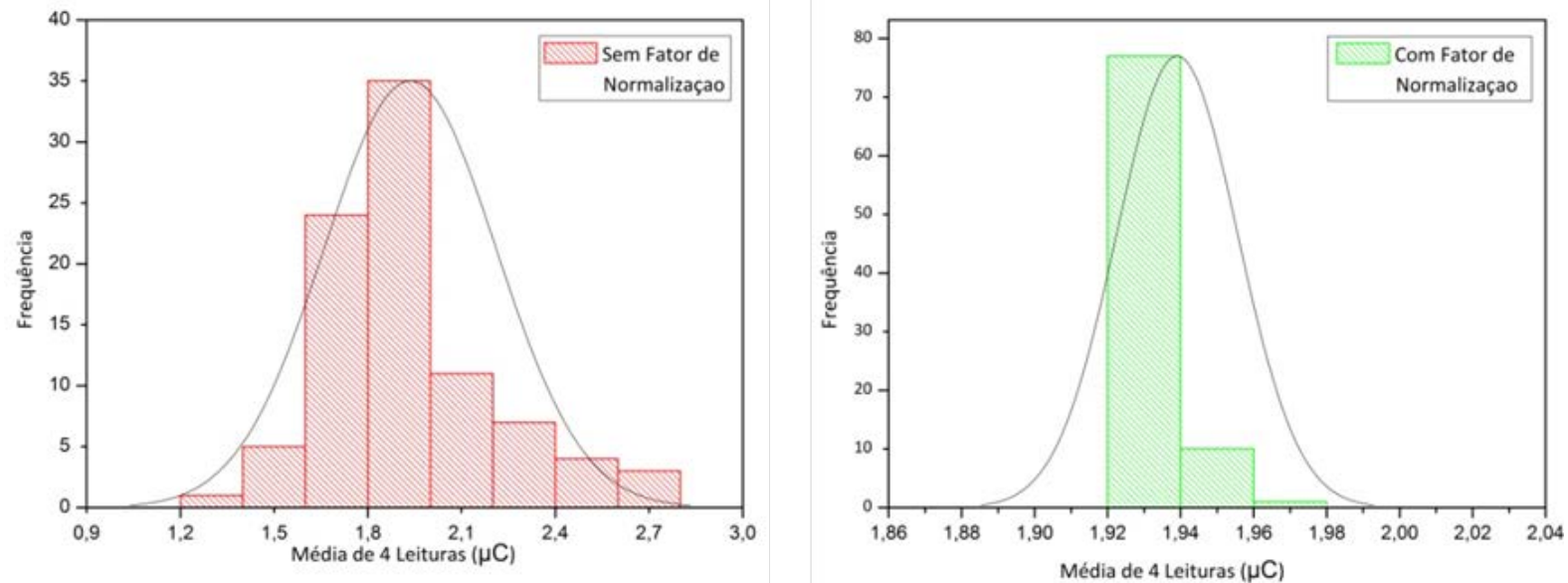

Figura 34. Histogramas das respostas dos TLDs-100 quando não aplicado (esquerda) e aplicado (direita) o fator de normalização.

Fonte: Elaborado pela autora. 
A Figura 34, através da representação das curvas de distribuição normal, permite observar que os valores de leitura TL convergem quando há aplicação do fator de normalização. Portanto os dados, com o uso deste fator, se mostram mais precisos quando comparados com aqueles onde não foram utilizados o fator de normalização.

\subsection{DEPENDÊNCIA ENERGÉTICA PARA FóTONS}

Os coeficientes de absorção de energia em massa $\left(\mu_{\mathrm{en}} / \rho\right)$ do material que compõe os dosímetros termoluminescentes (LiF) estão diretamente relacionados com sua resposta, pois determinam a quantidade de energia do feixe que é absorvida no volume sensível do dosímetro de acordo com cada energia de fóton. A Figura 35 apresenta o comportamento do coeficiente de absorção de energia em massa para diferentes energias de fótons.

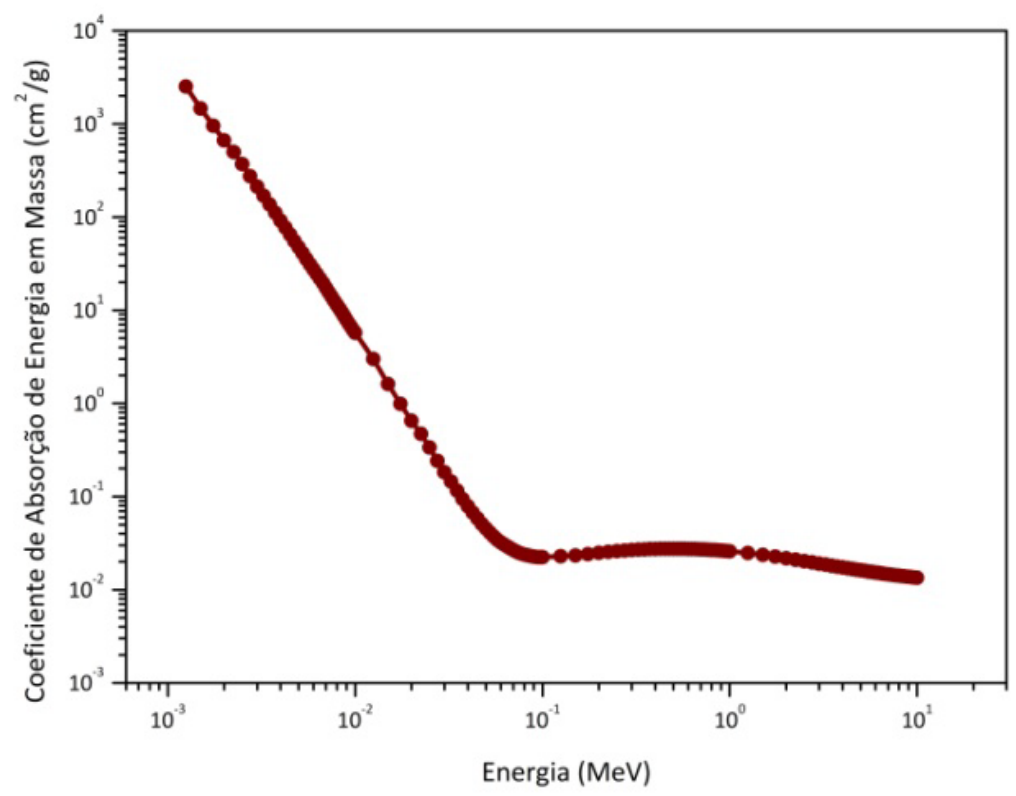

Figura 35. Coeficiente de absorção de energia em massa do LiF para diferentes energias de fótons. Fonte: Elaborado pela autora.

A Figura 35 evidencia a pouca variação dos valores de $\mu_{\mathrm{en}} / \rho$ para energias superiores a 0,1 MeV. Anteriormente a este valor o coeficiente apresenta aumento acentuado, ressaltando que estudos de dependência energética são indicados principalmente quando há utilização de fontes de baixa energia. 
A seguir são apresentados os resultados simulados dos parâmetros já descritos (Equação 16) para as diferentes fontes adotadas neste estudo (Tabela 5), além de dados correspondentes a diferentes energias apresentados por DAVIS et al, (2003), exibidas na Tabela 6, e por NUNN et al., (2008), Tabela 7. Analisando o comportamento da curva, nota-se menor variação dos parâmetros a partir de $100 \mathrm{keV}$, o que pode ser explicado de acordo com os dados de $\mu_{\mathrm{en}} / \rho$ referentes ao TLD. Os resultados deste estudo e de outros autores apresentam-se evidenciados na Figura 36.

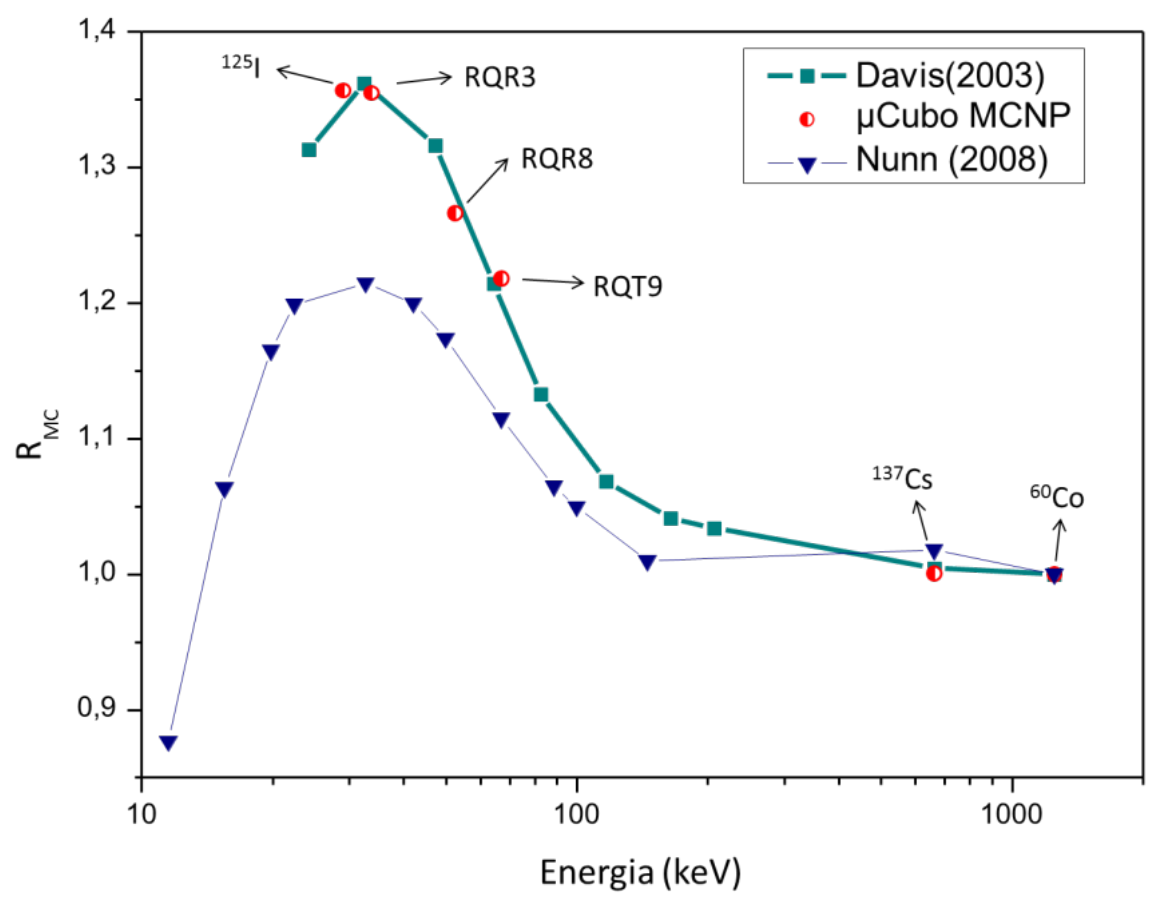

Figura 36. Comparação dos dados simulados neste estudo, de DAVIS et al, (2003) e de NUNN et al., (2008). para calculo da razão $D_{\mathrm{LiF}} / \mathrm{K}_{\mathrm{ar}}$ obtidos de acordo com o a energia do feixe estudado normalizados para razão $\mathrm{D}_{\text {LiF }} / \mathrm{K}_{\text {ar }}$ obtidos no ${ }^{60} \mathrm{Co}$, denominado $\mathrm{R}_{\mathrm{MC}}$.

Fonte: Elaborado pela autora.

Comparações entre os dados simulados $\left(R_{M C}\right)$ deste estudo e de DAVIS et al. (2003) apresentaram boa concordância provavelmente devido a semelhante geometria de irradiação e energias utilizadas. As diferenças relativas encontradas foram inferiores a 1,80\% para o parâmetro $R_{M c}$, sendo a maior referente a energia de $52,5 \mathrm{keV}$ do feixe RQR8.

Os dados simulados apresentados por NUNN et al., (2008) apresentaram divergências em comparação com este estudo, apresentando diferenças relativas de 
11,8\% para energia de $29 \mathrm{keV}$ do ${ }^{125} \mathrm{I}$, e em comparação com o artigo de DAVIS et al., (2003) a maior diferença relativa foi de $10,7 \%$ para a energia de $33,7 \mathrm{keV}$.

NUNN et al., (2008) também comparou os dados obtidos nas simulações com seus dados experimentais, obtendo uma diferença relativa de até $13 \%$, os quais constataram um aumento nas respostas dos TLDs. Outra perspectiva dos resultados favorece a argumentação de que o código MCNP não calcula a conversão de dose depositada na resposta TL devido à impossibilidade de considerar o processo de termoluminescência e armadilhamento de cargas.

As correções para a dependência energética utilizando o feixe de ${ }^{60} \mathrm{Co}$ para a baixa energia dos fótons emitidos pelo ${ }^{125}$ I foram realizadas através de simulações pois nas análises experimentais foram utilizados cálculos de dose relativa, onde estas correções se cancelam.

\subsection{DisTRIBUIÇÃo DE DOSE nOS OBJETOS SiMUlAdORES}

Os resultados referentes à distribuição de dose nos objetos simuladores foram obtidos segundo a metodologia previamente explicitada, tendo este estudo assumido vertentes distintas baseadas nos dados obtidos com as simulações e em sua comparação com os valores experimentais. A seguir são detalhados as análises e resultados obtidos em acordo com o objetivo de cada estudo.

\subsubsection{INFLUÊNCIA DA DENSIDADE E CoMPosição}

Para compreensão da mudança nos valores da dose influenciada pelos efeitos de densidade e composição dos materiais foram realizadas simulações que inicialmente atribuíram a todos os materiais tecido equivalente a mesma densidade do PMMA ( $\rho=1.18$

g. $\mathrm{cm}^{-3}$ ) e mantiveram as composições químicas originais de cada material. Em seguida, foram realizadas simulações onde as densidades originais dos materiais tecido equivalentes foram mantidas, mas utilizou-se a composição química do PMMA para todos os casos. 
A Figura 37 expressa a razão entre a dose calculada no TLD com a presença de material tecido equivalente, quando a composição deste material é mantida, mas, ao invés de sua densidade original, é adotada a densidade do PMMA (densidade fixa), normalizada pela dose transportada em um meio constituído inteiramente por PMMA

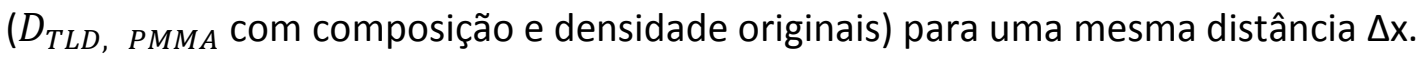

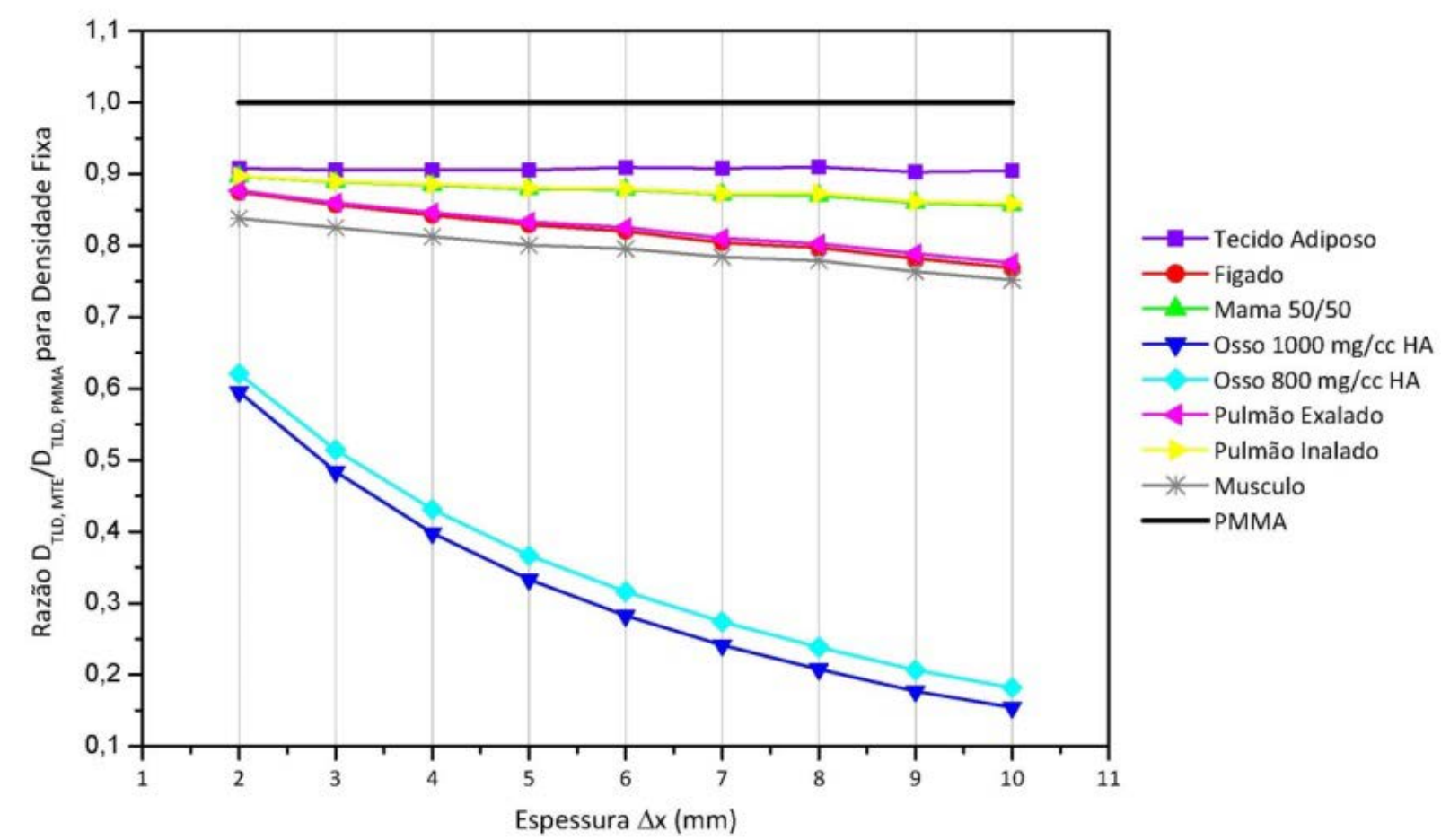

Figura 37. Dados simulados das razões de dose quando são mantidas fixas as densidades $\left(\rho=1.18 \mathrm{~g} / \mathrm{cm}^{3}\right)$ em cada um dos materiais heterogêneos. A Equação 17 exibe a fórmula utilizada para os cálculos. Fonte: Elaborado pela Autora.

A Figura 38 exibe a razão entre a dose calculada com a presença de material tecido equivalente, quando a densidade deste material é mantida, mas, ao invés de sua composição original, é adotada a composição do PMMA (composição fixa), normalizada pela dose transportada no meio constituído inteiramente por PMMA ( $D_{T L D}$, PMMA com composição e densidade originais) numa mesma distância $\Delta x$. 


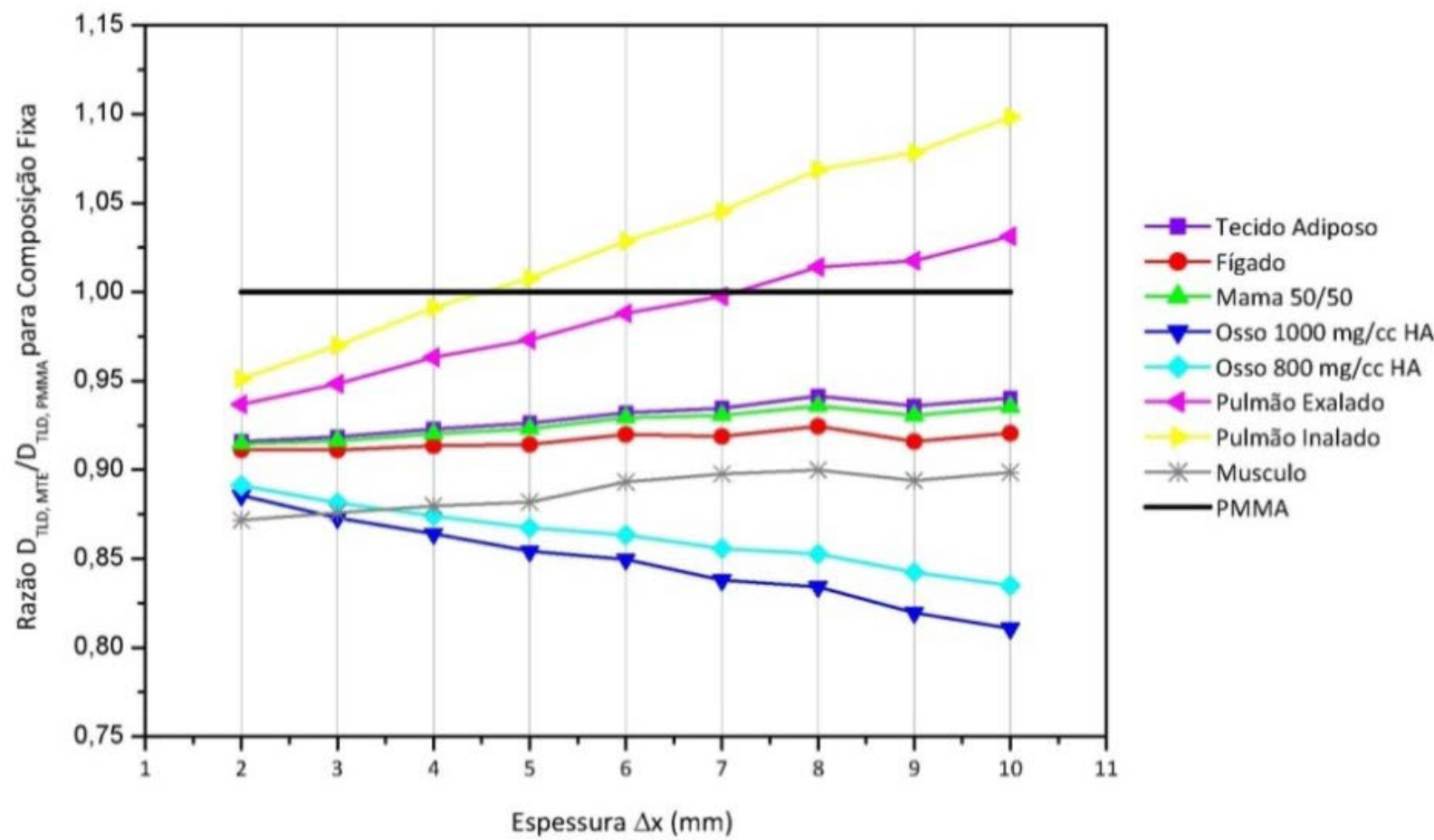

Figura 38. Dados Simulados das razões de dose quando é mantida fixa a composição química do PMMA e adotam-se as densidades originais dos materiais heterogêneos. A Equação 18 exibe a fórmula utilizada para os cálculos.

Fonte: Elaborado pela Autora.

Os dados obtidos com as simulações que continham cilindros de material tecido equivalente foram provenientes de $2,0.10^{9}$ histórias e o valor de propagação de incertezas máximo encontrado foi de $0,852 \%$ para o Osso $1000 \mathrm{mg} / \mathrm{cm}^{3} \mathrm{HA}$ com espessura de $\Delta x=10,0 \mathrm{~mm}$ quando a densidade foi fixada em $\rho=1,18 \mathrm{~g} \cdot \mathrm{cm}^{-3}$. Com os dados obtidos é possível observar que os efeitos da composição e densidades nos distintos materiais tecido equivalentes é mais evidente para maiores espessuras $\Delta x$ na maioria dos materiais estudados.

Nos objetos simuladores em que a densidade foi mantida fixa, sempre como sendo igual a do PMMA, intencionava-se observar a influência que as diferentes composições exerciam sobre a distribuição de dose, uma vez que elas eram o parâmetro variável. A situação inversa ocorreu quando a composição foi fixada, de modo a permitir o estudo conforme as diferentes densidades.

Em ambos os estudos, o material que apresentou maiores diferenças relativas em comparação ao PMMA foi o Osso $1000 \mathrm{mg} / \mathrm{cm}^{3} \mathrm{HA}$ com variação de dose de $40 \%$ a $85 \%$ 
no estudo em que a densidade foi mantida fixa para variação de $2,0 \mathrm{~mm}$ a $10,0 \mathrm{~mm}$ (Figura 37) e 19\% quando a composição foi mantida fixa (Figura 38).

O objeto simulador contendo material tecido equivalente que apresentou a deposição de dose semelhante a do PMMA, quando a sua composição original foi mantida (e a densidade fixada em 1,18 g. $\mathrm{cm}^{-3}$ ) foi o tecido adiposo, com diferenças relativas de cerca de 9,0\% para todas as espessuras, como ressalta a Figura 37 . Neste estudo os materiais, com exceção dos ossos, apresentaram diferenças menores que $15 \%$ para a espessura de $2,0 \mathrm{~mm}$.

No estudo da influência da densidade, onde as composições foram fixas (Figura 38), nota-se que a variação na dose com o aumento da espessura é menos acentuado, sendo a variação máxima na ordem de $20 \%$. O material tecido equivalente que mais se aproximou do comportamento característico da densidade do PMMA foi o Pulmão Exalado, com diferenças relativas máximas de cerca de $6,0 \%$.

Com as análises dos dados foi possível verificar que quando comparadas as mesmas espessuras para os mesmos materiais em ambos os estudos, os valores com maior variação em relação ao PMMA apresentavam-se quando a densidade era mantida fixa. De modo que, para todas as espessuras adotadas e para todos os materiais, o efeito que a composição de cada um deles exerce sobre a deposição de dose é mais expressivo que o efeito de sua densidade.

\subsubsection{Dose Relativa POR Profundidade}

Inicialmente foram analisados dados para configuração de objeto simulador que visavam observar somente o efeito da atenuação no PMMA conforme variação da espessura de interesse $(\Delta \mathrm{x})$. Para isto, nas simulações foram realizadas no meio de PMMA e as doses calculadas no TLD e no PMMA, seguindo as Equações 19 e 20 anteriormente demonstradas. Os dados experimentais e simulados deste estudo estão apresentados na Figura 39, todos foram normalizados para seus respectivos valores a $2 \mathrm{~mm}$.

As propagações de incerteza resultaram valores de cerca de $5 \%$ para medidas experimentais (exceto para as espessuras de $6,0 \mathrm{~mm}$ e $7,0 \mathrm{~mm}$, cujas propagações de 
incertezas foram respectivamente $14,5 \%$ e $8,0 \%$ ) e em valores menores que $0,4 \%$ em ambas as simulações com deposições de dose calculadas para $D_{T L D,}$ PMMA $\mathrm{e}$ DPMMA, РMMA

As espessuras de 3,0 e 4,0 $\mathrm{mm}$ apresentaram discrepâncias nas respostas experimentais obtidas quando comparadas com as simulações. Um fator que poderia ser associado a esta diferença é a sobreposição de placas com diferentes espessuras de PMMA em $\Delta x$, pois as superfícies das placas não eram totalmente planas visto que pertenciam a diferentes lotes e fabricantes. Deste modo, as placas de PMMA poderiam formar uma camada de ar entre elas, situação que não foi considerada nas simulações.

As altas incertezas experimentais foram associadas à variação das respostas dos dosímetros termoluminescentes, entretanto, quando comparados os dados obtidos por simulações $D_{T L D, ~}$ PMMA e experimentais nota-se uma diferença relativa máxima de cerca de $8,8 \%$ a 4,0 mm quando os dados das simulações são adotados como referência, exceto para a espessura de 10,0 mm, que apresentou uma diferença de 13,4\%. A menor diferença relativa encontrada ocorreu para $\Delta x=5,0 \mathrm{~mm}$, sendo de $1,3 \%$.

A diferença relativa máxima encontrada quando comparadas as duas simulações foi de apenas $1,02 \%$ sendo adotado o parâmetro $D_{T L D, P M M A}$ dos dados simulados como referência.

A análise de propagação de incertezas das razões simuladas resultou em valores maiores para a espessura de $10,0 \mathrm{~mm}$, sendo que para razão $P D P_{T L D, ~}$ PMMA (descrita anteriormente pela Equação 19 foi atribuída a incerteza de 0,41\% e para

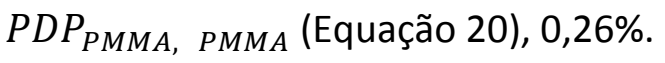




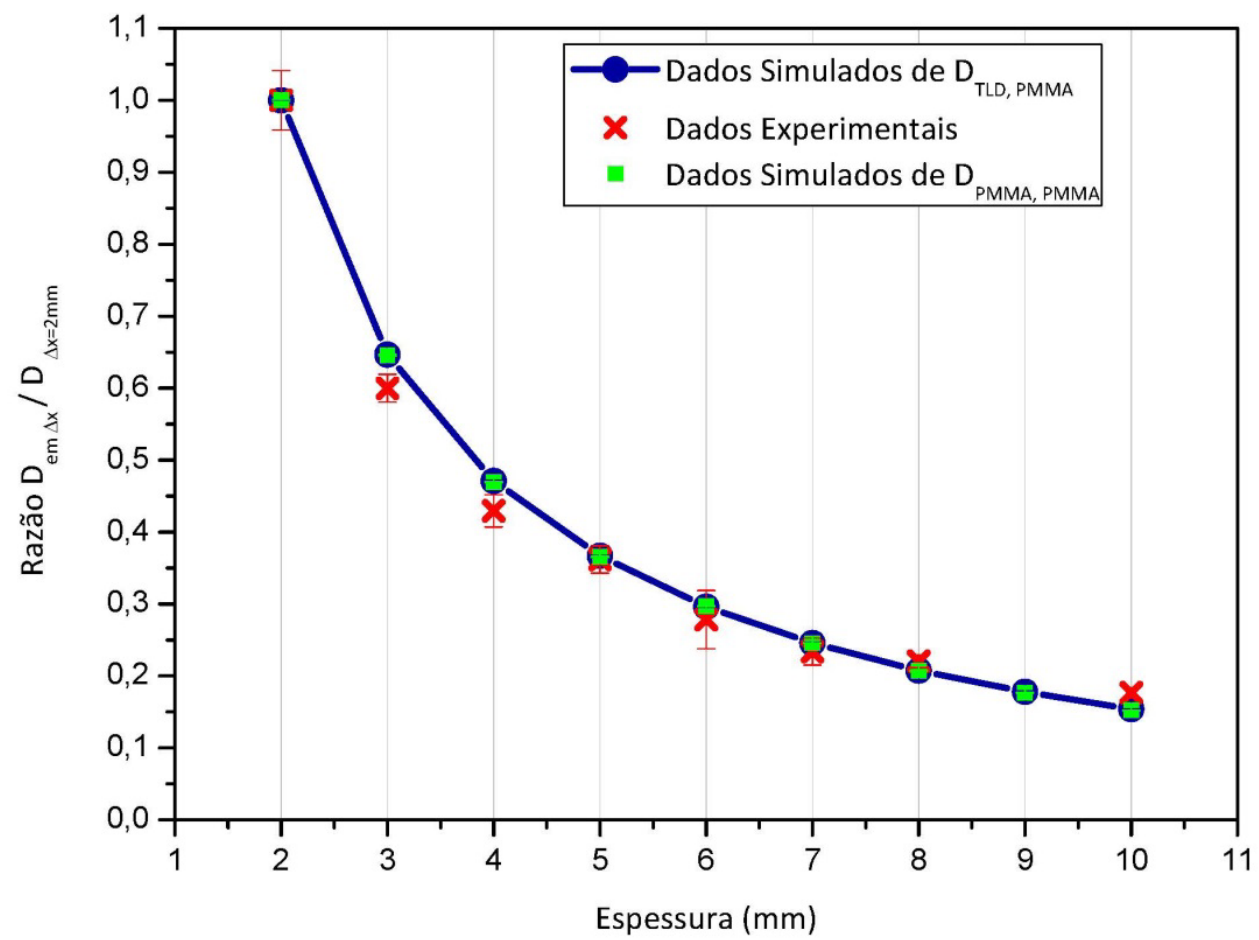

Figura 39. Dados simulados e experimentais da atenuação do PMMA conforme variação da distância fontedetector.

Fonte: Elaborado pela Autora.

A razão de dose relativa por profundidade também foi calculada para objetos simuladores contendo materiais tecido equivalentes, sendo eles Fígado, Pulmão Exalado e Osso (1000 mg/cm³ $\mathrm{HA})$, a normalização foi realizada pelos mesmos materiais em espessuras diferentes, sendo $\Delta x$ de referência fixo a $2,0 \mathrm{~mm}$, como definido anteriormente pelas Equações 21 e 22. Os gráficos das Figuras 40, 41 e 42 apresentam as razões obtidas para cada um dos materiais estudados tanto experimentalmente quanto por simulações onde se variou o meio em que a dose foi calculada (sendo no TLD ou PMMA). 


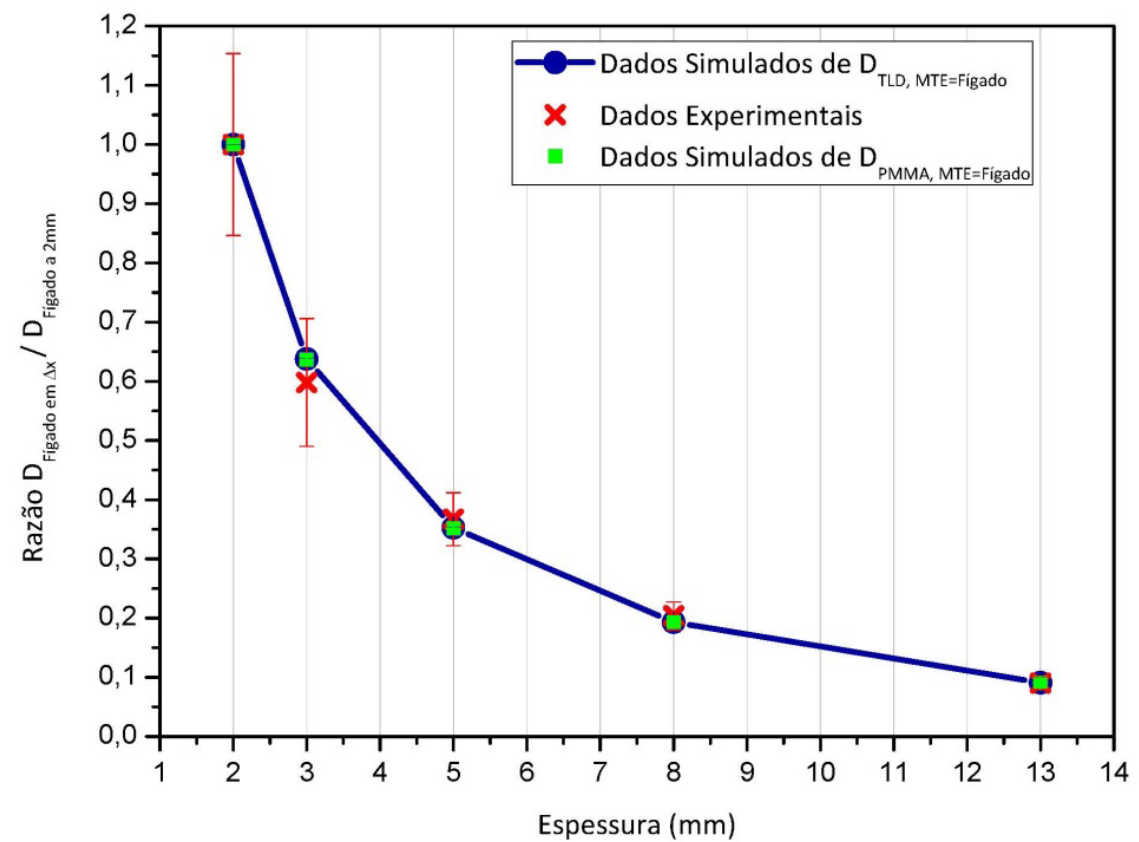

Figura 40. Dados simulados e experimentais da atenuação no cilindro que possuía como material tecido equivalente o Fígado conforme variação da distância fonte-detector.

Fonte: Elaborado pela Autora.

Os dados referentes a doses calculadas nos TLDs e no PMMA para o transporte de radiação realizado no material tecido equivalente de fígado, normalizados no mesmo meio a 2,0 $\mathrm{mm}$, apresentaram pequenas diferenças relativas, sendo o maior valor, de 0,22\%, correspondente a espessura de $5,0 \mathrm{~mm}$, a sendo a simulação com TLDs adotada como referência.

Os valores das razões experimentais quando comparados com os simulados com a presença de TLD apresentaram discrepâncias consideráveis sendo o maior valor de 6,22\% obtido para a espessura de $3,0 \mathrm{~mm}$, e o menor valor de $0,64 \%$ obtido para a espessura de 13,0 mm, também sendo a simulação com TLDs adotada como referência.

A análise de propagação de incertezas das razões simuladas resultou em valores maiores para a maior espessura (de $13,0 \mathrm{~mm}$ ), sendo que para razão $P D P_{T L D,}$ MTE=Fígado (descrita anteriormente pela Equação 21) foi atribuída a incerteza de

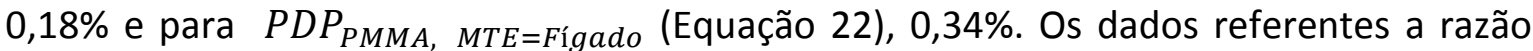
experimental obtida denotou o valor máximo de propagação de incerteza de $18,05 \%$ a $3,0 \mathrm{~mm}$. 


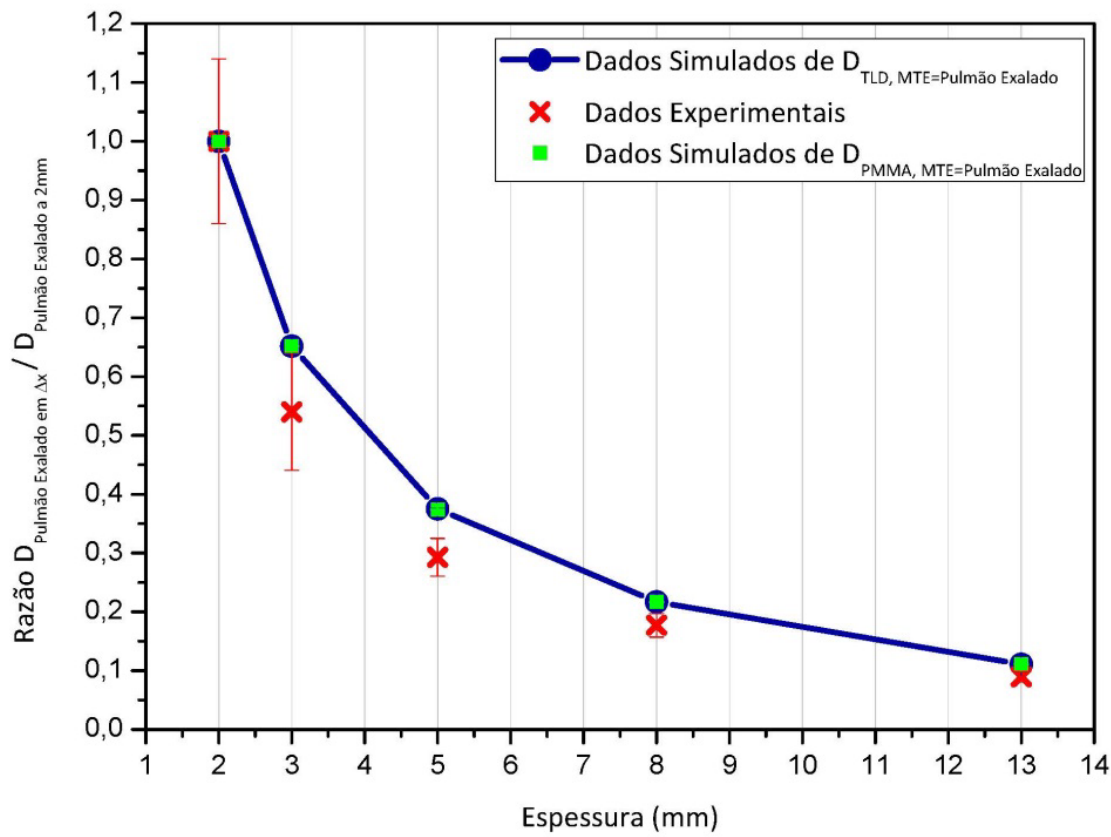

Figura 41. Dados simulados e experimentais da atenuação no cilindro que possuía como material tecido equivalente o Pulmão Exalado conforme variação da distância fonte-detector.

Fonte: Elaborado pela Autora.

Quando comparadas as doses simuladas calculadas nos TLDs e no PMMA para o transporte de radiação realizado no material tecido equivalente de pulmão exalado, normalizados no mesmo meio a $2,0 \mathrm{~mm}$, notam-se pequenas diferenças relativas, sendo o maior valor, de $0,20 \%$, correspondente a espessura de $5,0 \mathrm{~mm}$, a sendo a simulação com TLDs adotada como referência.

Na comparação entre os valores das razões experimentais e os simulados com a presença de TLD observam-se discrepâncias consideráveis sendo o maior valor de 21,9\% obtido para a espessura de 5,0 mm, e o menor valor de $17,14 \%$ obtido para a espessura de 3,0 mm, ainda sendo a simulação com TLDs adotada como referência.

A análise de propagação de incertezas das razões simuladas, assim como no objeto simulador contendo fígado apresentado anteriormente, resultou em valores maiores para

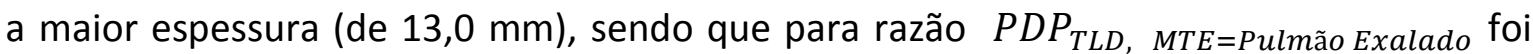
atribuída a incerteza de $0,16 \%$ e para $P D P_{P M M A}$ MTE=Pulmão Exalado 0,30\%. Os dados referentes a razão experimental obtida denotou o valor máximo de propagação de incerteza de $18,45 \%$ a $3,0 \mathrm{~mm}$, assim como ocorreu para o material tecido equivalente de fígado. 


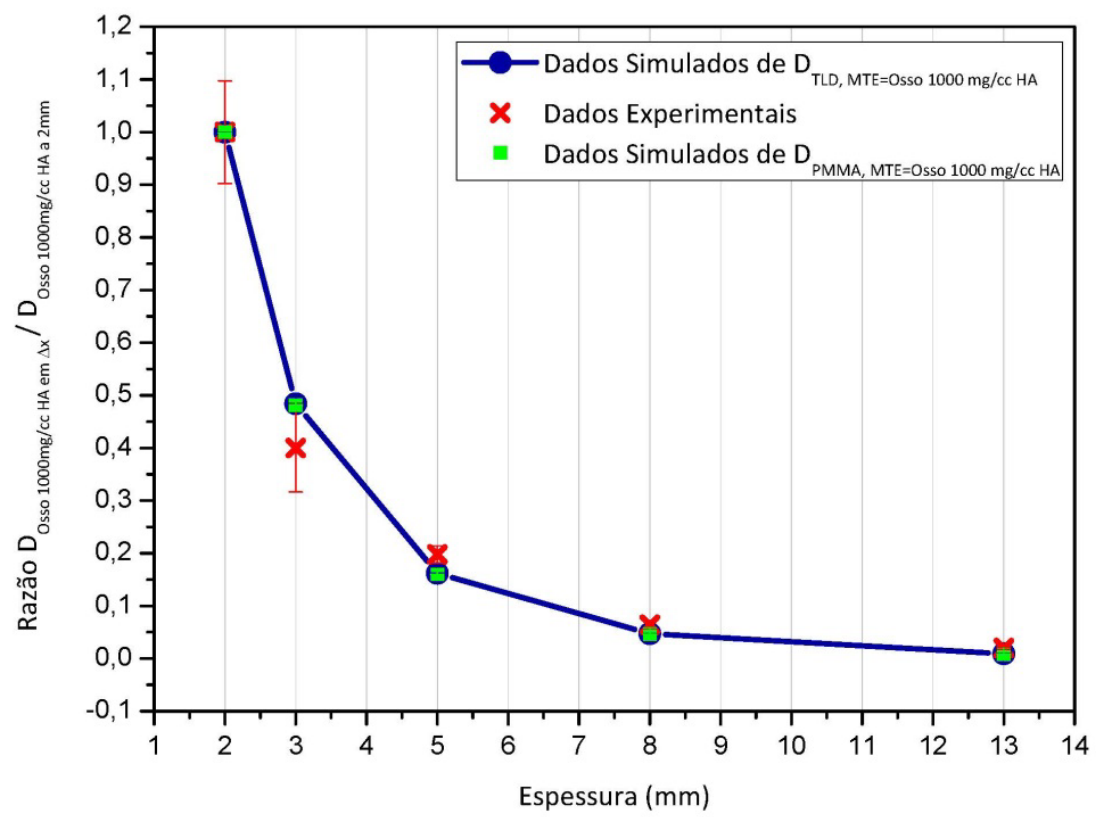

Figura 42. Dados simulados e experimentais da atenuação no cilindro que possuía como material tecido equivalente o Osso $1000 \mathrm{mg} / \mathrm{cm}^{3}$ HA conforme variação da distância fonte-detector.

Fonte: Elaborado pela Autora.

As razões exibidas no gráfico da Figura 42 ressaltam que a 3,0 $\mathrm{mm}$ de espessura a dose obtida para Osso $1000 \mathrm{mg} / \mathrm{cc}$ HA é a metade da dose inicial, isto é, quando comparado com os outros materiais tecido equivalentes, o osso apresenta maior atenuação logo nos primeiros milímetros. Para espessura de 5,0 $\mathrm{mm}$ a dose é menor que $20 \%$ do seu valor original e para espessura de $8,0 \mathrm{~mm}$ é cerca de $5 \%$.

As razões de doses simuladas calculadas nos TLDs e no PMMA para o transporte de radiação realizado nos distintos materiais heterogêneos normalizadas no mesmo meio a 2,0 $\mathrm{mm}$ apresentaram pequenas diferenças relativas, sendo o maior valor, de 7,27\%, correspondente ao Osso de $1000 \mathrm{mg} / \mathrm{cm}^{3}$ a 13,0 mm, sendo a simulação com TLDs adotada como referência.

Os valores experimentais quando comparados com os simulados com TLD apresentaram discrepâncias consideráveis, sendo as mais notáveis para o Osso de 1000 $\mathrm{mg} / \mathrm{cm}^{3}$, com valores maiores que $22 \%$ a partir de 5,0 mm e apresentando valores em torno de $20 \%$ para todos os pontos de Pulmão Exalado.

A análise de propagação de incertezas das razões simuladas, assim como os objetos simuladores contendo distintos materiais apresentados anteriormente, resultou em valores maiores para a maior espessura (de 13,0 mm), sendo que para razão $P D P_{T L D, M T E}=0$ sso $1000 \mathrm{mg} / \mathrm{cc} \mathrm{HA}$ foi atribuída a incerteza de $0,34 \%$ e para 
$P D P_{P M M A}$, MTE=OSso $1000 \mathrm{mg} / \mathrm{cc}$ HA $0,66 \%$. Os dados referentes a razão experimental obtida denotaram o valor máximo de propagação de incerteza de 20,90\% a 3,0 mm, assim como ocorreu para a mesma espessura dos distintos materiais.

As diferenças encontradas em relação aos dados experimentais foram atribuídas às incertezas dos dosímetros e as variações geométricas das placas nos objetos simuladores usinados. Os dados utilizados para a análise e comparação das curvas exibidas nas Figuras 39, 40, 41 e 42, assim como as incertezas associadas às razões, estão disponíveis no Apêndice B deste trabalho.

Através dos dados simulados é possível obter uma relação para estabelecer o Fator de Conversão $F_{C}$, previamente explicitado pela Equação 24. O gráfico demonstrado na Figura 43 estabelece os valores encontrados para FC em função da espessura entre fontedetector para os distintos materiais tecido equivalentes.

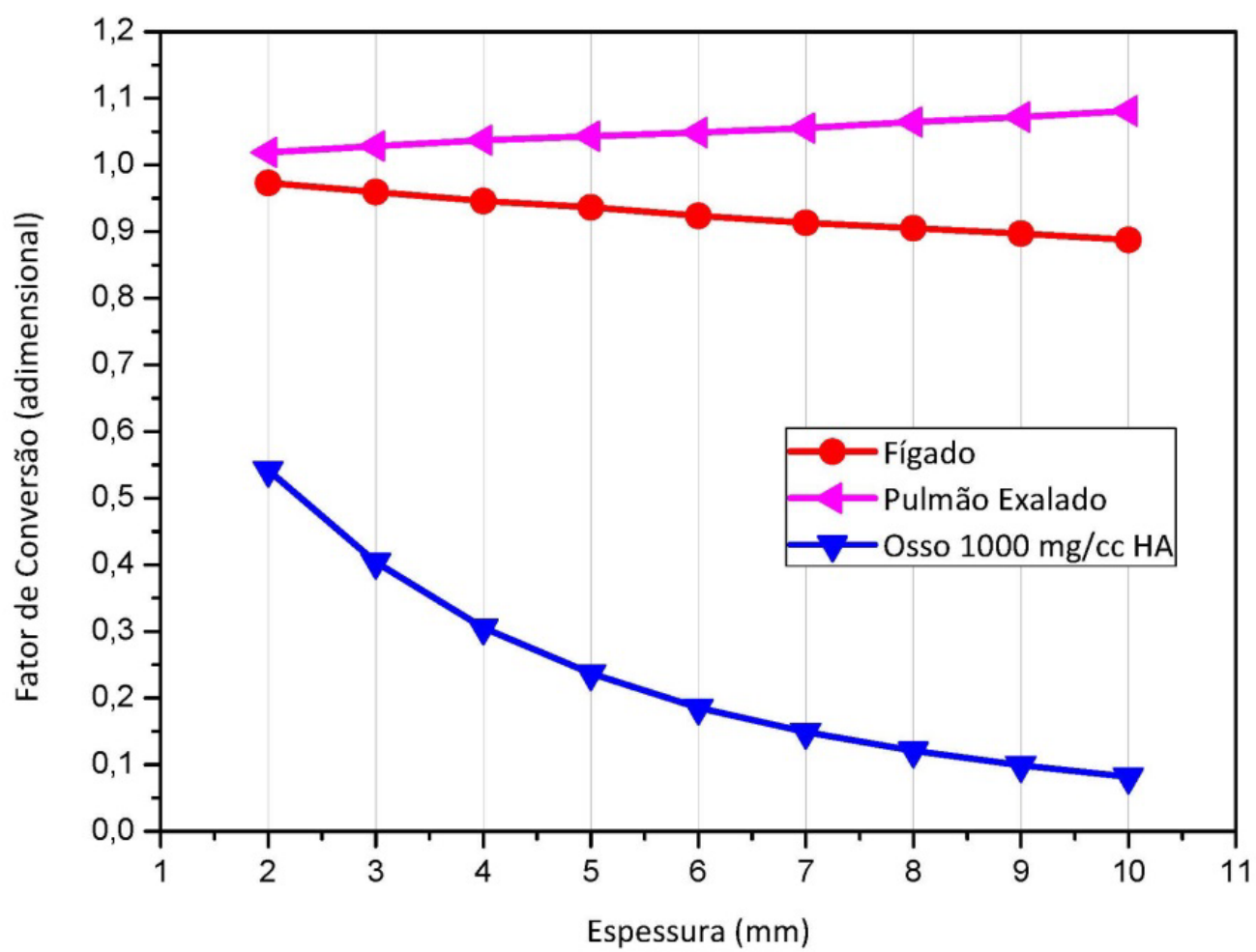

Figura 43. Fator de Conversão encontrado através da razão entre os parâmetros $D_{P M M A, M T E}$ e $D_{P M M A, P M M A}$ previamente estabelecidos para os materiais tecido equivalentes fígado, pulmão exalado e osso 1000 $\mathrm{mg} / \mathrm{cm}^{3} \mathrm{HA}$.

Fonte: Elaborado pela autora. 
Com base nas curvas obtidas pelos valores do Fator de Conversão, $\mathrm{F}_{\mathrm{C}}$, foi possível a determinação de funções que obedecem a seu comportamento, permitindo estimar novos e variados valores de $F_{C}$ em função da espessura $x$ (em milímetros) para cada material estudado. A Tabela 11 apresenta as funções obtidas.

Tabela 11. Fatores de Conversão obtidos de acordo com o cilindro de material tecido equivalente adotado em $\Delta x$.

\begin{tabular}{cc}
$\begin{array}{c}\text { Material Tecido } \\
\text { Equivalente }\end{array}$ & Função para Fator de Conversão \\
\hline Fígado & $F_{C}=-0,0106 x+0,9903$ \\
Pulmão Exalado & $F_{C}=0,0074 x+1,0054$ \\
\hline $\begin{array}{c}\text { Osso } \\
1000 \mathrm{mg} / \mathrm{cm}^{3} \mathrm{HA}\end{array}$ & $\mathrm{F}_{\mathrm{C}}=-0,0009 \mathrm{x}^{3}+0,0249 \mathrm{x}^{2}-0,2392 \mathrm{x}+0,9265$ \\
\hline & Fonte: Elaborado pela autora
\end{tabular}

Fonte: Elaborado pela autora

O Fator de Conversão $F_{C}$ estabelecido permite calcular a dose absorvida em um tecido humano a partir da multiplicação pela distribuição de dose obtida num objeto simulador de PMMA através da leitura de TLDs-100 de LiF. Como o fator $F_{C}$ é influenciado pela espessura do material entre a fonte e o detector, as funções definidas na Tabela 11 permitem estimar seu valor para os materiais tecido equivalentes de Fígado, Pulmão Exalado e Osso $1000 \mathrm{mg} . \mathrm{cm}^{-3}$. A fim de analisar os dados obtidos pelo Fator de Conversão $F_{C}$ foram realizados cálculos com os dados obtidos neste trabalho. A Tabela 12 apresenta estes valores.

Tabela 12. Estimativas de Doses a partir dos Fatores de Conversão obtidos de acordo com o cilindro de material tecido equivalente adotado e espessura $\Delta \mathrm{x}$.

\begin{tabular}{|c|c|c|c|c|c|c|c|c|}
\hline \multirow{2}{*}{$\begin{array}{c}\text { Material } \\
\text { Tecido } \\
\text { Equivalente }\end{array}$} & \multicolumn{4}{|c|}{ Espessura de $2 \mathrm{~mm}$} & \multicolumn{4}{|c|}{ Espessura de $5 \mathrm{~mm}$} \\
\hline & $\mathrm{Fc}_{\Delta \mathrm{x}}$ & 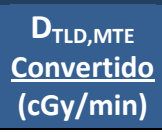 & $\begin{array}{l}D_{\text {TLD,MTE }} \\
\text { MCNP } \\
\text { (cGy/min) }\end{array}$ & $\begin{array}{c}\text { Diferença } \\
\text { Relativa } \\
(\%)\end{array}$ & $\mathrm{Fc}_{\Delta \mathrm{x}}$ & 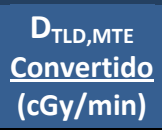 & $\begin{array}{c}D_{\text {TLD,MTE }} \\
\text { MCNP } \\
\text { (cGy/min) }\end{array}$ & $\begin{array}{c}\text { Diferença } \\
\text { Relativa } \\
\text { (\%) }\end{array}$ \\
\hline Fígado & 0,969 & 0,2761 & 0,2775 & 0,5057 & 0,937 & 0,0980 & 0,0978 & 0,2162 \\
\hline $\begin{array}{l}\text { Pulmão } \\
\text { Exalado }\end{array}$ & 1,020 & 0,2907 & 0,2902 & 0,1567 & 1,042 & 0,1090 & 0,1088 & 0,2160 \\
\hline $\begin{array}{c}\text { Osso } \\
1000 \mathrm{mg} / \mathrm{cm}^{3} \\
\mathrm{HA}\end{array}$ & 0,540 & 0,1540 & 0,1573 & 2,1052 & 0,240 & 0,0252 & 0,0254 & 1,1151 \\
\hline
\end{tabular}


A Tabela 12 exibe os valores de Fator de Conversão calculados para os distintos materiais tecido equivalentes e para espessuras de $\Delta x=2,0 \mathrm{~mm}$ ou $5,0 \mathrm{~mm}$. A dose absorvida obtida através de simulações com o Código MCNP calculada no TLD e com transporte de radiação no PMMA para espessura de $2,0 \mathrm{~mm}$ foi de $D_{T L D, P M M A}=0,284$ cGy/min. Já a dose calculada nas mesmas condições porém com espessura de 5,0 mm entre fonte e detector foi de $D_{T L D, P M M A}=0,104 \mathrm{cGy} / \mathrm{min}$. Estas doses foram ponderadas pelos respectivos Fatores de Conversão, resultando na dose $D_{T L D, M T E}$ Convertida. A diferença relativa foi calculada entre a dose obtida através de $F_{C}$ e a dose anteriormente simulada de $D_{T L D, M T E}$ através do Código MCNP.

Os valores de diferença relativa, exibidos na Tabela 12, demonstram que o Fator de Conversão permitiu estimar a dose $D_{T L D, M T E}$ de maneira eficaz, resultando em pequenas diferenças relativas obtidas quando comparada com a mesma configuração de objeto simulador calculada com código MCNP. Os cálculos referentes ao $F_{C}$ também permitem analisar a semelhança no comportamento das razões $\mathrm{D}_{P M M A, M T E} / D_{P M M A}$, PMMA $\mathrm{e}$ $\mathrm{D}_{T L D, M T E} / D_{T L D, ~ P M M A}$ através das quais foi possível estabelecer uma relação para estimar, de maneira simples, a dose de atenuação de tecidos heterogêneos a partir da aferição ou simulação da dose obtida num objeto simulador constituído por PMMA, metodologia que pode ser desenvolvida e implementada na rotina clínica.

\subsubsection{ObJetos Simuladores com Variados Materiais Tecidos EqUIVALENTES}

Os resultados preliminares deste estudo permitiram observar as linhas de isodose decorrentes da atenuação devido à inserção de variados materiais tecido equivalentes, sendo eles Pulmão exalado, Fígado e Osso $1000 \mathrm{mg} / \mathrm{cm}^{3}$ para espessuras de $2,0 \mathrm{~mm}$ ou $5,0 \mathrm{~mm}$ em cada um dos materiais e analisando as contribuições de dose em uma única semente. A Figura 29 mostra a configuração do objeto simulador utilizado para a realização dos cálculos. As matrizes exibidas na Figura 44 demonstram a distribuição de dose para estas configurações. 

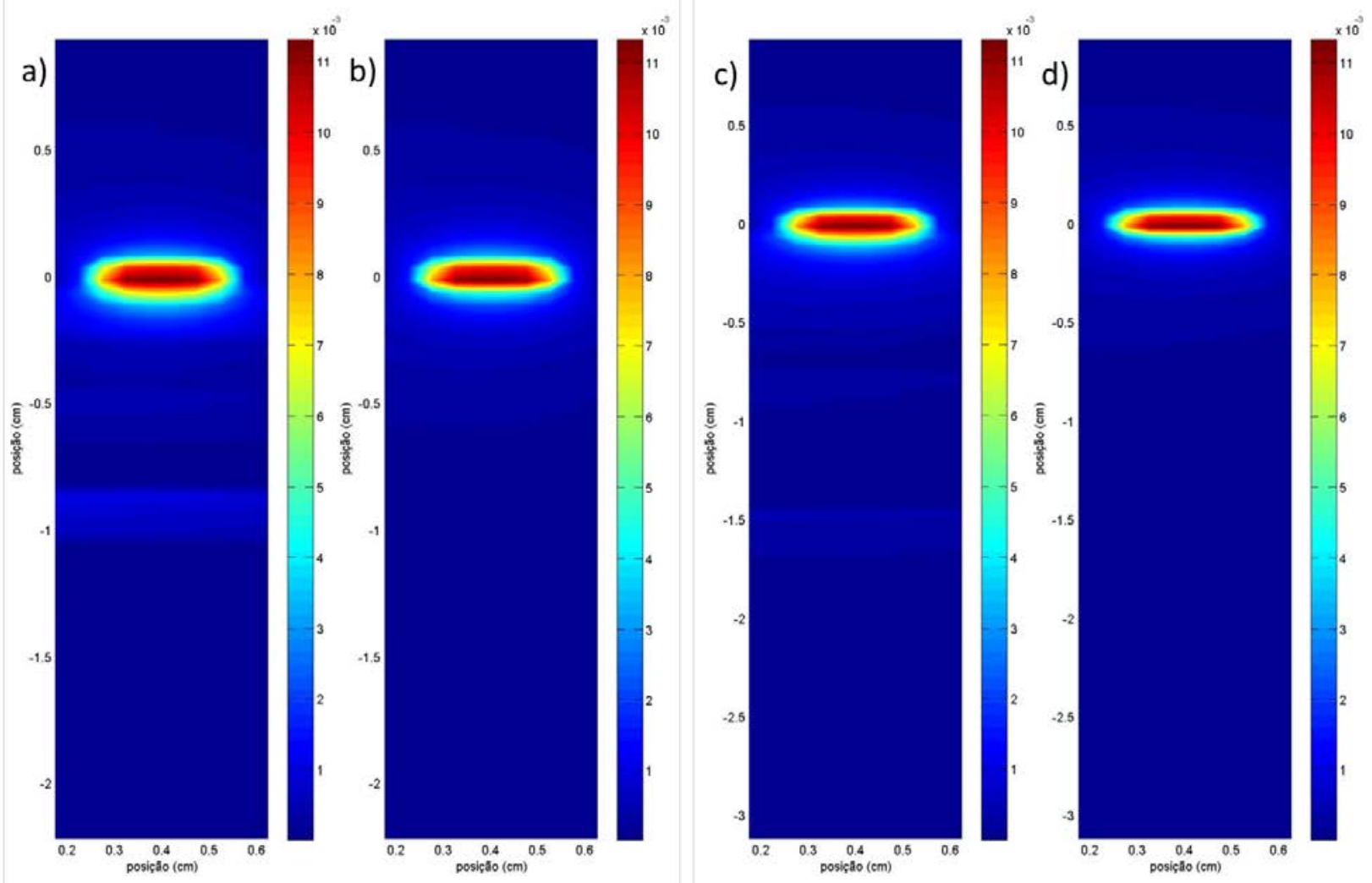

Figura 44. Matriz de cores explicitando as curvas de isodose obtidas em um objeto simulador contendo 3 distintos materiais tecidos equivalentes (representadas pelas letras a e c) e obtidas em um objeto simulador inteiriço de PMMA (letras b e d). As matrizes a) e b) apresentam a mesma dimensão, sendo as espessuras variáveis $(\Delta x)$ do objeto simulador fixadas em 2,0 mm. O mesmo ocorreu para as matrizes c) e d) porem sendo $\Delta x$ fixo em 5,0 mm. Todos os gráficos apresentam como unidade de seu espectro de cores MeV/g.

Fonte: Elaborado pela autora

O erro máximo $(\mathrm{R})$ encontrado em todos os cálculos foi de 1,13\% e o número de historias simuladas foi na ordem de $10^{10}$.

A partir das Figuras 29 e 44 e considerando que a semente está localizada no centro da matriz (ponto $x=0, y=0, z=0$ ) pode-se observar que objetos simuladores com $\Delta x$ fixos em 2,0 $\mathrm{mm}$ tinham preenchidas por cilindro de material tecido equivalente as posições (no eixo longitudinal) de -0,04 a -0,24 cm (Pulmão Exalado), de -0,44 a -0,64 cm (Fígado) e de $-0,84$ a $-1,04 \mathrm{~cm}$ (Osso $1000 \mathrm{mg} / \mathrm{cm}^{3}$ ). Já os objetos simuladores que apresentaram $\Delta \mathrm{x}$ fixos em 5,0 $\mathrm{mm}$ tinham preenchidas por cilindro de material tecido equivalente as posições ( também no eixo longitudinal) de -0,04 a -0,54 cm (Pulmão Exalado), de -0,74 a $1,24 \mathrm{~cm}$ (Fígado) e de $-1,44$ a $-1,94 \mathrm{~cm}$. 
Devido às diferenças de composição e densidade destes materiais em comparação com o PMMA, na Figura 44 podem ser observadas maiores doses absorvidas principalmente para os dois últimos materiais nas posições ocupadas devido a atenuação de fótons por estes materiais.

Os gráficos exibidos nas Figuras 46 e 47 foram derivados da Figura 44 de forma que seus dados foram obtidos coletando valores de cada um dos pontos médios longitudinais a partir do meio da semente em direção à porção inferior do objeto simulador. A Figura 45 exprime os pontos onde foi feita a coleta destes dados.

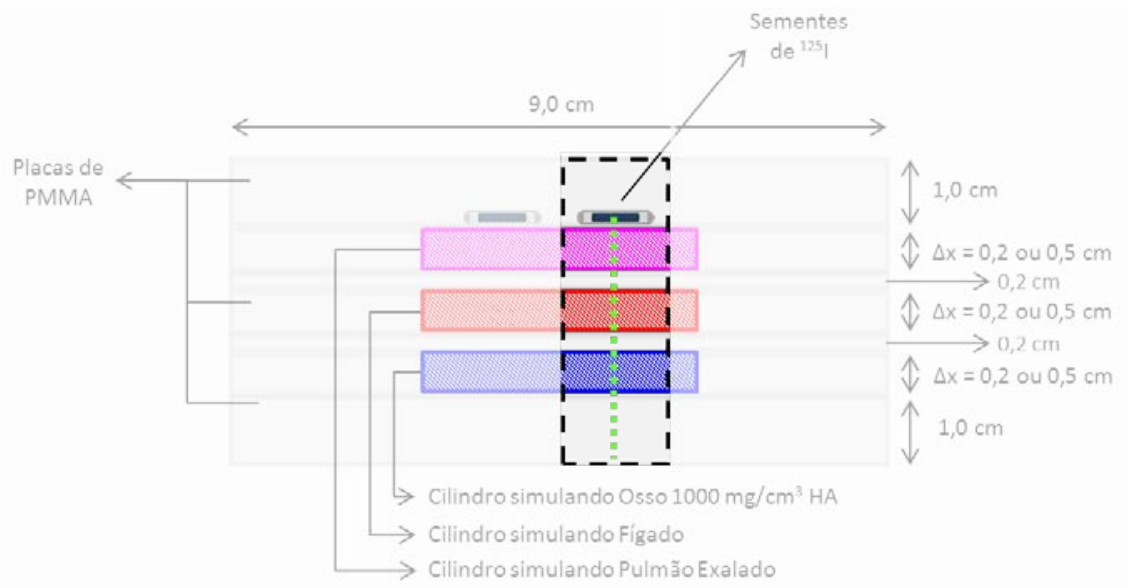

Figura 45. Objeto Simulador utilizado para o cálculo de deposição de dose quando inseridos mais de um material tecido equivalente. Nas simulações foram adotadas variações nas espessuras destes materiais $\Delta x=0,2 \mathrm{~cm}$ ou $0,5 \mathrm{~cm}$. O tracejado em preto indica os limites da matriz que permitiu estabelecer as linhas de isodose como resposta para o tally utilizado e a linha tracejada em verde denotam os dados que constituem os gráficos das Figuras 46 e 47.

Fonte: Elaborado pela autora.

Nos gráficos para ambas as espessuras notam-se que os distintos materiais apresentam entre si claras diferenças em relação à energia depositada no meio, já esperada pela análise do coeficiente de absorção de energia em massa destes materiais.

O alto poder de atenuação dos ossos faz com que a ocorra uma maior deposição de energia nos primeiros milímetros, resultando em doses absorvidas em torno de 10 vezes maiores do que o PMMA para as duas configurações de objetos simuladores adotados. Já os materiais tecido equivalentes como pulmão exalado e fígado, com baixo poder de absorção, apresentam uma distribuição de dose depositada mais próxima a do PMMA. 


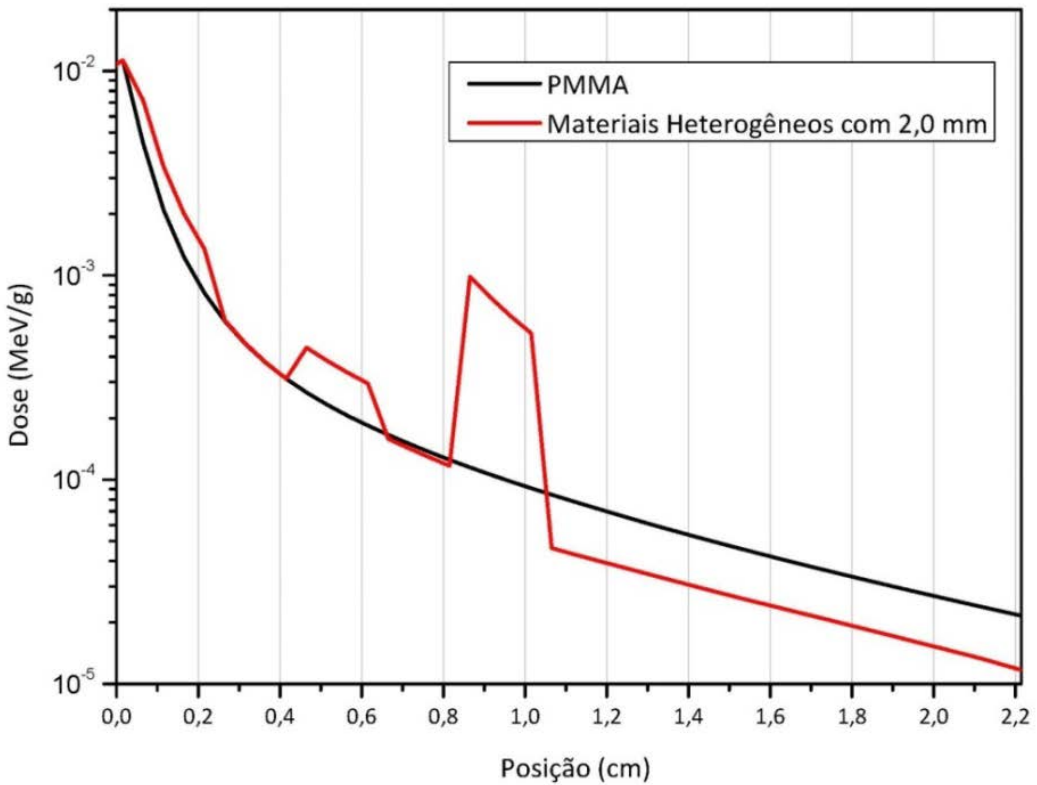

Figura 46. Distribuição de doses ao longo do eixo mediano da semente de ${ }^{125}$ I comparando os dados obtidos com objetos simuladores que continham distintos materiais tecidos equivalentes com espessuras de $2,0 \mathrm{~mm}$.

Fonte: Elaborado pela autora

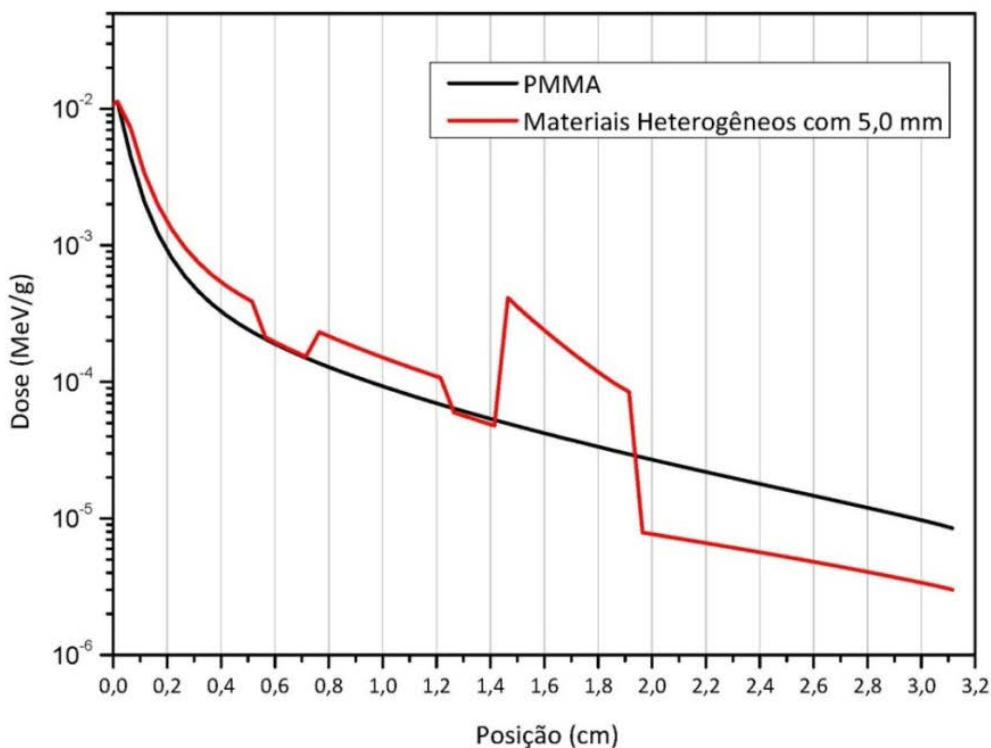

Figura 47. Distribuição de doses ao longo do eixo mediano da semente de ${ }^{125}$ I comparando os dados obtidos com objetos simuladores que continham distintos materiais tecidos equivalentes com espessuras de $5,0 \mathrm{~mm}$.

Fonte: Elaborado pela autora 
CAPÍTULO 6

CONCLUSÃO 


\section{CONCLUSÃo}

Avaliar a distribuição de dose absorvida com precisão é um dos objetivos dos planejamentos realizados em radioterapia. $\mathrm{O}$ advento de algoritmos baseados em modelos (MBDCAs) permitiu a otimização e exatidão nas medidas experimentais e clínicas. O estudo de deposição da dose considerando as heterogeneidades dos diferentes tecidos permite o desenvolvimento de modelos fisicamente muito mais acurados para a avaliação de dose efetivamente entregue ao paciente, estendendo sua aplicabilidade à verificação de sistemas de planejamento em braquiterapia que considerem as heterogeneidades dos diferentes tecidos humanos.

Neste trabalho foram estudadas configurações de objetos simuladores confeccionados para medidas experimentais e simulações através do código de Monte Carlo, MCNP, a fim de observar as diferenças ocasionadas pela introdução de heterogeneidades quando presentes fontes de ${ }^{125}$ I de baixa taxa de dose. Outros estudos foram derivados destas análises como a validação da geometria simulada da semente de ${ }^{125} \mathrm{I}$, onde foi realizada a reprodução da metodologia de cálculo presente no TG-43 da AAPM, e o estudo teórico da dependência energética dos dosímetros termoluminescentes devido a sua relação com a resposta TL, pois determinam a quantidade de energia do feixe que é absorvida no volume sensível do dosímetro de acordo com cada energia de fóton.

Os resultados simulados para reprodução da metodologia de cálculo da deposição de dose de acordo com o TG-43U apresentaram ótima concordância com os dados presentes na literatura, principalmente quando comparados com o de DOLAN et al, (2006) devido a semelhanças nos códigos utilizados para simulação, espectro de energia para emissão de iodo e geometria das sementes de ${ }^{125} \mathrm{I}$.

Os dados da dependência energética exibiram compatibilidade entre as curvas de calibração calculadas deste trabalho e de DAVIS et al, (2003), de modo que foi possível observar o comportamento da absorção de energia dependendo da qualidade do feixe. As diferenças relativas exibidas entre os dois trabalhos foram inferiores a $2,7 \%$.

Para os experimentos com ${ }^{125} \mathrm{I}$, na comparação dos diferentes materiais tecido equivalentes, observa-se claramente as diferenças significantes de energia depositada no 
meio em cada material, resultado dos diferentes coeficientes de atenuação. Estas diferenças são quantificadas com a obtenção do Fator de Conversão.

O estudo simulado da influência da densidade e composição dos distintos materiais tecido equivalentes verificou que, quando comparadas às mesmas espessuras para os mesmos materiais, o efeito que a composição de cada um deles exerce sobre a deposição de dose é mais expressivo que o efeito de sua densidade. Deste modo, reafirma-se a importância da atribuição das heterogeneidades nos cálculos de deposição de dose nos planejamento a serem realizados em braquiterapia.

As análises dos parâmetros dosimétricos apresentados neste trabalho exibiram, de modo geral, um grau de discrepância entre os valores simulados e experimentais. Justificativas prováveis seriam a dificuldade de construir um arranjo ideal devido à limitação na precisão das dimensões dos objetos simuladores e imperfeições que causam a presença de ar entre as placas utilizadas para confeccionar os objetos simuladores ou a composição da placa de PMMA utilizada. As maiores discrepâncias estão na ordem de $22 \%$, entretanto, estão na região onde a dose é menor que $20 \%$ da dose máxima.

A metodologia desenvolvida é recomendada para avaliação de sistemas de planejamento computadorizados que possuem algoritmos para cálculo de dose baseados em modelos, para fontes de ${ }^{125} \mathrm{I}$ com baixa taxa de dose, de forma a contribuir na incorporação de novas estimativas de doses com maior acurácia. 


\section{REFERÊNCIAS}

AFSHARPOUR, $\mathrm{H}$. et al. Influence of breast composition and interseed attenuation in dose calculations for post-implant assessment of permanent breast 103Pd seed implant. Physics in medicine and biology, v. 55, n. 16, p. 4547-61, 2010.

AGOSTINELLI, S. et al. GEANT4-a simulation toolkit. Nuclear instruments and methods in physics research section A: Accelerators, Spectrometers, Detectors and Associated Equipment, v. 506, n. 3, p. 250-303, 2003.

AHNESJÖ, A.; ASPRADAKIS, M. M. Dose calculations for external photon beams in radiotherapy. Physics in medicine and biology, v. 44, n. 11, p. R99, 1999.

AMERICAN CANCER SOCIETY. Global Cancer Facts \& Figures 3rd Edition. American Cancer Society, n. 800, p. 1-64, 2015.

ANTUNES, P. C. G. Reconstrução de Objetos Simuladores Segmentados Aplicáveis a Dosimetria de Pele. São Paulo. Dissertação de Mestrado - Instituto de Pesquisas Energéticas e Nucleares, Universidade de São Paulo, 2010.

ATTIX, F. H. Introduction to radiological physics and radiation dosimetry. [s.l.] John Wiley \& Sons, 2008.

BALTAS, D.; SAKELLIOU, L.; ZAMBOGLOU, N. The Physics of Modern Brachytherapy for Oncology. New York: Taylor \& Francis Group, 2007.

BARO, J. et al. PENELOPE: an algorithm for Monte Carlo simulation of the penetration and energy loss of electrons and positrons in matter. Nuclear Instruments and Methods in Physics Research Section B: Beam Interactions with Materials and Atoms, v. 100, n. 1, p. 31-46, 1995.

BEAULIEU, L. et al. Report of the Task Group 186 on model-based dose calculation methods in brachytherapy beyond the TG-43 formalism: current status and recommendations for clinical implementation. Medical physics, v. 39, n. 10, p. 6208-36, 2012.

BERGER, M. J. et al. XCOM: photon cross sections database. NIST Standard reference database, v. 8, n. 1, p. 3587-3597, 1998.

BERGER, M. J. et al. ESTAR, PSTAR, and ASTAR: Computer Programs for Calculating Stopping-Power and Range Tables for Electrons, Protons, and Helium lons (version 1.2.3). National Institute of Standards and Technology, 2005. 
BIELAJEW, A. F. Fundamentals of the Monte Carlo method for neutral and charged particle transport. 2006.

BONNICK, S. L. Bone Densitometry in Clinical Practice: Application and Interpretation. [s.I.] Humana Press, 2009.

BRIESMEISTER, J. . MCNP - A General Monte Carlo N-Particle Transport Code, Version 4C. Los Alamos National Laboratory, n. March, 2000.

CAVALIERI, T. A. Emprego do MCNP no Estudo dos TLDs 600 e 700 Visando a Implementação da Caracterização do Feixe de Irradiação na Instalação de BNCT do IEAR1. São Paulo. Dissertação de Mestrado - Instituto de Pesquisas Energéticas e Nucleares, Universidade de São Paulo, 2013.

CHIBANI, O.; WILLIAMSON, J. F.; TODOR, D. Dosimetric effects of seed anisotropy and interseed attenuation for [sup 103]Pd and [sup 125]। prostate implants. Medical Physics, v. 32, n. 8, p. $2557,2005$.

CIRS TISSUE SIMULATION \& PHANTOM TECHNOLOGY. CIRS Models 062M/062MA/062MAQ Tissue-equivalent Materials Elemental Composition Data, 2013a. Disponível em: <http://www.cirsinc.com/>. Acesso em: 07 jun. 2015.

CIRS TISSUE SIMULATION \& PHANTOM TECHNOLOGY. CBCT Electron Density \& Image Quality Phantom System, 2013b. Disponível em: <http://www.cirsinc.com/file/Products/062MQA/062 PB 092515.pdf>. Acesso em: 16 jun. 2015.

CULLEN, D. E. et al. EPDL97: the evaluated photo data library '97 version. Uclr-50400, v. Vol.6-Rev., p. 1-35, 1997.

DAVIS, S. D. et al. The response of LIF thermoluminescence dosemeters to photon beams in the energy range from $30 \mathrm{kV} x$ rays to $60 \mathrm{Co}$ gamma rays. Radiation protection dosimetry, v. 106, n. 1, p. 33-43, 2003.

DOLAN, J.; LIA, Z.; WILLIAMSON, J. F. Monte Carlo and experimental dosimetry of an 1251 brachytherapy seed. Medical physics, v. 33, n. 12, p. 4675-4684, 2006.

FERNANDES, M. A. R. Utilização de Moldes Radioativos Especiais de Folhas De Ouro198 para Braquiterapia em Tumores de Pele. São Paulo. Tese de Doutorado - Instituto de Pesquisas Energéticas e Nucleares, Universidade de São Paulo, 2000.

FONSECA, G. P. Projeto e construção de placas espalhadoras e degradadoras de energia para uso em radioterapia com feixes de elétrons para doenças de pele. . São 
Paulo. Dissertação de Mestrado - Instituto de Pesquisas Energéticas e Nucleares, Universidade de São Paulo, 2010.

FONSECA, G. P. Monte Carlo modeling of the patient and treatment delivery complexities for high dose rate brachytherapy. São Paulo. Tese de Doutorado - Instituto de Pesquisas Energéticas e Nucleares, Universidade de São Paulo, 2015.

FORMAN D et al. Cancer incidence in five continents. [s.I.] IARC - International Agency for Research on Cancer, 2014. v. X

GOORLEY, T. et al. Initial MCNP6 release overview. Nuclear Technology, v. 180, n. 3, p. 298-315, 2012.

HARSHAW TLD. Materials and Assemblies for Thermoluminescence Dosimetry. [s.I: S.n.].

HUGHES, H. G. I.; JAMES, M. R. MCNP6 ClassMCNP6 class at Alabama Agricultural and Mechanical University, $2014 . \quad$ Disponível em: <http://permalink.lanl.gov/object/tr?what=info:lanl-repo/lareport/LA-UR-14-21281>. Acesso em: 15 jul. 2015.

HUMPHREY, P. A. Gleason grading and prognostic factors in carcinoma of the prostate. Modern Pathology, v. 17, n. 3, p. 292-306, 2004.

INCA. Programa Nacional de Controle do Câncer da Próstata: documento de consenso. Rio de Janeiro. Instituto Nacional de Cancer José Alencar Gomes da Silva (INCA), , 2002.

INCA. ABC DO CÂNCER: Abordagens Básicas para o Controle do Câncer. Rio de Janeiro: Instituto Nacional de Cancer José Alencar Gomes da Silva (INCA), 2011.

INCA. Instituto Nacional de Câncer - Estimativa 2016. [s.l: s.n.].

INTERSTITIAL COLLABORATIVE WORKING GROUP. Interstitial brachytherapy: Physical biological and clinical considerations. New York: Raven press Itd., 1990.

JENKINS, T. M.; NELSON, W. R.; RINDI, A. Monte Carlo transport of electrons and photons. [s.I.] Springer Science \& Business Media, 2012. v. 38

KATAKURA, J. Nuclear Data Sheets for $A=125$. Nuclear Data Sheets, v. 112, n. 3, p. 495-705, 2011.

KHAN, F. M. Physics of Radiation Therapy. 3rd. ed. Philadelphia, PA: Lippincott Williams \& Wilkins, 2003.

LANDRY, G. et al. Dose reduction in LDR brachytherapy by implanted prostate gold 
fiducial markers. Medical Physics, v. 39, n. 3, p. 1410, 2012.

LANDRY, G. et al. Sensitivity of low energy brachytherapy Monte Carlo dose calculations to uncertainties in human tissue composition Sensitivity of low energy brachytherapy Monte Carlo dose calculations to uncertainties in human tissue composition. Medical Physics, v. 5188, n. 2010, 2016.

MAAROUF, M. et al. Radiotherapy in the management of keloids: Clinical experience with electron beam irradiation and comparison with X-ray therapy. Strahlentherapie und Onkologie, v. 178, n. 6, p. 330-335, 2002.

MAGNABOSCO, W. J. Estadiamento do Câncer de Próstata. p. 22-25, 2014.

MASHOUF, S. et al. Dose heterogeneity correction for low-energy brachytherapy sources using dual-energy CT images. Physics in Medicine \& Biology, v. 59, n. 18, p. 53055316, 2014.

MCKEEVER, S. W. S. Thermoluminescence of solids. [s.I.] Cambridge University Press, 1988. v. 3

MEURANT, G. The dosimetry of ionizing radiation. [s.I.] Elsevier, 2012. v. 3

MOURA, E. S. Estudo e Levantamentos de Parâmetros para Dosimetria de Fontes de Iodo-125 Aplicadas em Braquiterapia. São Paulo. Dissertação de Mestrado - Instituto de Pesquisas Energéticas e Nucleares, Universidade de São Paulo, 2011.

MOURA, E. S. Desenvolvimento de um Objeto Simulador para Investigação de Heterogeneidades em Braquiterapia de Alta Taxa de Dose. São Paulo. Tese de Doutorado - Instituto de Pesquisas Energéticas e Nucleares, Universidade de São Paulo, , 2015.

NATH, R. et al. Dosimetry of interstitial brachytherapy sources: recommendations of the AAPM Radiation Therapy Committee Task Group No. 43. American Association of Physicists in Medicine. Medical physics, v. 22, n. 2, p. 209-34, fev. 1995.

NATH, R.; YUE, N. Dosimetric characterization of an encapsulated interstitial brachytherapy source of 125 I on a tungsten substrate. Brachytherapy, v. 1, n. 2, p. 102109, 2002.

NATIONAL CANCER INSTITUTE. Prostate Cancer Treatment. Rockville, 2016. Disponível em: <http://www.cancer.gov/types/prostate/patient/prostate-treatmentpdq>. Acesso em: 15 jun. 2016.

NUNN, A. A. et al. LiF:Mg,Ti TLD response as a function of photon energy for 
moderately filtered $\mathrm{x}$-ray spectra in the range of $20-250 \mathrm{kVp}$ relative to $60 \mathrm{Co}$. Medical physics, v. 35, n. 5, p. 1859-1869, 2008.

OBERHOFER, M.; SCHARMANN, A. Applied thermoluminescence dosimetry. [s.I.] Adam Hilger Ltd., 1981.

PODGORSAK, E. B. Radiation Oncology Physics: A Handbook for Teachers and Students. Vienna: [s.n.].

POLETTI, M. E.; GONÇALVES, O. D.; MAZZARO, I. Measurements of X-ray scatter signatures for some tissue-equivalent materials. Nuclear Instruments and Methods in Physics Research, Section B: Beam Interactions with Materials and Atoms, v. 213, n. June 2016, p. 595-598, 2004.

POON, E. et al. Patient-Specific Monte Carlo Dose Calculations for High-Dose-Rate Endorectal Brachytherapy With Shielded Intracavitary Applicator. International Journal of Radiation Oncology Biology Physics, v. 72, n. 4, p. 1259-1266, 2008.

RIVARD, M. J. et al. Update of AAPM Task Group No. 43 Report: A revised AAPM protocol for brachytherapy dose calculations. Medical physics, v. 31, n. 3, p. 633-674, 2004.

RIVARD, M. J. et al. Supplement to the 2004 update of the AAPM Task Group No. 43 Report. Medical physics, v. 34, n. 6, p. 2187-2205, 2007.

ROGERS, D. W. O. Fifty years of Monte Carlo simulations for medical physics. Physics in medicine and biology, v. 51, n. 13, p. R287--301, 2006.

ROGERS, D. W. O.; KAWRAKOW, I. Distribution Area for EGSnrc: A Unix/Linux-based System for Monte Carlo Simulation of Electron and Photon Transport, 2000. Disponível em: <http://www. irs. inms. nrc. ca/inms/irs/EGSnr>. Acesso em: 15 jun. 2015.

ROSTELATO, M. E. C. M. Estudo e Desenvolvimento de uma Nova Metodologia Para Confecção De Sementes De lodo-125 para Aplicação em Braquiterapia. São Paulo. Tese de Doutorado - Instituto de Pesquisas Energéticas e Nucleares, Universidade de São Paulo, , 2005.

SALVAJOLI, J. V.; SOUHAMI, L.; FARIA, S. L. Radioterapia em oncologia. 2 ed. [s.I.] Ed. Atheneu, 2013.

SANCHEZ, A. Projeto e Confecção de Simuladores Oftálmicos para Aplicações Clinicas. São Paulo. Tese de Doutorado - Instituto de Pesquisas Energéticas e Nucleares, Universidade de São Paulo, 2006. 
SCAFF, L. A. M. Física da Radioterapia: A Base Analógica de Uma Era Digital. 2 ed. [s.l.] Ed. Projeto Saber, 2010.

SELTZER, S. M. et al. New National Air-Kerma-Strength Standards for 125 I and 103 Pd Brachytherapy Seeds. Journal of Research of the National Institute of Standards and Technology, v. 108, n. 5, p. 337-358, 2003.

SHULTIS, J. K.; FAW, R. E. An MCNP Primer. Structure, v. 66506, n. c, p. 0-45, 2006.

SIEMENS HEALTHINEERS. Online tool for the simulation of X-ray Spectra. Disponível em: <https://www.oem-products.siemens.com/x-ray-spectra-simulation>. Acesso em: 15 jun. 2015.

STANNARD, C. et al. Postenucleation orbits in retinoblastoma: Treatment with $125 \mathrm{I}$ brachytherapy. International Journal of Radiation Oncology Biology Physics, v. 54, n. 5, p. 1446-1454, 2002.

SUTHERLAND, J. G. H.; FURUTANI, K. M.; THOMSON, R. M. Monte Carlo calculated doses to treatment volumes and organs at risk for permanent implant lung brachytherapy. Physics in medicine and biology, v. 58, n. 20, p. 7061-80, 2013.

TAYLOR, R. E. P. Monte Carlo calculations for brachytherapy. phd thesis-[s.I.] Institute of Physics, 2006.

TAYLOR, R. E. P.; ROGERS, D. W. O. An EGSnrc Monte Carlo-calculated database of TG-43 parameters. Medical physics, v. 35, n. 9, 2008.

TAYLOR, R. E. P.; ROGERS, D. W. O. The Carleton Laboratory for Radiotherapy Physics TG-43 Parameter Database, 2013. Disponível em: <http://www.physics.carleton.ca/clrp/seed_database>. Acesso em: 05 set. 2015.

TEDGREN, A. C. et al. Response of LiF:Mg,Ti thermoluminescent dosimeters at photon energies relevant to the dosimetry of brachytherapy ( $<1 \mathrm{MeV})$. Medical Physics, v. 38, $\mathrm{n}$. 10, p. 5539, 2011.

THERMO ELECTRON CORPORATION. Model 3500 Manual TLD Reader with WinRens. Ohio: [s.n.].

X-5 MONTE CARLO TEAM. MCNP - A General Monte Carlo N-Particle Transport Code, Version 5. Los Alamos Nuclear Laboratory, v. I, p. 2-71-2-80, 2005.

YAFFE, M. J. et al. The myth of the 50-50 breast. Medical Physics, v. 36, n. 12, p. 5437, 2009.

YANG, Y.; RIVARD, M. J. Evaluation of brachytherapy lung implant dose distributions 
from photon-emitting sources due to tissue heterogeneities. Medical Physics, v. 38, n. 11, p. 5857, 2011.

YORIYAZ, H. Monte Carlo Method: principles and applications in Medical Physics. Revista Brasileira de Física Médica, v. 3, n. 1, p. 141-149, 2009.

ZEITUNI, C. A. Dosimetria de Fontes de lodo-125 Aplicadas em Braquiterapia. São Paulo. Tese de Doutorado - Instituto de Pesquisas Energéticas e Nucleares, Universidade de São Paulo, 2008.

ZHOU, F. et al. lodine-125 interstitial brachytherapy for experimental liver cancer. Journal of Medical Colleges of PLA, v. 22, n. 2, p. 87-91, 2007. 


\section{APÊNDICE A}

\section{GEOMETRIA DA SEMENTE DE 125I - AMERShAM Modelo 6711}

\section{CÉlULAS}

c SEED

c Titanium Tube

$22-4.54 \quad(-78-10$ 12):(-9 10):

$(-11-12)$ imp:p,e=1

c Silver rod

$33-10.5 \quad(-23-17$ 15):(-14 -15 18):

$(-24-1820)$ imp:p,e=1

c Radioactive Coating

$44 \quad-6.2 \quad(-1314-15$ 18):(-21 $2315-17)$ :

$(-2224-18$ 20):(-21 -16 17):

$(-2219-20)$ imp:p,e=1

c Air

55 -0.001205 (21 -10 -8 15):(-21 $16-10)$ :

SUPERFíCIES

$(-813-1518):(2212-8-18):$

$(-22-19$ 12) imp:p,e=1

c SEED

c Titanium Tube

$7 \mathrm{cz} 0.04$

$8 \mathrm{cz} 0.033$

9 sz 0.18750 .04

$10 \mathrm{pz} 0.1875$

$11 \mathrm{sz}-0.18750 .04$

$12 \mathrm{pz}-0.1875$

$c$

c Silver rod and Radioactive Coating

$13 \mathrm{cz} 0.025175$

$14 \mathrm{cz} 0.025$

$15 \mathrm{pz} 0.1325$

16 pz 0.140175

$17 \mathrm{pz} 0.14$

$18 \mathrm{pz}-0.1325$

$19 \mathrm{pz}-0.140175$

$20 \mathrm{pz}-0.14$

21 kz $0.1576751-1$

$22 \mathrm{kz}-0.15767511$

$23 \mathrm{kz} 0.15751-1$

$24 \mathrm{kz}-0.157511$

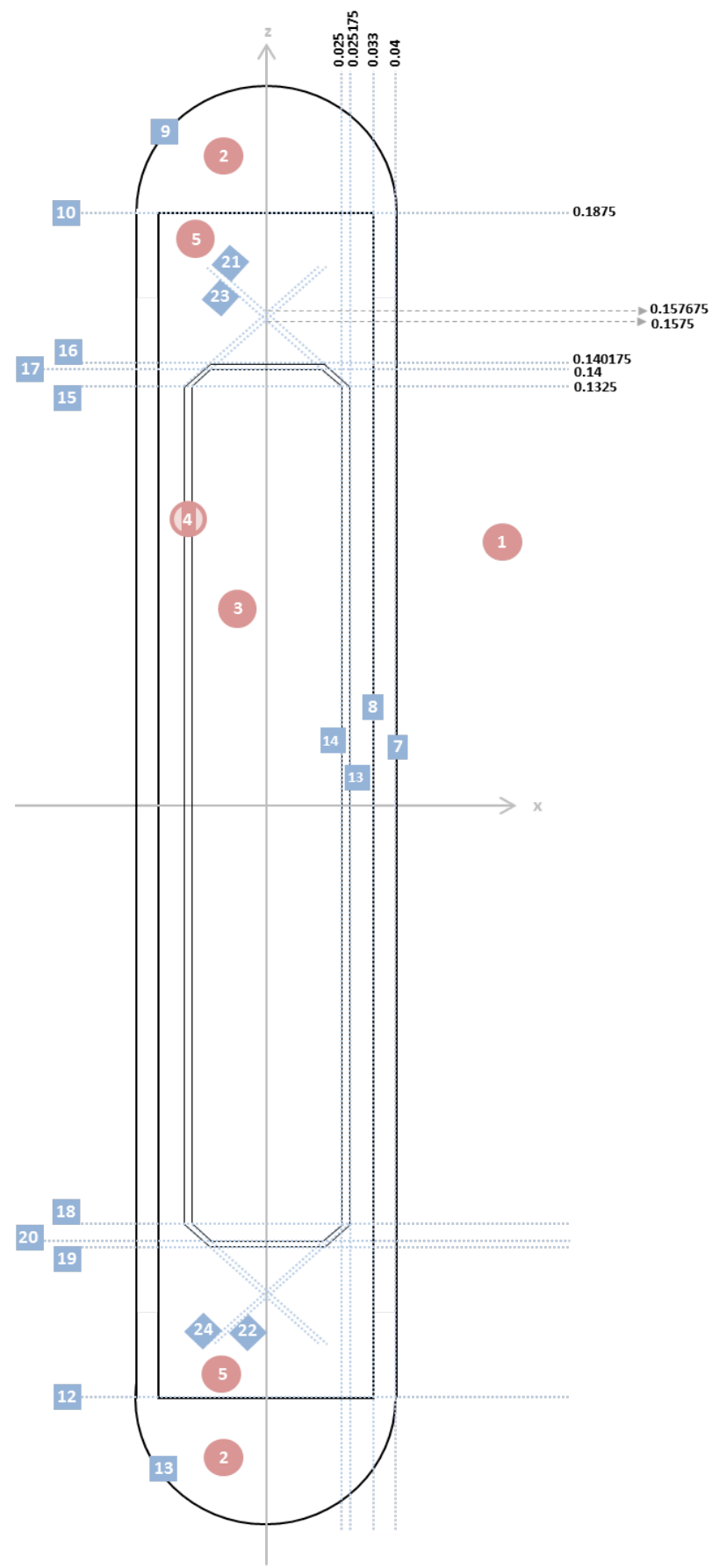

Figura 48. Representação Esquemática das dimensões (em centímetros) e estruturas simuladas da Semente de ${ }^{125}$ ( (Modelo Amersham 6711) utilizadas neste trabalho. Os quadrados azuis e círculos vermelhos correspondem, respectivamente, a numeração das superfícies e células descritas conforme os fragmentos do input (arquivo de entrada) do MCNP à esquerda.

Fonte: Elaborado pela Autora. 


\section{APÊNDICE B}

\section{BANCO DE DADOS DAS SimULAÇõES E EXPERIMENTOS COM ObJETOS SiMULADORES}

Tabela 13. Dados simulados e experimentais da atenuação no PMMA conforme variação da distância fonte-detector, correspondentes às curvas exibidas na Figura 39.

\begin{tabular}{|c|c|c|c|c|c|c|c|c|c|}
\hline \multirow[b]{3}{*}{$\begin{array}{l}\text { Espessura } \\
\text { (mm) }\end{array}$} & \multicolumn{8}{|c|}{ Material PMMA } & \\
\hline & \multicolumn{3}{|c|}{$\begin{array}{l}\text { D } \\
\text { SiLD, PMMA } \\
\text { Simulado }\end{array}$} & \multicolumn{3}{|c|}{$\begin{array}{l}\text { DPMMA, PMMA } \\
\text { Simulado }\end{array}$} & \multicolumn{3}{|c|}{$\begin{array}{c}\text { D }_{\text {TLD, PMMA }} \\
\text { Experimental }\end{array}$} \\
\hline & $\begin{array}{c}\text { Média dos } \\
4 \text { TLDs } \\
\text { MCNP } \\
\text { (MeV/g) }\end{array}$ & $\begin{array}{c}\text { Normalizados } \\
\text { a 2,0 } \mathrm{mm}\end{array}$ & $\begin{array}{c}\text { Propagação } \\
\text { de } \\
\text { Incertezas } \\
\text { (\%) }\end{array}$ & $\begin{array}{l}\text { Média dos } \\
4 \text { TLDs } \\
\text { MCNP } \\
\text { (MeV/g) }\end{array}$ & $\begin{array}{c}\text { Normalizados } \\
\text { a 2,0 mm }\end{array}$ & $\begin{array}{c}\text { Propagação } \\
\text { de } \\
\text { Incertezas } \\
(\%)\end{array}$ & $\begin{array}{l}\text { Média dos } \\
4 \text { TLDs } \\
\text { (nC) }\end{array}$ & $\begin{array}{l}\text { Normalizados } \\
\text { a 2,0 mm }\end{array}$ & $\begin{array}{c}\text { Propagação } \\
\text { de } \\
\text { Incertezas } \\
\text { (\%) }\end{array}$ \\
\hline 2 & $2,543.10^{-6}$ & 1,000 & 0,099 & $6,395 \cdot 10^{-7}$ & 1,000 & 0,141 & $1,205.10^{4}$ & 1,000 & 4,123 \\
\hline 3 & $1,644.10^{-6}$ & 0,647 & 0,114 & $4,130 \cdot 10^{-7}$ & 0,646 & 0,156 & $7,226.10^{3}$ & 0,600 & 3,203 \\
\hline 4 & $1,198.10^{-6}$ & 0,471 & 0,126 & $3,002 \cdot 10^{-7}$ & 0,469 & 0,176 & $5,174.10^{3}$ & 0,429 & 5,216 \\
\hline 5 & $9,333 \cdot 10^{-7}$ & 0,367 & 0,135 & $2,337.10^{-7}$ & 0,365 & 0,189 & $4,362 \cdot 10^{3}$ & 0,362 & 5,284 \\
\hline 6 & $7,532.10^{-7}$ & 0,296 & 0,303 & $1,898.10^{-7}$ & 0,297 & 0,206 & $3,353 \cdot 10^{3}$ & 0,278 & 14,514 \\
\hline 7 & $6,251.10^{-7}$ & 0,246 & 0,328 & $1,571 \cdot 10^{-7}$ & 0,246 & 0,224 & $2,819.10^{3}$ & 0,234 & 8,060 \\
\hline 8 & $5,278.10^{-7}$ & 0,208 & 0,170 & $1,327.10^{-7}$ & 0,207 & 0,237 & $2,656.10^{3}$ & 0,220 & 4,098 \\
\hline 9 & $4,532 \cdot 10^{-7}$ & 0,178 & 0,386 & $1,131 \cdot 10^{-7}$ & 0,177 & 0,255 & - & - & - \\
\hline 10 & $3,914.10^{-7}$ & 0,154 & 0,411 & $9,742.10^{-8}$ & 0,152 & 0,269 & $2,103.10^{3}$ & 0,175 & 3,298 \\
\hline
\end{tabular}


Tabela 14. Dados simulados e experimentais da atenuação no material tecido equivalente de fígado conforme variação da distância fonte-detector, correspondentes às curvas exibidas na Figura 40.

\begin{tabular}{|c|c|c|c|c|c|c|c|c|c|}
\hline \multicolumn{10}{|c|}{ Material Fígado } \\
\hline \multirow[b]{2}{*}{$\begin{array}{l}\text { Espessura } \\
\text { (mm) }\end{array}$} & \multicolumn{3}{|c|}{$\begin{array}{l}\text { D }_{\text {TLD, MTE=Figado }} \\
\text { Simulado }\end{array}$} & \multicolumn{3}{|c|}{$\begin{array}{l}\text { DPMMA, MTE=Fígado } \\
\text { Simulado }\end{array}$} & \multicolumn{3}{|c|}{$\begin{array}{l}\text { D }_{\text {TLD, MTE=Fígado }} \\
\text { Experimental }\end{array}$} \\
\hline & $\begin{array}{l}\text { Média dos } \\
4 \text { TLDs } \\
\text { MCNP } \\
\text { (MeV/g) }\end{array}$ & $\begin{array}{l}\text { Normalizados } \\
\text { a } 2,0 \mathrm{~mm}\end{array}$ & $\begin{array}{c}\text { Propagação } \\
\text { de } \\
\text { Incertezas } \\
(\%)\end{array}$ & $\begin{array}{c}\text { Média dos } \\
4 \text { TLDs } \\
\text { MCNP } \\
\text { (MeV/g) }\end{array}$ & $\begin{array}{l}\text { Normalizados } \\
\text { a } 2,0 \mathrm{~mm}\end{array}$ & $\begin{array}{c}\text { Propagação } \\
\text { de } \\
\text { Incertezas } \\
(\%)\end{array}$ & $\begin{array}{c}\text { Média dos } \\
4 \text { TLDs } \\
\text { (nC) }\end{array}$ & $\begin{array}{l}\text { Normalizados } \\
\text { a } 2,0 \mathrm{~mm}\end{array}$ & $\begin{array}{c}\text { Propagação } \\
\text { de } \\
\text { Incertezas } \\
(\%)\end{array}$ \\
\hline 2 & $2,477.10^{-6}$ & 1,000 & 0,099 & $6,223.10^{-7}$ & 1,000 & 0,141 & $1,160.10^{4}$ & 1,000 & 15,380 \\
\hline 3 & $1,579.10^{-6}$ & 0,638 & 0,114 & $3,963 \cdot 10^{-7}$ & 0,637 & 0,160 & $6,934.10^{3}$ & 0,598 & 18,051 \\
\hline 4 & $1,136.10^{-6}$ & 0,459 & 0,126 & $2,840.10^{-7}$ & 0,456 & 0,176 & - & - & - \\
\hline 5 & $8,732.10^{-7}$ & 0,353 & 0,139 & $2,189.10^{-7}$ & 0,352 & 0,197 & $4,256.10^{3}$ & 0,367 & 12,162 \\
\hline 6 & $6,989 \cdot 10^{-7}$ & 0,282 & 0,152 & $1,753.10^{-7}$ & 0,282 & 0,215 & - & - & - \\
\hline 8 & $4,784.10^{-7}$ & 0,193 & 0,135 & $1,201.10^{-7}$ & 0,193 & 0,246 & $2,364.10^{3}$ & 0,204 & 11,539 \\
\hline 13 & $2,249.10^{-7}$ & 0,091 & 0,184 & $5,659.10^{-8}$ & 0,091 & 0,345 & $1,046.10^{3}$ & 0,090 & 12,062 \\
\hline
\end{tabular}


Tabela 15. Dados simulados e experimentais da atenuação no material tecido equivalente de pulmão exalado conforme variação da distância fonte-detector, correspondentes às curvas exibidas na Figura 41

\begin{tabular}{|c|c|c|c|c|c|c|c|c|c|}
\hline \multicolumn{10}{|c|}{ Material Pulmão Exalado } \\
\hline \multirow[b]{2}{*}{$\frac{\text { Espessura }}{(\mathrm{mm})}$} & \multicolumn{3}{|c|}{$\begin{array}{l}\text { D }_{\text {TLD, }} \text { MTE=Pulmão Exalado } \\
\text { Simulado }\end{array}$} & \multicolumn{3}{|c|}{$\begin{array}{l}\text { D PMMA, MTE=Pulmão Exalado } \\
\text { Simulado }\end{array}$} & \multicolumn{3}{|c|}{$\begin{array}{l}\text { D }_{\text {TLD, MTE=Pulmão Exalado }} \\
\text { Experimental }\end{array}$} \\
\hline & $\begin{array}{l}\text { Média dos } \\
4 \text { TLDs } \\
\text { MCNP } \\
\text { (MeV/g) }\end{array}$ & $\begin{array}{c}\text { Normalizados } \\
\text { a 2,0 mm }\end{array}$ & $\begin{array}{c}\text { Propagação } \\
\text { de } \\
\text { Incertezas } \\
(\%)\end{array}$ & $\begin{array}{c}\text { Média dos } \\
4 \text { TLDs } \\
\text { MCNP } \\
\text { (MeV/g) }\end{array}$ & $\begin{array}{c}\text { Normalizados } \\
\text { a 2,0 mm }\end{array}$ & $\begin{array}{c}\text { Propagação } \\
\text { de Incertezas } \\
\text { (\%) }\end{array}$ & $\begin{array}{c}\text { Média dos } \\
4 \text { TLDs } \\
\text { (nC) }\end{array}$ & $\begin{array}{c}\text { Normalizados } \\
\text { a 2,0 } \mathrm{mm}\end{array}$ & $\begin{array}{c}\text { Propagação } \\
\text { de } \\
\text { Incertezas } \\
\text { (\%) }\end{array}$ \\
\hline 2 & $2,590.10^{-6}$ & 1,000 & 0,099 & $6,517.10^{-7}$ & 1,000 & 0,134 & $1,491.10^{4}$ & 1,000 & 14,012 \\
\hline 3 & $1,688.10^{-6}$ & 0,652 & 0,110 & $4,247.10^{-7}$ & 0,652 & 0,153 & $8,051.10^{3}$ & 0,540 & 18,445 \\
\hline 4 & $1,240.10^{-6}$ & 0,479 & 0,122 & $3,114.10^{-7}$ & 0,478 & 0,169 & - & - & - \\
\hline 5 & $9,712 \cdot 10^{-7}$ & 0,375 & 0,135 & $2,439.10^{-7}$ & 0,374 & 0,186 & $4,365 \cdot 10^{3}$ & 0,293 & 10,982 \\
\hline 6 & $7,904 \cdot 10^{-7}$ & 0,305 & 0,148 & $1,991.10^{-7}$ & 0,306 & 0,199 & - & - & - \\
\hline 8 & $5,619.10^{-7}$ & 0,217 & 0,126 & $1,412.10^{-7}$ & 0,217 & 0,230 & $2,642.10^{3}$ & 0,177 & 11,267 \\
\hline 13 & $2,870.10^{-7}$ & 0,111 & 0,166 & $7,218.10^{-8}$ & 0,111 & 0,305 & $1,333.10^{3}$ & 0,089 & 9,913 \\
\hline
\end{tabular}


Tabela 16. Dados simulados e experimentais da atenuação no material tecido equivalente de Osso 1000 mg/cc HA conforme variação da distância fonte-detector, correspondentes às curvas exibidas na Figura 42.

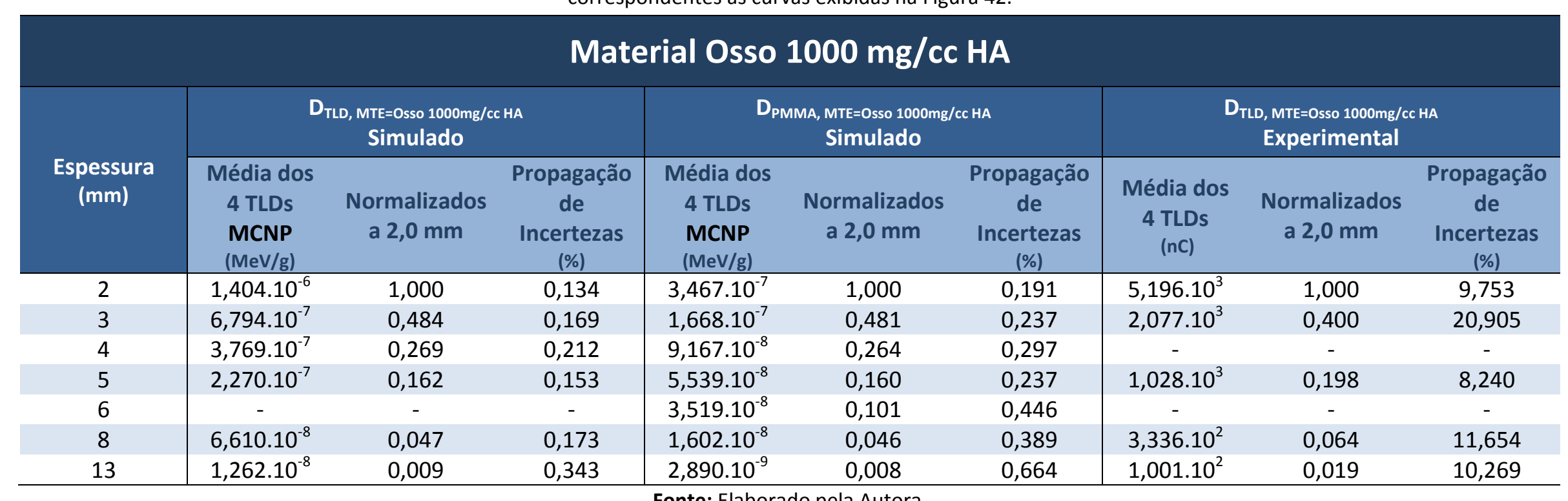

